Fábio Lopes Caversan

\title{
Exploração de Relações entre Técnicas Simbólicas e Conexionistas da Inteligência Computacional
}

Dissertação apresentada à Escola Politécnica da Universidade de São Paulo (EPUSP) como parte dos requisitos para a obtenção do Título de Mestre em Engenharia no Departamento de Engenharia de Computação e Sistemas Digitais (PCS). 


\section{Fábio Lopes Caversan}

\section{Exploração de Relações entre Técnicas Simbólicas e Conexionistas da Inteligência Computacional}

Dissertação apresentada à Escola Politécnica da Universidade de São Paulo (EPUSP) como parte dos requisitos para a obtenção do Título de Mestre em Engenharia no Departamento de Engenharia de Computação e Sistemas Digitais (PCS).

Área de concentração: Inteligência Artificial

Orientador:

Prof. Dr. Marco Túlio C. de Andrade 
Ficha Catalográfica

Caversan, Fábio Lopes

Exploração de Relações entre Técnicas Simbólicas e Conexionistas da Inteligência Computacional. São Paulo, 2006.

$140 \mathrm{p}$.

Dissertação (Mestrado) — Escola Politécnica da Universidade de São Paulo. Departamento de Engenharia de Computação e Sistemas Digitais.

1. Inteligência Artificial. 2. Fuzzy (Inteligência Artificial). 3. Redes Neurais. I. Universidade de São Paulo. Escola Politécnica. Departamento de Engenharia de Computação e Sistemas Digitais. II. t 



\section{Dedicatória}

A minha eterna amada que acumula, momentaneamente, a função de minha esposa. 


\section{Agradecimentos}

Agradeço especialmente meu caríssimo orientador Professor Marco Túlio Carvalho de Andrade, por acreditar em mim quando eu mesmo não acreditava, e pelo exemplo de conduta pessoal e profissional.

À todos os meus colegas (alunos e professores) da Escola Politécnica da Universidade de São Paulo (EPUSP), em especial do Laboratório de Engenharia de Conhecimento (KNOMA), meus sinceros agradecimentos. Fui muito bem acolhido nesta família. Se hoje não me sinto mais um estranho no ninho, é graças a estas pessoas. As discussões sempre de alto nível intelectual e cultural contribuiram muito para a construção deste trabalho.

A finalização deste trabalho, delimitação do escopo e incorporação de novas idéias foram resultado de meu exame de qualificação, e não poderia deixar de agradecer aos Professores Júnio Barrera e Luiz Henrique Alves Monteiro pelas críticas construtivas realizadas naquela ocasião.

A Faculdade de Engenharia de Sorocaba (FACENS) me forneceu grande apoio, e merece também minha gratidão. Aos meus alunos, com os quais aprendo a cada dia, e aos meus colegas professores, cuja convivência é um privilégio e grande honra para mim.

Aos meus queridos pais, minha eterna gratidão, pelo apoio incondicional. Não apenas na condução dos trabalhos de mestrado, mas, principalmente, na vida pessoal, seu suporte foi essencial. Se um dia eu for para meus filhos metade do que meus pais são para mim, me considerarei bem sucedido na função de pai. Na figura deles agradeço ao incentivo de toda minha família: avós, sogros, tios.

À minha amada esposa, não somente agradeço como dedico este trabalho. A percepção mais próxima do que estes anos foram para mim pertence à ela. E é graças a ela, e por ela, que persisti. Ela, de fato, não me permitiu abandonar o mestrado, nos momentos mais difíceis, em que a covardia me apresentou a fuga como uma opção de saída. 
"Vós sois deuses. Deixai brilhar a vossa luz." - O Mestre dos mestres. 


\section{Resumo}

CAVERSAN, F. L. Exploração de Relações entre Técnicas Simbólicas e Conexionistas da Inteligência Computacional. 2006. 140 f. Dissertação (Mestrado) Escola Politécnica da Universidade de São Paulo, São Paulo, 2006.

Este trabalho consiste em uma contribuição à área de Inteligência Computacional, no que tange à algumas de suas principais técnicas: Computação Nebulosa e Computação Neural. Estas técnicas vêm sendo utilizadas para obter-se soluções de problemas que se apresentam complexos demais para a abordagem algorítmica ou modelagem matemática tradicionais. Entretanto, estes problemas são solucionados de forma trivial pelo aparato que compõe a chamada inteligência humana.

A existência de relações, regras e transformações capazes de transferir modelos de problemas de um domínio para outro, traz grandes vantagens para a área de Inteligência Computacional. Teorias e modelos bem estabelecidos em uma das técnicas podem ser utilizados em outras, como por exemplo, os diversos métodos de aprendizado de Computação Neural e a capacidade de utilização de conhecimento especialista de Computação Nebulosa. Problemas modelados classicamente em uma técnica podem ser vistos à luz de outra, possibilitando uma melhor compreensão e otimização das soluções.

É realizada uma exploração destas relações. São abordados alguns trabalhos anteriores que indicam a existência de algumas relações, e propostos alguns modelos para desenvolver o trabalho de pesquisa. Uma plataforma para realização de simulações e coleta de dados empíricos para as explorações é especificada. Parte da plataforma foi implementada, e simulações de uma transformação de modelos nebulosos para neurais foram realizadas. Os resultados destes experimentos são apresentados.

Palavras-chave: Inteligência Artificial (IA), Inteligência Computacional, Computação Nebulosa, Computação Neural. 


\section{Abstract}

CAVERSAN, F. L. Relations Exploration between Symbolic and Connectionist Techniques of Computational Intelligence. 2006. $140 \mathrm{f}$. Dissertation (Master's Degree) - Escola Politécnica da Universidade de São Paulo, São Paulo, 2006.

This work consists of a contribution to the area of Computational Intelligence, relating to some of its main techniques: Fuzzy Computing and Neural Computing. These techniques are being used to solve problems that are too complex for traditional algorithmic approach or mathematical modeling. However, these problems are solved easly with the apparatus that composes the so-called human intelligence.

The existence of relations, rules and transformations capable to transfer problems models from a domain to another, brings great advantages for the area of Computational Intelligence. Well established theories and models in one of the techniques can be used in others, for example, the various learning methods from Neural Computing and the use of expert knowledge capacity of Fuzzy Computing. Problems classically modeled in one technique can be seen from another point of view, possibiliting a better understanding and optimization of the solutions.

An exploration of these relations is accomplished. Some previous works indicating the existence of some relations and models to develop the research work are presented. A platform for simulation and empirical data collection, for the explorations, is specified. Part of the platform was implemented, and simulations of a transformation from fuzzy to neural models had been carried through. The results of these experiments are presented.

Keywords: Artificial Intelligence, Computational Intelligence, Fuzzy Computing, Neural Computing. 


\section{Lista de Figuras}

2.1 Ciências relacionadas à inteligência. . . . . . . . . . . . . . . . . . 27

2.2 Áreas da Inteligência Computacional. . . . . . . . . . . . . . . . . . . . . 28

2.3 Conjuntos nebulosos nas formas trapezoidal (A) e gaussiana (B). . . . . . . 33

2.4 Possíveis valores lingüísticos para variável lingüística distância. . . . . . . 36

2.5 Arquitetura típica de um Sistema de Inferência Nebuloso (SIN). . . . . . . 39

2.6 Estrutura do sistema nervoso central. . . . . . . . . . . . . . . . 43

2.7 Neurônios biológicos. . . . . . . . . . . . . . . . . . . . . . . . . . 44

2.8 Modelo de neurônio artificial. . . . . . . . . . . . . . . . . . 45

2.9 Topologia do Perceptron de Múltipla Camada. . . . . . . . . . . . . . . . . 51

2.10 Exemplo de classificação em duas classes, adaptado de Mehrotra, Mohan e Ranka (1997, p. 142). . . . . . . . . . . . . . . . 53

2.11 Topologia das Redes de Funções de Base Radial. . . . . . . . . . . . . . . . 54

2.12 Exemplo de execução de um algoritmo em Computação Evolutiva (CE). . . 57

2.13 Aplicações híbridas de Inteligência Computacional (IC) . . . . . . . . . . . 58

2.14 Rede ANFIS equivalente a um SIN com regras do tipo Tsukamoto, adaptado de Jang $(1993$, p. 668). . . . . . . . . . . . . . . . . . . . . 60

3.1 Diagrama Gajski-Kuhn. . . . . . . . . . . . . . . . . . . 68

3.2 Diagrama Gajski-Kuhn (GK) base para pesquisa das técnicas de IC. . . . . 69

3.3 Diagrama GK estendido para a IC . . . . . . . . . . . . . . . . . . . 71

3.4 Diagrama Andrade-Caversan (AC) . . . . . . . . . . . . . . . . . 73

3.5 Diagrama da IC com eixos adicionais para representação das técnicas. . . . 76

3.6 Diagrama da $\mathrm{IC}$ com eixo único da IC . . . . . . . . . . . . . . . 78 
3.7 Diagrama das linguagens da IC e sua expressividade. . . . . . . . . . . . . 79

3.8 Transporte de elementos entre os eixos do diagrama AC. . . . . . . . . . . 81

4.1 Diagrama de estados de uma instância da Unified Computational Intelligence Plataform (UCIP) . . . . . . . . . . . . . . . . . . . 85

4.2 Diagrama de caso de uso e componentes da plataforma UCIP. . . . . . . . 86

4.3 Modelo lógico do pacote para realização de Computação Nebulosa (CF). 89

4.4 Diagrama de classes do pacote para realização de CF. . . . . . . . . . . . . 90

4.5 Diagrama de atividades representando a operação com CF. . . . . . . . . . 91

4.6 Modelo lógico do pacote para realização de Computação Neural (CN). . . . 93

4.7 Diagrama de classes do pacote para realização de CN. . . . . . . . . . . . . . 94

4.8 Diagrama de atividades representando a operação com CN. . . . . . . . . . 95

4.9 Modelo lógico do pacote para realização de CE. . . . . . . . . . . . . . . 96

4.10 Diagrama de classes do pacote para realização de CE. . . . . . . . . . . . 97

4.11 Diagrama de atividades representando a operação com CE. . . . . . . . . . 98

4.12 Diagrama de classes do pacote para realização de transformações da IC. . 100

5.1 Veículo Autoguiado (F, L e R: distância frontal, esquerda e direita; $\theta$ : variação na direção. . . . . . . . . . . . . . . . . . . . . . . . . . . 104

5.2 Ferramenta de simulação de navegação de veículo autoguiado. . . . . . . . 105

5.3 Exemplo de mapa arbitrário para navegação do robô. . . . . . . . . . . . 106

5.4 Interface para criação e manipulação do SIN . . . . . . . . . . . . . . . 107

5.5 Exemplo de visualização de variável lingüística. . . . . . . . . . . . . . . 107

5.6 Exemplo de visualização de regra lingüística. . . . . . . . . . . . . . . . 108

5.7 Variáveis lingüísticas para navegação do robô autoguiado. . . . . . . . . . . 109

5.8 Trajeto do robô utilizando o SIN em dois mapas diferentes. . . . . . . . . . 111

5.9 Trajeto do robô utilizando o Rede Neural Artificial (RNA) em dois mapas diferentes. . . . . . . . . . . . . . . . . . . 111

5.10 Variáveis lingüísticas simples para simulação de transformação. . . . . . . . 113 
5.11 Potencial de ativação da (a) regra nebulosa e do (b) neurônio radial obtido a partir dela. . . . . . . . . . . . . . . . . . . . . . . . 114

5.12 Saída obtida do (a) SIN simples e da (b) RNA obtida a partir dele. . . . . 115

5.13 Teste comparativo da navegação do robô com SIN nos mapas (a) reto e (c) curvo com a navegação com RNA nos mapas reto (b) e curvo (d). . . . . . 120 


\section{Lista de Tabelas}

3.1 Isomorfismos entre sistemas lógicos formais . . . . . . . . . . . . . 67

5.1 Regras lingüísticas para navegação do robô autoguiado . . . . . . . . . . 110 


\section{Lista de Algoritmos}

1 Conversão de Conjunto Nebuloso para Sinapse . . . . . . . . . . . . . . . . 115

2 Conversão de Regra Nebulosa para Neurônio . . . . . . . . . . . . . . . . . 116

3 Conversão de Base de Regras para Camada . . . . . . . . . . . . . . . . . 117

4 Conversão de SIN para RNA . . . . . . . . . . . . . . . . . . . 118 


\section{Lista de Abreviaturas}

AC Andrade-Caversan

AG Algoritmo Genético

ANFIS Adaptative-Network-Based Fuzzy Inference System

APM Adaptable Process Model

CE Computação Evolutiva

CF Computação Nebulosa

CN Computação Neural

CP Computação Probabilística

FBR Funções de Base Radial

FBRP Funções de Base Radial com Peso

GK Gajski-Kuhn

IA Inteligência Artificial

IC Inteligência Computacional

ICM Intelligent Computational Model

MT Model Transformation

PMC Perceptron de Múltipla Camada

RNA Rede Neural Artificial

SIN Sistema de Inferência Nebuloso

UCIP Unified Computational Intelligence Plataform

UML Unified Modelling Language 


\section{Lista de Símbolos}

\begin{tabular}{ll}
\hline Símbolo & Descrição \\
\hline$\Re$ & Conjunto dos números reais. \\
$P(x)$ & Predicado de um conjunto. \\
$U$ & Universo de discurso. \\
$\mu_{A}(x)$ & Grau de pertinência de um elemento $x$ a um conjunto nebuloso \\
& $A$. \\
$T(x, y)$ & Operação de Norma Triangular entre $x$ e $y$. \\
$S(x, y)$ & Operação de Co-Norma Triangular entre $x$ e $y$. \\
$N(x)$ & Operação de Complemento de $x$. \\
$T_{i=1}^{n}\left(A_{i}\right)$ & Operação de Norma Triangular nos conjuntos $A_{i}$. \\
$S_{i=1}^{n}\left(A_{i}\right)$ & Operação de Co-Norma Triangular nos conjuntos $A_{i}$. \\
$M I N_{i=1}^{n}\left(x_{i}\right)$ & O menor valor entre os elementos $x_{i}$. \\
$M A X_{i=1}^{n}\left(x_{i}\right)$ & O maior valor entre os elementos $x_{i}$. \\
$\varphi(v)$ & Função de Ativação sobre o potencial de ativação $v$. \\
$D_{n}(a, b)$ & Função de Distância de ordem $n$ entre $a$ e $b$. \\
\hline
\end{tabular}




\section{Sumário}

1 Introdução 19

1.1 Motivação e Justificativa . . . . . . . . . . . . . . . . . . . . . . . . . 21

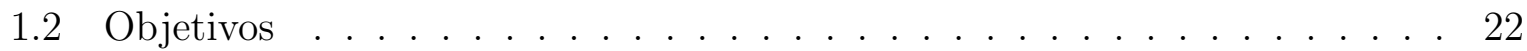

1.3 Metodologia . . . . . . . . . . . . . . . . . 22

1.4 Estrutura do Texto . . . . . . . . . . . . . . . . . . 23

2 Inteligência Computacional 24

2.1 Computação Nebulosa $(\mathrm{CF}) \ldots \ldots$. . . . . . . . . . . . . . . 30

2.1.1 Conjuntos Nebulosos . . . . . . . . . . . . . . . . . . . . 31

2.1.2 Operações sobre Conjuntos Nebulosos . . . . . . . . . . . . . . . . . 32

2.1.3 Variáveis Lingüísticas . . . . . . . . . . . . . . . . . . . 35

2.1.4 Regras Lingüísticas (Fuzzy If-Then Rules) . . . . . . . . . . . . 36

2.1 .5 Inferência Aproximada . . . . . . . . . . . . . . . . 37

2.1.6 Sistemas de Inferência Nebulosos (SINs) . . . . . . . . . . . . . . 38

2.1.7 Algoritmos Nebulosos . . . . . . . . . . . . . . . . . . 42

2.2 Computação Neural $(\mathrm{CN}) \ldots \ldots \ldots$. . . . . . . . . . . . . . . 43

2.2.1 Neurônio Artificial . . . . . . . . . . . . . . . . . . . . 44

2.2.2 Redes Neurais Artificiais (RNAs) . . . . . . . . . . . . . 47

2.2 .3 Perceptrons . . . . . . . . . . . . . . . . . . 49

2.2.4 Redes de Funções de Base Radial (FBR) . . . . . . . . . . . . . . 53

2.3 Computação Evolutiva $(\mathrm{CE}) \ldots \ldots \ldots \ldots \ldots$. . . . . . . . . . 56

2.4 Aplicações Híbridas . . . . . . . . . . . . . . . . . . . . . . . . . . 58 
2.5 Unificação das Abordagens da IC . . . . . . . . . . . . . . . . . . . . . . . 59

2.6 Considerações Finais do Capítulo . . . . . . . . . . . . . . . . . 65

3 Modelos para Exploração de Relações da IC 66

3.1 Isomorfismos entre Sistemas . . . . . . . . . . . . . . . . . 67

3.2 O Diagrama Gajski-Kuhn $(\mathrm{GK}) \ldots \ldots \ldots \ldots$

3.3 O Diagrama Andrade-Caversan $(\mathrm{AC}) \ldots \ldots \ldots$. . . . . . . . . 70

3.3.1 Pontos Notáveis Baseados no diagrama GK original . . . . . . . . . 72

3.3 .2 Pontos Notáveis Baseados na IC . . . . . . . . . . . . . . . . 73

3.4 Modelos Alternativos de Diagramas da IC . . . . . . . . . . . . . . 75

3.4 .1 Os Eixos Segmentados . . . . . . . . . . . . . . 76

3.4.2 A Proposta do Quarto Eixo . . . . . . . . . . . . . . . . 77

3.4.3 Expressividade das Linguagens da IC . . . . . . . . . . . . . . . 77

3.5 Transportes no Diagrama $\mathrm{AC} \ldots \ldots . \ldots . \ldots . \ldots$. . . . . . . . 80

3.6 Considerações Finais do Capítulo . . . . . . . . . . . . . . . . . 81

4 Plataforma Computacional para Exploração das Relações da IC 83

4.1 Especificação dos Requisitos . . . . . . . . . . . . . . . . . . . 84

$4.1 .1 \quad$ Introdução . . . . . . . . . . . . . . . . . . . . . . . . . 84

4.1 .2 Utilização . . . . . . . . . . . . . . . . . . . . . . . . . . 85

4.1.3 Descrição Funcional e de Dados . . . . . . . . . . . . . . . . . . . . 86

4.1 .4 Critérios de Validação . . . . . . . . . . . . . . . . 87

4.2 Especificação do Projeto . . . . . . . . . . . . . . . . . . 88

4.2 .1 Pacote FC . . . . . . . . . . . . . . . . . . . 88

4.2 .2 Pacote $\mathrm{NC} \ldots \ldots \ldots \ldots$. . . . . . . . . . . . . . . . . 92

4.2 .3 Pacote EC . . . . . . . . . . . . . . . . . . . . 94

4.2 .4 Pacote $\mathrm{MT} \ldots \ldots \ldots \ldots 9$

4.3 Considerações Finais do Capítulo . . . . . . . . . . . . . . . . . . 100 
5.1 Navegação de Robôs Autoguiados . . . . . . . . . . . . . . . . . . . . . . . 102

5.1 .1 O Ambiente de Simulação . . . . . . . . . . . . . . . . . . . . . . . 104

5.1 .2 A Implementação da Solução com CF . . . . . . . . . . . . . . . . . 108

5.1 .3 A Implementação da Solução com CN . . . . . . . . . . . . . . . 110

5.2 Desenvolvimento do Pacote Model Transformation (MT) . . . . . . . . . . 112

5.2.1 Resultados das Transformações por Aproximação . . . . . . . . . . . 113

5.2.2 Algoritmo Proposto para Conversão de um SIN em RNA . . . . . . 114

5.3 Transformação do SIN do Robô em RNA . . . . . . . . . . . . . . . . . . . 119

5.4 Considerações Finais do Capítulo . . . . . . . . . . . . . . . . . . . . 121

6 Considerações Finais

6.1 Cumprimento dos Objetivos Propostos . . . . . . . . . . . . . . . 123

6.2 Contribuições do Trabalho . . . . . . . . . . . . . . . . . . . . . . 124

6.3 Comentários Gerais . . . . . . . . . . . . . . . . . . . . 124

6.4 Trabalhos Futuros . . . . . . . . . . . . . . . . . 125

$\begin{array}{ll}\text { Referências } & 127\end{array}$

Apêndice A - SIN no formato XML 131

Apêndice B - Código da Classe FuzzyTransform 138 


\section{Introdução}

Inteligência Artificial (IA) possui uma vasta abrangência e relações com diversas áreas do conhecimento. Pode ser vista como a ciência cujo objetivo é compreender e construir entidades inteligentes (RUSSEL; NORVIG, 2004). A definição formal de IA, entretanto, não é tão simples e clara. As controvérsias surgem, em geral, devido à dificuldade da definição do próprio atributo "inteligência".

Segundo Bender (1996) a IA classicamente apoiou-se na abordagem simbólica. Nesta abordagem, o conhecimento é representado e manipulado em um alto nível de abstração, um nível de símbolos, compreensíveis para o ser humano. Os pesquisadores desta linha acreditam que a manipulação destes símbolos imita o processo de raciocínio humano. Entretanto, não está claro como os símbolos devem ser manipulados, de forma analítica ou numérica, por exemplo. Nas últimas décadas uma outra abordagem, a conexionista, ganhou força. O princípio básico desta alternativa é de que os processos mentais podem ser obtidos como uma rede interconectada de unidades simples. Pode-se considerar que a abordagem simbólica busca "inteligência através de projeto" e a conexionista a "inteligência como uma propriedade emergente", que surge a partir de um determinado arranjo de unidades em rede.

Recentemente destacou-se na IA um segmento de pesquisa denominado Inteligência Computacional (IC). Enquanto a IA busca construir entidades inteligentes através de qualquer método disponível, seja inspirado na inteligência biológica ou não, a IC explora o potencial de criação de soluções através da simulação de características subjacentes aos seres biologicamente constituídos. Pode-se destacar três áreas principais dentro da IC: Computação Nebulosa (CF)(Fuzzy), Computação Neural (CN) e Computação Evolutiva (CE), conforme Fogel, Fukuda e Guan (1999).

A CF abrange técnicas para tratar problemas vagos e mal definidos, resolvidos de forma trivial pelos seres humanos através da abstração dos detalhes irrelevantes e raciocínio aproximado. Muitas outras técnicas simbólicas possam ser encontradas na IA, como, por exemplo, a lógica proposicional e a lógica de primeira ordem (BENDER, 1996). 
Entretanto, a CF representa o ramo simbólico da IC, e está fundamentada nos conjuntos e na lógica nebulosa (NGUYEN; WALKER, 1996).

A CN se baseia na construção de modelos estruturalmente similares à estrutura cerebral, composta de bilhões de neurônios interconectados, representando a abordagem conexionista dentro da IC. Estes modelos são as Redes Neurais Artificiais (RNAs), constituídas de neurônios artificiais. Através deles é possível criar-se entidades artificiais com capacidade de processamento paralelo e aprendizado, entre outras relacionadas à estrutura neural biológica (HAYKIN, 2001). Embora as RNAs sejam os maiores representantes do conexionismo, não são as únicas. Modelos propostos normalmente pela ciência cognitiva, como redes nas quais as unidades representam conceitos e as ligações representam relações semânticas também são considerados exemplos de conexionismo (BODEN, 1988).

A CE por sua vez tem seu foco na teoria da evolução das espécies, adaptada para modelos computacionais. Uma população de determinada espécie é vista como um conjunto de candidatos à solução para um determinado problema, que gera descendentes, como no processo natural. No caso de sistemas digitais o processo envolve técnicas de variação aleatória para simular os processos de herança e mutação existentes na natureza (MITCHELL, 1996).

As três técnicas constituintes da IC vêm sendo aplicadas atualmente em diversas áreas que necessitam de sua abordagem computacional não tradicional. Em várias situações em que a necessidade abrange mais que uma das técnicas, modelos híbridos foram propostos e atualmente as três técnicas são vistas como complementares.

Recentemente, vislumbrou-se a possibilidade destas três técnicas apresentarem um certo grau de equivalência, e da provável existência de um conjunto de regras e transformações que possam traduzir um problema de um domínio para outro, e vice-versa (ANDRADE, 2002). Trabalhos anteriores já haviam proposto algumas destas relações, como o modelo ANFIS proposto por Jang (1993) e a rede FBRP proposta por Reyneri (1996).

A definição destas relações possibilitaria a abertura de novos horizontes na área de IC, no tratamento de um problema, nas suas diferentes etapas, em domínios diferentes, e até mesmo da possibilidade de se estabelecer um modelo unificado da IC, um modelo fundamental do qual as técnicas citadas seriam derivadas.

Para realizar a exploração mais detalhada desta hipótese foi formulada uma plataforma de trabalho, constituída de modelos abstratos para realização de pesquisa e ferramentas computacionais de simulação com o objetivo de obter resultados empíricos das 
hipóteses experimentais. Um protótipo capaz de simular alguns casos foi desenvolvido. Baseado no levantamento bibliográfico e nos modelos propostos, um algoritmo com algumas transformações foi incorporado à plataforma. O resultado destes experimentos são analisados e apresentados.

\subsection{Motivação e Justificativa}

A motivação original deste trabalho foi a possibilidade da existência de relações entre as técnicas de IC (ANDRADE, 2002). Trabalhos anteriores indicaram a existência de algumas relações. O modelo ANFIS, por exemplo, é capaz de mapear entradas e saídas baseadas em conhecimento humano ou em dados de entrada e saída, características de CF e CN, respectivamente (JANG, 1993).

A modelagem de sistemas utilizada pela comunidade de redes de crença e a modelagem utilizada pela comunidade de redes neurais são equivalentes. Uma Rede Bayesiana utilizada para classificação pode ser vista como uma rede neural (JORDAN, 1995). Alguns pesquisadores incluem sob a égide da IC a Computação Probabilística (CP), que abrange as Redes Bayesianas (BONISSONE et al., 1999). Foi comprovada também a equivalência de representação de conhecimento entre autômatos finitos nebulosos e redes neurais recorrentes (GILES; OMLIN; THORNBER, 1999).

Modelos híbridos, que mesclam as três técnicas, vêm sendo utilizados na solução de diversos problemas nos quais as características de uma técnica isolada são insuficientes (BONISSONE et al., 1999). Existem, entretanto, deficiências no processo de modelagem em relação ao uso adequado de cada técnica, métricas para avaliação de desempenho, entre outras. A pesquisa de relações entre as técnicas pode auxiliar a resolver estes problemas.

As relações entre CF e CN, em particular, apresentam um atrativo adicional que transcende a própria IC. Atualmente a ciência cognitiva busca modelos que possam explicar as relações entre cérebro e mente (CHURCHLAND, 1989) (CHURCHLAND, 2004). A modelagem do cérebro é característica da abordagem conexionista, através da CN. A modelagem da mente, por sua vez, pode ser vista como característica da abordagem simbólica, que pode ser representada pela CF. Os resultados de possíveis relações podem auxiliar na pesquisa da neurofilosofia, compreendendo melhor o o problema mente / cérebro, assim como a neurofilosofia pode auxiliar na evolução dos modelos, conceituação de termos e definição de rumos de pesquisa para a IC. 


\subsection{Objetivos}

Neste trabalho são apresentados argumentos que sustentam a hipótese da existência de relações entre as técnicas da IC e da proposta de novas abordagens e modelos para a busca das relações entre seus métodos. O foco deste trabalho está nas relações entre CF e CN, representantes das abordagens simbólicas que modelam comportamento humano (mente) e conexionistas, que modelam a sua estrutura (cérebro).

Além da pesquisa e sistematização dos indícios de existência das relações, este trabalho objetiva a proposta de alguns modelos para explorar as relações, e a criação de uma plataforma computacional para auxiliar a pesquisa, através da realização de simulações e análise de dados empíricos. A especificação desta plataforma, o desenvolvimento de um protótipo resultante desta especificação, e a realização de experimentos com este protótipo também fazem parte do escopo.

\section{$1.3 \quad$ Metodologia}

A abordagem proposta para realização do trabalho consiste na comparação e análise crítica das duas técnicas de IC em questão, e posterior obtenção de um modelo que represente de forma adequada as possíveis relações entre as duas técnicas. Finalmente, pode-se proceder com a implementação de uma solução utilizando cada um dos modelos, dentro do escopo de uma plataforma mais ampla que procura realizar investigações na área de IC como um todo.

O estudo aprofundado destes modelos pode indicar a existência das relações que se pretende identificar. Pode-se implementar, então, uma ferramenta que efetivamente realize as operações necessárias para a mudança de domínio. Finalmente, pode-se avaliar seus resultados através da comparação das soluções implementadas utilizando as duas técnicas isoladamente.

Para atingir-se o objetivo proposto, pretende-se seguir os seguintes passos, tidos como metas intermediárias do processo de desenvolvimento do trabalho:

- Propor e analisar modelos que suportem as transformações em questão, baseados nos diagramas propostos originalmente em (ANDRADE, 2002).

- Estudar e analisar as possibilidades de soluções baseadas em Sistemas de Inferência Nebulosos $(\mathrm{CF})$, através do estudo de um caso e implementação de uma aplicação. 
- Estudar e analisar as mesmas possibilidades, utilizando RNAs (CN), do mesmo caso, implementando, se possível, a mesma aplicação.

- Pesquisar as características e estruturas das implementações anteriores, buscando as similaridades e possíveis operações capazes de transportar a solução do problema, em um determinado estado, de um domínio para outro.

- Uma vez encontrada alguma relação, implementar uma ferramenta que realize a operação necessária para o transporte de domínio.

- Analisar os resultados obtidos com esse transporte em relação aos modelos isolados desenvolvidos anteriormente.

\subsection{Estrutura do Texto}

O capítulo 2 apresenta uma descrição das definições e aplicações inerentes à área de IC, seus modelos, técnicas e situação atual. Detalha as idéias originais da busca de relações isomórficas dentro da IC, os modelos que foram propostos e a situação em que se encontrava a pesquisa no início do trabalho.

No capítulo 3 é apresentado o primeiro modelo utilizado para a busca de relações, baseado no Diagrama de Gajski-Kuhn original. Alguns de seus pontos importantes são explorados. Um modelo novo, um Diagrama da IC, é apresentado, e alguns de seus pontos importantes são explorados. Outro modelo que sugere a inexistência de um isomorfismo completo, mas apenas pontos-chaves de transformação, é apresentado e algumas reflexões a seu respeito são realizadas.

No capítulo 4 a plataforma computacional para a exploração das relações através de simulações e e coleta de dados empíricos é proposta. Os resultados obtidos através de um protótipo desenvolvido são analisados e discutidos no capítulo 5.

Na conclusão, apresentada no capítulo 6 são feitas as considerações finais, analisados os resultados do trabalho e apontados os possíveis rumos da linha de pesquisa. 


\title{
2 Inteligência Computacional
}

\author{
O objetivo deste capítulo é contextualizar a Inteligência \\ Computacional e descrever suas principais técnicas consti- \\ tuintes (Computação Nebulosa, Computação Neural e Computação \\ Evolutiva). Modelos criados com o objetivo de unificar as técnicas, \\ em particular de CF e CN, são apresentados, bem como as \\ noções de isomorfismos entre sistemas e sua importância para a \\ modelagem dos mesmos.
}

A IA é uma ciência recente, que possui uma vasta abrangência e relações com diversas áreas do conhecimento. De acordo com Russel e Norvig (2004), pode ser vista como a ciência cujo objetivo é "compreender e construir entidades inteligentes". Nilsson (1998) define como ocupação da inteligência artificial "o comportamento inteligente em artefatos, envolvendo percepção, raciocínio, aprendizado, comunicação e atuação em ambientes complexos". Através desta perspectiva o ser humano se torna, inevitavelmente, uma importante referência. Existem, todavia, abordagens que visam à obtenção da racionalidade formal, correta, independente do modelo humano, que nem sempre apresenta comportamento racional. Uma discussão comparativa mais detalhada pode ser encontrada em Russel e Norvig (2004).

Surgem controvérsias, entretanto, devido à dificuldade da definição do próprio atributo denominado inteligência, e de suas várias derivações. As dificuldades de estudo e compreensão de processos cognitivos de alto nível de abstração, observados em seres humanos, como livre-arbítrio e consciência, acompanham a área de IA. Ciência Cognitiva é o nome dado a um conjunto multidisciplinar que visa ao estudo dos processos cognitivos da inteligência consciente, englobando filosofia, neurociência, psicologia e inteligência artificial, entre outros (POSNER, 1996).

A Ciência Cognitiva possui muitas questões em aberto, entretanto uma delas é a mais polêmica: o problema mente/corpo. Diversas teorias foram propostas no campo 
filosófico, mas não chegou-se a um consenso, embora algumas apresentem resultados mais promissores no campo experimental. Conforme a descrição apresentada em Churchland (2004), as principais correntes filosóficas são:

- Dualismo: nas diversas linhas dualistas, a característica comum é que a mente não é física, ou seja, existe a dualidade matéria/mente, constituindo o ser inteligente.

- Dualismo de substância: defende a existência de um outro elemento nãomaterial, do qual seria constituído a mente. A abordagem encontra grande aceitação pelo fato de prover possibilidades como a sobrevivência da mente após a morte do corpo, mas de fato não existem provas convincentes a respeito.

- Dualismo de propriedade: propõe que a partir de um certo nível crítico de complexidade o cérebro produz os estados mentais, que, embora possam ser observados através de introspecção, não influenciam na direção oposta o cérebro como sistema físico. Uma alternativa dentro desta linha é que as propriedades mentais são propriedades fundamentais da realidade, como eletromagnetismo, massa, duração, etc. que serão descobertas em breve (dualismo de propriedade elementar).

- Materialismo (monismo): defende a existência de uma só substância, a matéria.

- Behaviorismo: propõe a inexistência da mente. Os estados mentais poderiam ser representados através do comportamento do ser se considerado em uma situação que colocasse à prova estes estados. Eles seriam, assim, disposições para realizar determinadas ações, com múltiplas possibilidades. Esta abordagem encontrou problemas para representar mesmo estados mentais mais simples, e acabou perdendo a força original.

- Teoria da Identidade: defende que os estados mentais são, em última instância, estados físicos. Os avanços da neurociência devem chegar a ponto de obter um isomorfismo, que transporte qualquer estado mental para físico e viceversa. Assim como luz, som e calor foram descritos mais recentemente como eletromagnetismo e mecânica estatística. Esta linha vem ganhando muita força com os avanços da neurociência.

- Funcionalismo: sugere que os estados mentais são relações causais com o meio ambiente, outros estados mentais e comportamento do corpo. A principal divergência com a teoria da identidade é a idéia que a importância para a 
existência da mente não é a matéria da qual ela é feita, e sim estrutura das atividades internas desta matéria. (tipo mental diferente do tipo físico, espécime mental igual ao espécime físico).

- Eliminacionista: propõe que a redução interteórica é impossível; a psicologia popular é uma representação distorcida de nossos estados internos que deve ser eliminada pela neurociência amadurecida. A história mostra situações em que teorias foram abandonadas, substituídas por outras corretas (calor fluídico, bruxas, etc), assim também a introspecção deve mudar, pois um especialista observa as coisas de forma diferente de um leigo em um determinado assunto.

O funcionalismo é amplamente aceito entre filósofos, pesquisadores de psicologia cognitiva e IA. Esta corrente possibilita a construção de um ser inteligente independente da estrutura biológica, reproduzido apenas sua estrutura e organização. Muitos modelos vêm sendo propostos pela Ciência Cognitiva para tentar reproduzir características encontradas nos seres inteligentes como pensamento, vontade, emoção, consciência, entre outros (KANDEL; SCHWARTZ; JESSEL, 1991) (POSNER, 1996), (NERO, 1997).

A curta história da IA (aproximadamente 60 anos) caracterizou-se por uma diversidade grande de abordagens, na tentativa de obter-se dispositivos inteligentes. Dois grandes conjuntos de técnicas que podem ser destacados são a abordagem simbólica e a abordagem conexionista.

As técnicas simbólicas envolvem a representação e manipulação do conhecimento através de símbolos em alto nível de abstração, compreensíveis por parte do ser humano. Não há, entretanto, um modelo definitivo ou consenso quanto à maneira de manipulação e representação destes símbolos, embora diversos modelos tenham sucesso na solução de determinado grupo de problemas. Bender (1996) classifica estas técnicas como a busca da "inteligência através de projeto".

As técnicas conexionistas representam os processos mentais como uma rede interconectada de unidades simples. Nestas redes as unidades podem representar conceitos e suas ligações, as relações semânticas entre estes conceitos, por exemplo (BODEN, 1988). Por outro lado, se as undiades representam neurônios, tratam-se de modelos neurais, os modelos conexionistas em destaque na atualidade. Bender (1996) classifica estas técnicas como a busca da "inteligência como uma propriedade emergente", que surge a partir da estrutura e organização de unidades interconectadas.

Recentemente se destacou da área de IA um subcampo denominado IC ou soft computing (ZADEH, 1994) (FOGEL; FUKUDA; GUAN, 1999). Essa nova perspectiva explora a 


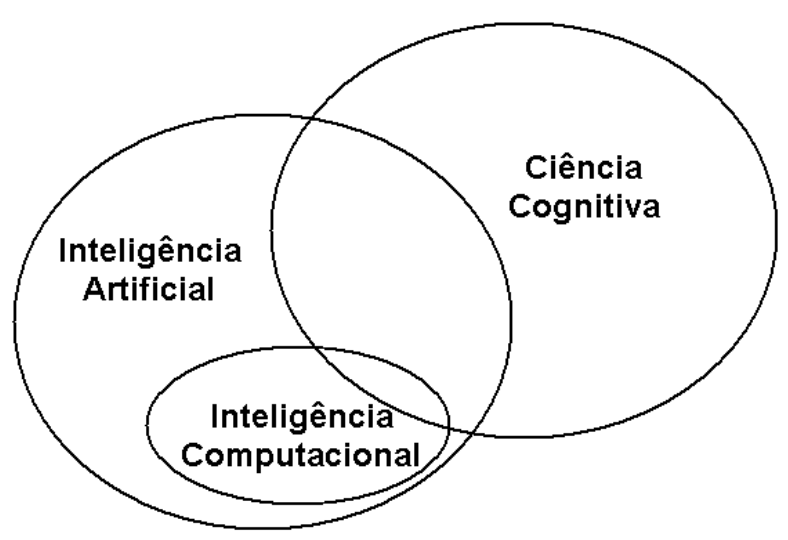

Figura 2.1: Ciências relacionadas à inteligência.

possibilidade de criar entidades que possam resolver problemas simples para os seres humanos mas complexos demais para abordagem algorítmica tradicional. A IA busca a construção de seres inteligentes, utilizando para isso quaisquer meios disponíveis, sem restringir-se necessariamente aos meios de que a natureza se utilizou para criar a vida inteligente. Assim, modelos estatísticos podem ser utilizados para simular a inteligência, embora não exista uma relação direta destes modelos com a estrutura ou o comportamento dos seres inteligentes. A IC, por sua vez, é a parte da IA que preocupa-se em construir estas máquinas modelando comportamentos e mecanismos dos seres inteligentes encontrados na natureza. A figura 2.1 apresenta a relação entre Ciência Cognitiva, IA e IC. Uma definição encontrada em Andrade (2002):

- IA: Pode-se interpretar como um conjunto de técnicas que explora a possibilidade de criar programas que possam competir com seres humanos em certas atividades. Para tal se faz uso, por exemplo, de procedimentos heurísticos, conhecimento encapsulado, lógica simbólica, etc.

- IC: Trata-se de um conjunto de técnicas que exploram o potencial para criar "máquinas inteligentes" por meio da modelagem dos comportamentos e mecanismos que são subjacentes aos organismos biologicamente inteligentes.

As técnicas de IC diferem das técnicas de computação tradicionais, pois tratam de características como abstração, imprecisão, aprendizado, busca através de evolução, fatores que os tais modelos não conseguem tratar de maneira eficiente. As três áreas principais da IC, que refletem suas três principais técnicas são: CF (Fuzzy), CN e CE, representadas na figura 2.2 . 


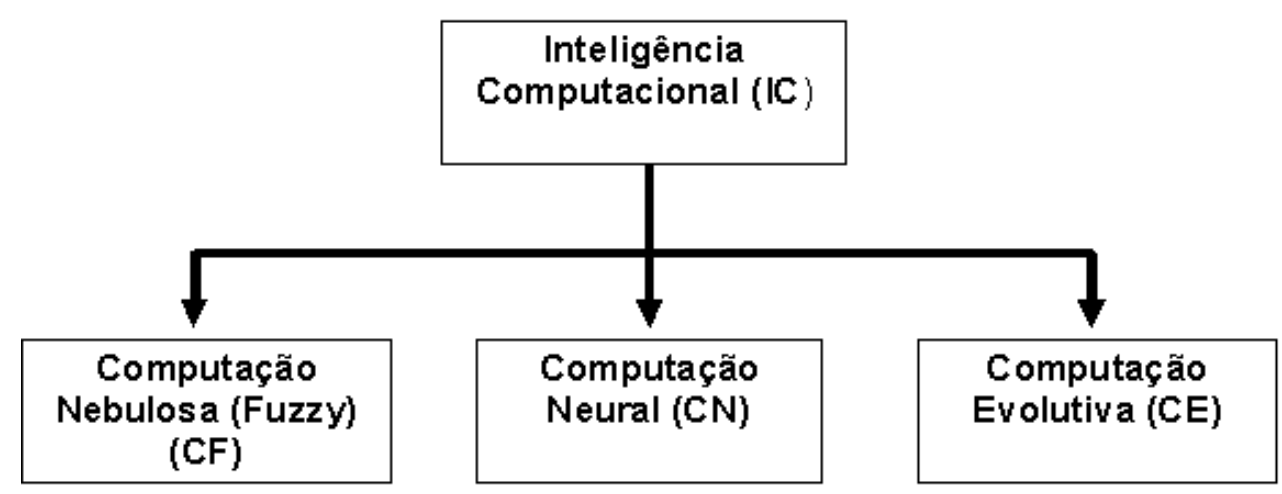

Figura 2.2: Áreas da Inteligência Computacional.

A CF são técnicas para tratar problemas vagos e mal definidos, mas que são resolvidos facilmente pelos seres humanos através da abstração dos detalhes irrelevantes. Estes modelos se baseiam no comportamento humano, buscando simular sua forma de raciocinar e manipular conceitos. É considerada uma técnica simbólica, e está fundamentada no trabalho original de (ZADEH, 1965) que propôs os conjuntos nebulosos.

A CN se apóia na construção de modelos com a estrutura e funcionamento similares ao cérebro, que é composto de bilhões de neurônios interconectados, enquadrando-se na abordagem conexionista. Estes modelos são Redes Neurais Artificiais (RNAs), constituídas de neurônios artificiais. Através destes modelos é possível obter-se características como aprendizado, classificação, generalização, entre outras relacionadas à estrutura neural biológica.

A CE por sua vez tem seu foco no modelo da evolução das espécies, tratando todo problema a ser resolvido como sendo de sobrevivência de uma espécie. As possíveis soluções do problema são representadas como uma população de indivíduos. Esta população produz novas gerações, sendo que os indivídus mais adequados possuem maior chance de gerar descendentes. Estes modelos são aplicados na solução de problemas não lineares de muitas dimensões e de otimização. As técnicas de programação genética surgiram através dos esforços de diversos pesquisadores nas décadas de 50 e 60 (MITCHELL, 1996).

Embora a abordagem clássica de IC aponte como as suas principais técnicas constituintes CF, CN e CE, encontramos em Bonissone et al. (1999) uma alternativa que apresenta uma quarta técnica, a Computação Probabilística (CP), como uma das técnicas constituintes da IC.

A CP pode ser dividida em: Redes Bayesianas, modelos que simplificam a inferência probabilística através da adição de conhecimento sobre o domínio do problema e in- 
formações estruturais; sistemas Dempster-Shafter, que trabalham com margens superiores e inferiores de probabilidade ao invés de valores simples (BONISSONE et al., 1999). São utilizados quando se tem incerteza sobre as probabilidades, ou seja, incerteza sobre as incertezas de um problema.

A relevância deste abordagem torna-se mais clara se considerarmos o trabalho de Jordan (1995), em que é proposto que uma Rede Bayesiana pode ser vista como uma RNA, e vice-versa. Este trabalho torna-se um importante indicador da existência de relações entre modelos distintos dentro do escopo da IA.

As três técnicas constituintes da IC vêm sendo aplicadas atualmente em diversas áreas que necessitam de sua abordagem computacional não tradicional. Em várias situações em que a necessidade abrange mais que uma das técnicas, modelos híbridos foram propostos e atualmente as três técnicas são vistas como complementares.

Finalmente, pode-se citar o campo da ciência cognitiva denominado neurofilosofia, nomenclatura utilizada em Churchland (1989) para denominar uma ciência que busca uma teoria que unifique os modelos conhecidos de duas entidades estudadas até então de forma separada: o cérebro e a mente.

A neurociência estuda as estruturas que compõe o cérebro, as unidades funcionais, topologia, funcionamento integrado, etc. A área da computação se aproveitou, com sucesso, destas descobertas nos modelos de RNAs utilizados em CN. Tais redes são muito mais simples que a do cérebro, mas ainda sim capazes de imitar parte de suas capacidades. A psicologia, por sua vez, estuda o comportamento do ser, a exteriorização das suas disposições mentais. A representação e utilização do conhecimento, capacidade de raciocínio, etc. Essas características também foram utilizadas pelas técnicas de IC, particularmente as de CF.

A busca das relações mente/corpo pode ser transportada para a IA. Se a teoria unificada da mente/cérebro for realmente alcançada, pode-se utilizar seus resultados para nortear a criação da ponte definitiva entre simbólicos e conexionistas, entre CF e CN. Da mesma maneira, se as relações entre essas duas técnicas forem descobertas elas podem auxiliar a neurofilosofia na busca da teoria unificada. A ciência cognitiva vem se utilizando dos resultados da IA para compreender melhor a inteligência natural (CHURChlAnd, 2004). Resumidamente, os campos de IC e neurofilosofia estão em busca de algo similar: uma teoria unificadora dos diferentes pontos de vista e abordagem que possuem. 


\subsection{Computação Nebulosa (CF)}

O princípio da incompatibilidade enunciado por Zadeh (1973) afirma que "conforme a complexidade de um sistema aumenta, nossa capacidade de fazer declarações precisas e significantes sobre seu comportamento diminui até um limite em que precisão e significado se tornam mutuamente exclusivos.". O ser humano é capaz de extrair de sistemas extremamente complexos apenas as características relevantes parar trabalhar com o mesmo, com um mínimo grau de precisão, que podemos chamar de significado do sistema. Nesse contexto, declarações com precisão matemática sobre o comportamento do sistema não tem sentido, nem são importantes para trabalhar com o sistema da maneira como o ser humano faz. Resumidamente, quanto maior a precisão sobre um comportamento, menor o significado desta, e quanto maior o significado que temos, menor a precisão. Assim, para tratar de problemas que o ser humano pode resolver, é preciso uma abordagem que não utilize a precisão, o rigor e o formalismo matemático, e sim uma abordagem tolerante à falhas e verdades parciais.

A Lógica Nebulosa (ou Lógica Fuzzy) com as bases nos conjuntos nebulosos criados por Zadeh (1965), explorada e consolidada posteriormente em Zadeh (1968), Zadeh (1973), Zadeh (1983), Lee (1990a), Lee (1990b), Zadeh (1996), e finalmente aplicada na construção de sistemas inteligentes em diversas aplicações, como controle de trens subterrâneos, máquinas de lavar roupa, equipamentos fotográficos e automóveis (KOSKO, 1997). Sua utilização permite um tratamento baseado em valores qualitativos e não quantitativos, utilizando as chamadas variáveis lingüísticas, não numéricas, para representar problemas e as regras utilizadas para resolvê-los. Ainda que utilize etiquetas de linguagem, essa abordagem permite tratar de maneira categórica ou quantitativa questões imprecisas ou mal definidas, como:

“- Este indivíduo é alto."

“- Este objeto é leve."

"- Aqueça muito este alimento."

“- Aumente um pouco a velocidade."

Nestes casos, os significados de alto, leve, muito e razoavelmente são verdadeiramente relevantes, e não o seu valor numérico categórico, que poderia ser 10 centímetros e 100 gramas, nos dois primeiros casos. Para representar e poder trabalhar com esses valores imprecisos, utilizam-se os Conjuntos Nebulosos (Fuzzy) (ZADEH, 1965). 


\subsubsection{Conjuntos Nebulosos}

Segundo Tremblay e Manohar (1975) um conjunto é uma coleção de objetos de qualquer tipo. Formalmente, um conjunto pode ser definido ou caracterizado por um predicado $P(x)$. Alguns exemplos de conjuntos podem ser:

$$
\begin{aligned}
& C_{1}=\{x \mid P(x)\} \\
& C_{2}=\{x \mid x \in \Re\} \\
& C_{3}=\{x \mid x \text { seja um nome de cidade }\}
\end{aligned}
$$

O predicado $P(x)$ é uma função que assume o valor 1 (verdadeiro) se $x$ pertence ao conjunto $C_{1}$. Caso contrário, a função assume o valor 0 (falso). Assim, pode-se dizer que um conjunto clássico é definidos por uma função de pertinência (ou predicado), cujo resultado pode ser 0,1 , indicando se elementos são ou não membros deste conjunto.

Pode-se encontrar em Nguyen e Walker (1996)[p. 3] a definição de conjuntos nebulosos: "Um subconjunto nebuloso de um conjunto $U$ é uma função $U \rightarrow[0,1]$ " ${ }^{1}$, sendo que $U$ representa o universo de discurso. Pode-se considerar que os conjuntos nebulosos são uma coleção mal definida de objetos, definidos por um predicado (ou função de pertinência) que, diferente dos predicados de conjuntos clássicos, pode assumir valores no intervalo $[0,1]$. Estes valores significam o grau de pertinência de um elemento a esse conjunto.

Tais funções de pertinência são denotadas, tipicamente, por $\mu_{A}(x)$, sendo $x$ um ponto do universo de discurso $(U)$, caracterizando um conjunto nebuloso $A$ composto pelos pares ordenados $\left(x, \mu_{A}(x)\right)$. Os conjuntos nebulosos são considerados uma generalização da teoria de conjuntos clássicos, em que um elemento pertence em um certo grau (pertinência) a um determinado conjunto, possibilitando a manipulação de verdades parciais.

Algumas definições importantes para a operação de conjuntos nebulosos, segundo Zadeh (1973):

- Suporte: o conjunto de pontos de $U$ em que $\mu_{A}(x)$ é positivo.

- Crossover point: elemento $x$ de $U$ tal que $\mu_{A}(x)$ é 0,5 .

- Fuzzy singleton: um conjunto nebuloso cujo suporte é um único elemento.

Um singleton $A$ pode ser representado através da notação $A=\mu / x$, sendo $\mu$ o grau de

\footnotetext{
${ }^{1}$ tradução do autor.
} 
associação de $x$ ao conjunto. Um conjunto nebuloso que não seja um singleton pode ser representado pela união os seus singletons constituintes. Alguns exemplos de conjuntos nebulosos:

$$
\begin{aligned}
& L E V E=1 / 10+0,8 / 100+0,6 / 1000+0,2 / 10000 \\
& A L G U N S=0,2 / 2+0,6 / 3+1 / 5+0,8 / 10 \\
& I D O S O=0,1 / 40+0,3 / 50+0,8 / 60+1 / 80
\end{aligned}
$$

Sendo que os itens do conjunto $L E V E$ estão expressos em gramas, do conjunto $A L G U N S$ em unidades e do conjunto IDOSO em anos. Através do formalismo nebuloso derivado desta teoria de conjuntos pode-se trabalhar com verdades parciais. No exemplo acima, um quilograma não é classificado categoricamente como leve, mas também não é excluído, como se não fosse leve. Asseverações que trabalhem com o conceito de $L E V E$ devem considerar uma medida de um quilo para chegar à conclusões, com o seu devido grau de veracidade, que no caso em questão é 0,6 .

Os conjuntos apresentados nas equações 2.2 são discretos. Conjuntos nebulosos podem também ser definidos através de funções contínuas. As mais utilizadas na construção de modelos nebulosos são as funções que apresentam formato de sino ou trapezoidal, exemplificados na figura 2.3. Este tipo de função parece representar com mais fidelidade o conhecimento humano sobre a pertinência de elementos em conjuntos, com uma faixa em que claramente os elementos não pertencem a um conjunto, uma faixa em que claramente eles pertencem (platô) e faixas nebulosas interpolando suavemente estas duas.

\subsubsection{Operações sobre Conjuntos Nebulosos}

A teoria dos conjuntos nebulosos possui os operadores derivados da teoria clássica como união, intersecção e complemento. Sejam $A$ e $B$ conjuntos nebulosos, sendo $a=\mu_{A}(x)$ e $b=\mu_{B}(x)$. A operação $A \cap B$ é caracterizada por um operador de conjunção $T(a, b)$, denominado Norma Triangular (T-Norma) tal que (NGUYEN; WALKER, 1996):

$$
\begin{aligned}
& T(1, x)=x \\
& T(x, y)=T(y, x) \\
& T(x, T(y, z))=T(T(x, y), z) \\
& w \leq x \text { e } y \leq z \text { então } T(w, y) \leq T(x, z)
\end{aligned}
$$

O resultado de operações com estas características são próximos do valor 1 (equivalente 

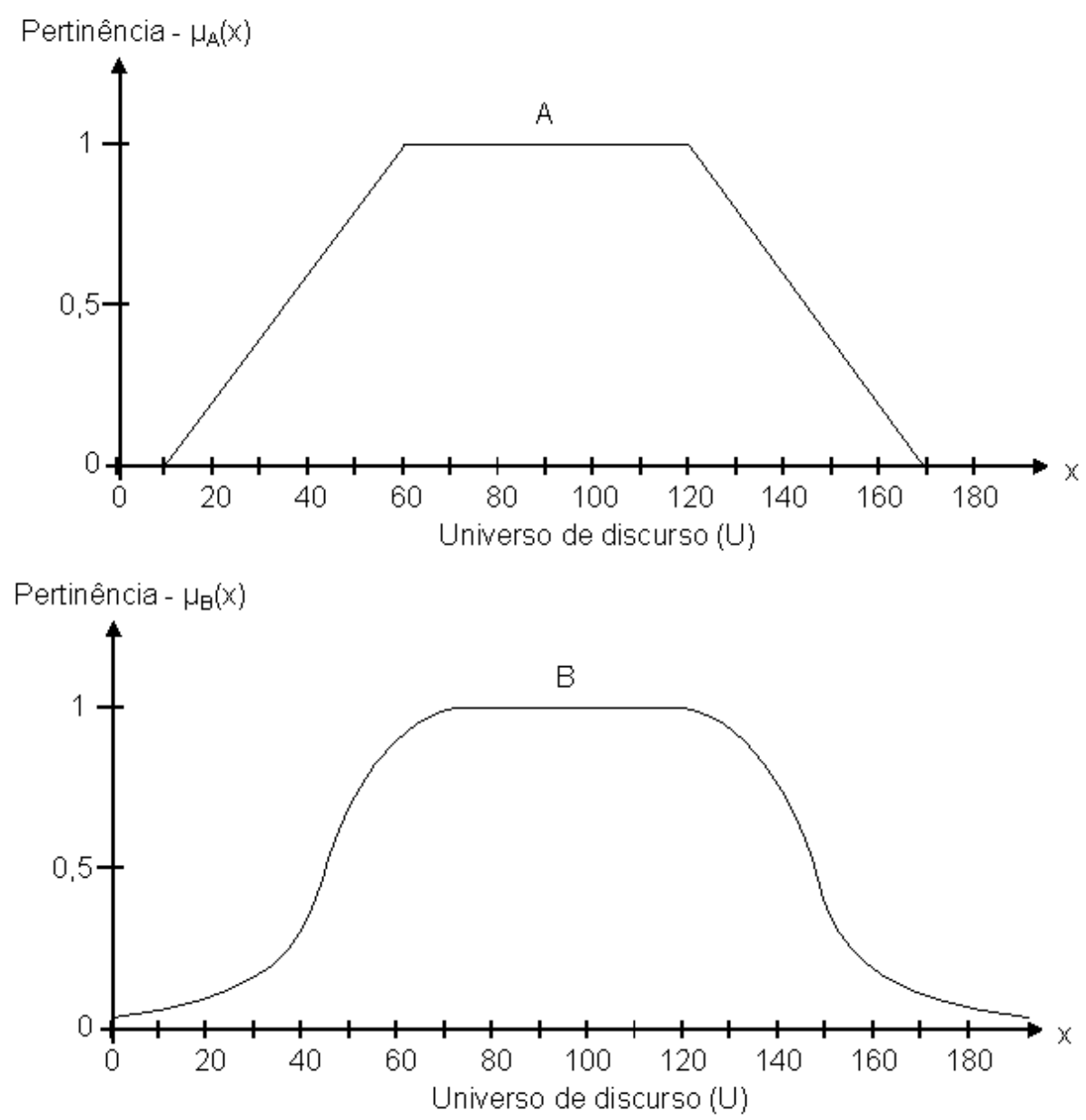

Figura 2.3: Conjuntos nebulosos nas formas trapezoidal (A) e gaussiana (B). 
à verdadeiro) na proporção em que seus dois operandos são próximos do valor 1. Sendo assim, as T-Normas podem ser utilizadas para operar com o termo lingüístico $E(A N D)$ em modelos nebulosos. Alguns exemplos de operações de conjunção que satisfazem as condições e são utilizados como T-Normas são (LEE, 1990b):

$$
\begin{aligned}
& T(x, y)=\min (x, y) \\
& T(x, y)=x \times y \\
& T(x, y)=\max (0, x+y-1) \\
& T(x, y)= \begin{cases}x & \text { se } y=1 \\
y & \text { se } x=1 \\
0 & \text { se } x, y<1\end{cases}
\end{aligned}
$$

Pode-se observar em 2.4 que os resultados das operações tendem ao valor 1 quando os dois operandos possuem o valor 1 . No caso do operador mínimo, por exemplo, o resultado só será 1 quando os dois operandos forem exatamente 1.

A operação $A \cup B$ é caracterizada por um operador de disjunção $S(a, b)$, denominado Co-Norma Triangular (ou T-Conorma) tal que (NGUYEN; WALKER, 1996):

$$
\begin{aligned}
& S(0, x)=x \\
& S(x, y)=S(y, x) \\
& S(x, T(y, z))=S(T(x, y), z) \\
& w \leq x \text { e } y \leq z \text { então } S(w, y) \leq S(x, z)
\end{aligned}
$$

O resultado de operações com estas características são próximos do valor 1 (equivalente à verdadeiro) na proporção em que um de seus operandos são próximos do valor 1. Sendo assim, as T-Conormas são utilizadas para operar com o termo lingüístico $O U$ $(O R)$ em modelos nebulosos. Alguns exemplos de operações de conjunção que satisfazem as condições de T-Conorma são (LEE, 1990b):

$$
\begin{aligned}
& S(x, y)=\max (x, y) \\
& S(x, y)=x+y-x y \\
& S(x, y)=\min (1, x+y) \\
& S(x, y)=\max (\min (x, 1-y), \min (1-x, y)) \\
& S(x, y)= \begin{cases}x & \text { se } y=0 \\
y & \text { se } x=0 \\
1 & \text { se } x, y>0\end{cases}
\end{aligned}
$$


Pode-se observar em 2.6 que os resultados das operações tendem ao valor 1 quando algum dos dois operandos possuem o valor 1. No caso do operador máximo, por exemplo, o resultado será 1 se qualquer um dos dois operandos tiverem valor 1 .

Finalmente o complemento $\bar{A}$ de um conjunto nebuloso $A$ é caracterizado por um operador de negação $N(a)$, tal que:

$$
N(a)=\mu_{\bar{A}}(x)=1-\mu_{A}(x)
$$

Outras operações podem ser realizadas sobre conjuntos nebulosos, como a dilatação, concentração e intensificação, utilizadas como modificadores lingüísticos (ZADEH, 1973).

\subsubsection{Variáveis Lingüísticas}

Através dos conjuntos nebulosos é possível realizar a modelagem de variáveis lingüísticas. Uma variável lingüística é uma variável que pode assumir termos ou valores lingüísticos, ou ainda, sentenças em uma linguagem específica, como, por exemplo, uma variável lingüística altura poderia assumir os valores baixo, alto, muito baixo ou pouco alto. Seu propósito é trabalhar mais próximo ao raciocínio humano e mais distante das características quantitativas classicamente utilizadas em sistemas computacionais.

Segundo a definição de Lee (1990a), uma variável lingüística pode ser caracterizada por uma quíntupla $(x, T(x), U, G, M)$ sendo $x$ o nome da variável; $T(x)$ são os valores lingüísticos que a variável pode assumir, que são números nebulosos ${ }^{2} ; U$ é o universo de discurso; $G$ é a regra sintática para gerar nomes dos valores de $x ; M$ é a regra semântica para associar cada valor ao seu significado.

Seja, por exemplo, uma variável lingüística utilizada para modelar um sistema que trabalha com medidas aproximadas de distâncias:

$$
\begin{aligned}
& X=(\text { distância, } T(x),[0,100], G, M) \\
& T(x)=\{\text { encostado, perto, médio, longe, longe demais }\}
\end{aligned}
$$

Sendo $U$ expresso em metros. A figura 2.4 exemplifica os conjuntos nebulosos de cada um dos termos lingüísticos deste exemplo. Esta variável possibilita a manipulação computacional de asseverações como:

“... se distância é perto ..."

\footnotetext{
${ }^{2}$ Ainda segundo (LEE, 1990a) um número nebuloso é um conjunto nebuloso normal e convexo.
} 


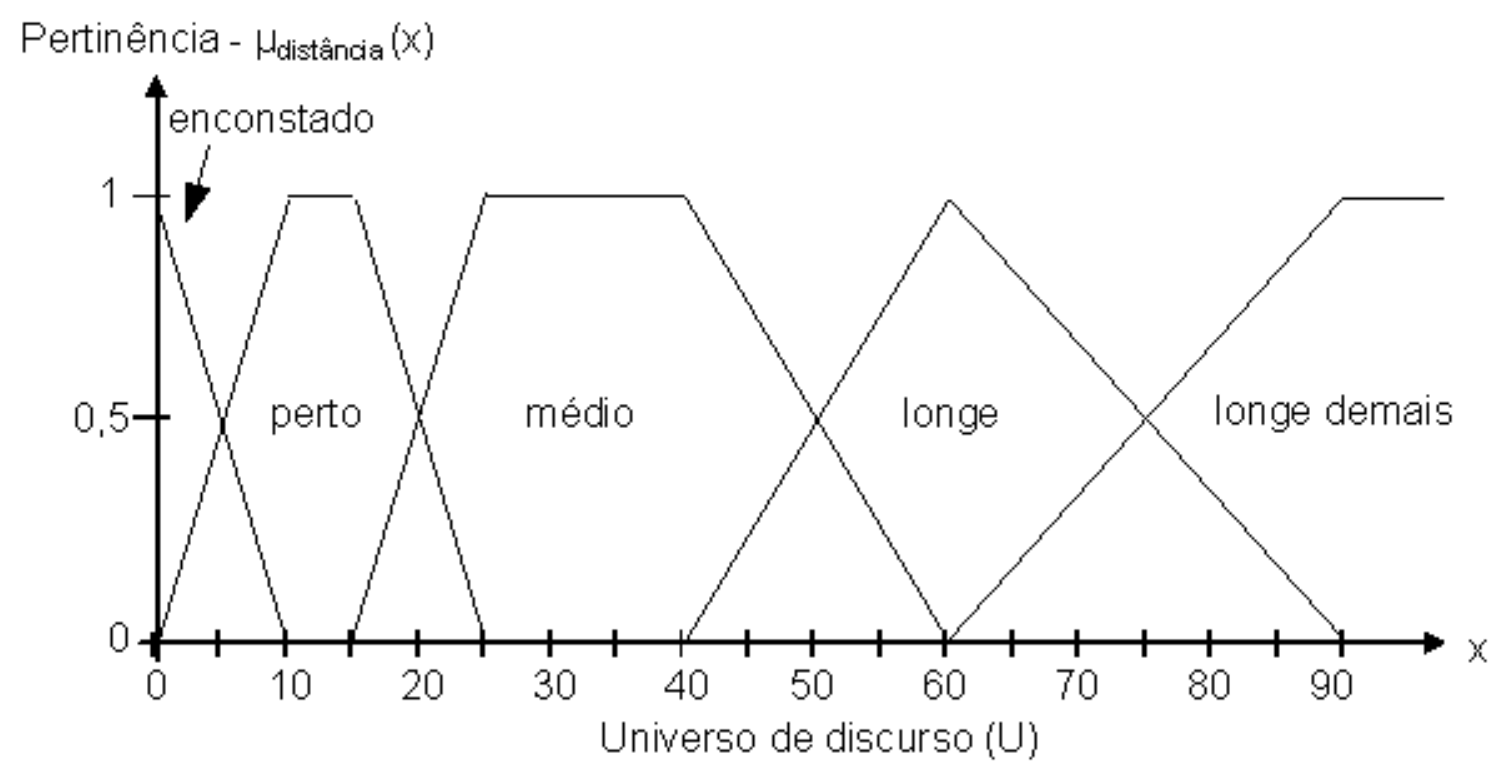

Figura 2.4: Possíveis valores lingüísticos para variável lingüística distância.

“... então distância é longe ..."

Uma distância quantitativa de 20 metros deve ser considerada, por exemplo, qualitativamente, como perto e médio ao mesmo tempo, com graus de confiança diferentes. Asseverações que contenham estas duas etiquetas em suas premissas devem ser consideradas simultaneamente, com graus de confiança baseados na pertinência destes valores aos respectivos conjuntos nebulosos.

\subsubsection{Regras Lingüísticas (Fuzzy If-Then Rules)}

A maioria dos SINs são modelados através de conhecimento especialista sobre o problema, conhecimento este que é representado e passado através de regras lingüísticas, do tipo:

"- Se a parede está longe então vá em frente."

"- Se a parede está perto então vire rapidamente."

Generalizando a forma dessas regras, temos cláusulas do tipo: "SE $X$ ENTÃO $Y$ ", em que " $X$ " é o antecedente e " $Y$ " é o conseqüente. Quando o antecedente e/ou o conseqüente são asseverações lingüísticas, esta regra é lingüística ou nebulosa, sendo $X$ um conjunto de condições a serem satisfeitas e $Y$ é um conjunto de conseqüências que 
podem ser inferidas. Estas regras também são conhecidas como declarações condicionais nebulosas, e podem ser vistas como uma relação nebulosa entre $X$ e $Y$.

As regras nebulosas podem ser vistas, também, como uma propagação de restrições do antecedente para o conseqüente. Tomando como exemplo as asseverações:

"- Se a iluminação é escura então a luz é acesa."

"- Se a iluminação é clara então a janela é aberta."

A etiqueta "escura" é uma restrição sobre a variável iluminação. Esta restrição deve ser transportada para o conseqüente, que será responsável por acender a luz. O grau de confiança na expressão "iluminação é escura" será transportado para a ação de "acender a luz". Assim, se a sala estiver um pouco escura a luz se acenderá um pouco. Além disso, pode-se observar que as duas regras do exemplo aparentam ser mutuamente exclusivas. Entretanto, em computação nebulosa, a iluminação pode ser um pouco clara e um pouco escura ao mesmo tempo, indicando que a luz deve ser um pouco acesa e a janela um pouco aberta.

\subsubsection{Inferência Aproximada}

Para realizar a propagação das restrições ou inferir os conseqüentes nas regras nebulosas, é necessário a tradução das regras para o domínio nebuloso e a realização de operações sobre elas. Considerando uma regra completa do tipo (NGUYEN; WALKER, 1996):

"SE $x$ é $A$ E $y$ é NÃO $B$ ENTÃO $z$ é $C$ OU $z$ é $D$ "

As variáveis $x$ e $y$ são lingüísticas. $A$ e $B$ são etiquetas lingüísticas, de maneira que é possível calcular o grau de confiança na asseveração " $x$ é $A$ " bem como na asseveração " $y$ é $B$ ". Os conectivos E, OU e NÃO podem ser aplicados a estes resultados através das operações nebulosas: T-Norma, T-Conorma e Complemento citadas em 2.1.2. Finalmente, a declaração condicional "SE..ENTÃO" deve ser resolvida através de um mecanismo de inferência.

O conjunto resultante desta inferência é uma relação $R$ entre o antecedente $A$, definido em um universo $U$ e o conseqüente $C$, definido em um universo $W$, e pode ser obtido pela regra composicional de inferência (ZADEH, 1983), $y=x \circ R$, sendo $y$ um elemento de $C, x$ um elemento de $A$. Diversas abordagens foram propostas para a realização das inferências (LEE, 1990b), entre elas o Modus Ponens Generealizado: 
" $x$ é $A^{\prime \prime}$

"SE $x$ é $A$ ENTÃO $y$ é $B$ "

"y é $B^{\prime \prime}$

Que permite inferir o valor de $y$ dado um $x$ que não é exatamente igual ao $A$ existente na regra.

\subsubsection{Sistemas de Inferência Nebulosos (SINs)}

Os SINs surgiram a partir da utilização da teoria nebulosa, e estão presentes nas diversas áreas de aplicação de CF, como controle, autômatos e algoritmos nebulosos. São capazes de mapear entradas em saídas, atuando como aproximadores de funções, utilizando para tanto o conhecimento especialista no formato de variáveis e regras nebulosas. São constituídos, segundo Lee (1990a) por:

- Fuzzificação: se valores numéricos serão as entradas do SIN, deve-se realizar a fuzzificação, ou seja, a transformação de medidas em valores lingüísticos. Pode-se utilizar a conversão direta de medidas em singletons, ou a adição de imprecisão às medidas para que os números se tornem menos sensíveis à ruídos. Se as entradas já são valores lingüísticos esta etapa é desnecessária.

- Base de Dados: são as variáveis lingüísticas, com suas etiquetas lingüísticas, modeladas normalmente através da observação do domínio do problema e das figuras de linguagem utilizadas na sua descrição.

- Base de Regras: regras nebulosas que descrevem o comportamento do sistema a ser modelado. Podem ser inferidas a partir de alguns métodos, se estiverem disponíveis exemplos de entrada e saída ou obtidas através de um especialista humano.

- Unidade de Inferência: unidade que realiza a inferência aproximada.

- Defuzzificação: o SIN trabalha com valores lingüísticos. Freqüentemente é necessário um resultado numérico em um processo de inferência, e para que isto seja possível é necessário realizar uma conversão do resultado qualitativo em quantitativo.

Uma arquitetura típica de SIN é apresentada na figura 2.5. Os passos para o raciocínio aproximado em CF são descritos em Jang (1992): 


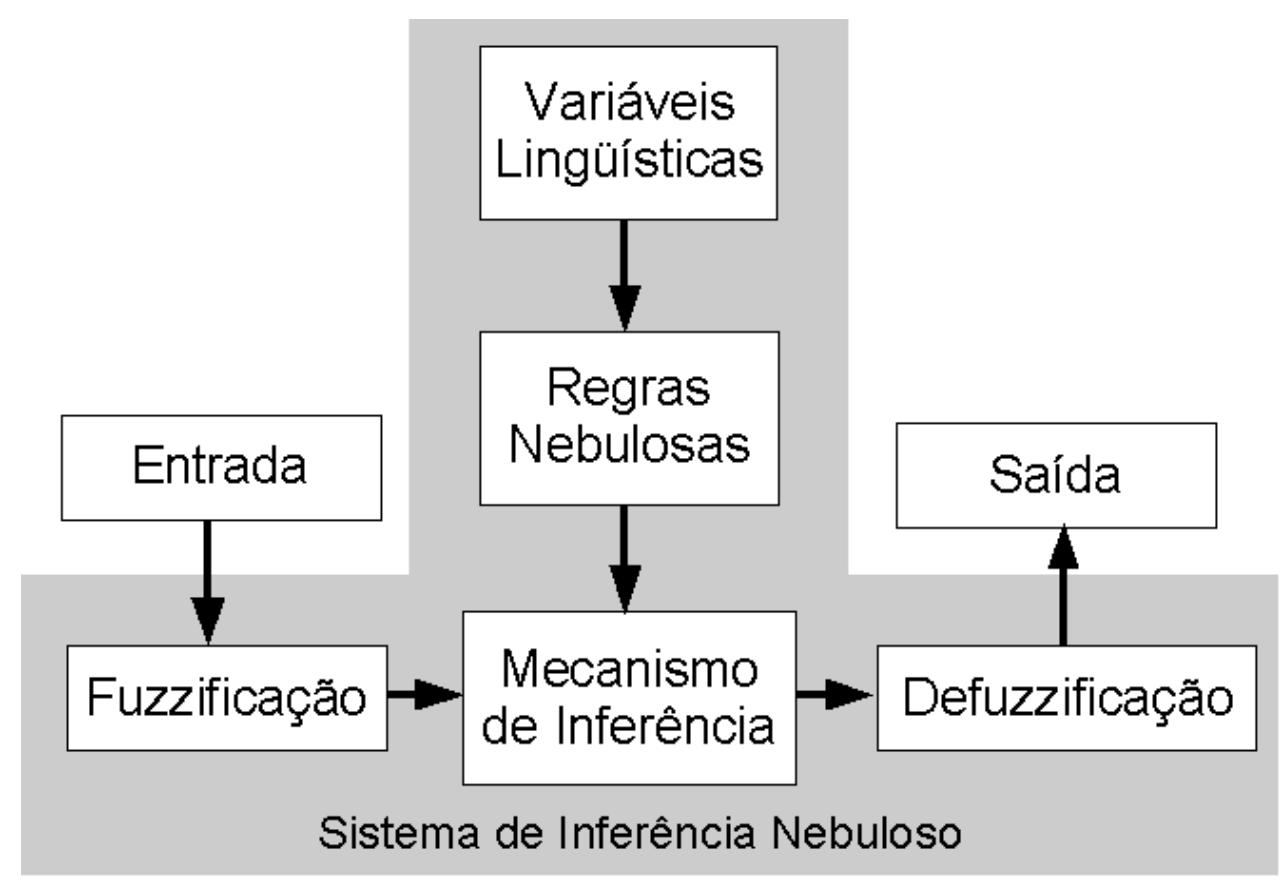

Figura 2.5: Arquitetura típica de um SIN.

1. Comparar os valores de entrada com as variáveis lingüísticas das premissas para obter o grau de casamento parcial entre os dados da entrada e as premissas da base de regras.

2. Combinar os graus de confiança (através de uma T-Norma) para obter o peso (firing strengh) de cada regra.

3. Gerar o conseqüente de cada regra, de acordo com seu peso através do mecanismo de inferência aproximada.

4. Agregar os conseqüentes no caso de geração de saída numérica.

A defuzzificação desempenha papel importante nas aplicações envolvendo CF, visto que em grande parte estas necessitam de resultados numéricos ou categóricos. Seu objetivo pode ser definido como produzir uma saída que representa da melhor forma a distribuição possibilística resultante de uma inferência nebulosa (LEE, 1990b). Embora não haja um método formal para definir-se a estratégia de defuzzificação adotada em um sistema, algumas técnicas vêm sendo utilizadas com sucesso em aplicações de $\mathrm{CF}$ (TSOUKALAS; UHRIG, 1997):

- Centro de Gravidade: a saída numérica y é o centro geométrico da saída nebulosa $\mu_{o}(x)$, que é obtida através da união do resultado de todas as regras que envolvem 
uma determinada variável lingüística de saída. Utilizando uma amostragem de $n$ pontos para o cálculo numérico do centro de gravidade, $y$ é definido por:

$$
y=\frac{\sum_{i=1}^{n} \mu_{o}\left(x_{i}\right) x_{i}}{\sum_{i=1}^{n} \mu_{o}\left(x_{i}\right)}
$$

- Centro das Somas: uma variante do centro de gravidade em que as regiões sobrepostas da saída nebulosa $\mu_{o}(x)$ são contadas mais de uma vez. Utilizando uma amostragem de $n$ pontos para o cálculo numérico do centro de gravidade, $y$ é definido por:

$$
y=\frac{\sum_{i=1}^{n} x_{i} \sum_{j=1}^{m} \mu_{o_{j}}\left(x_{i}\right)}{\sum_{i=1}^{n} \sum_{j=1}^{m} \mu_{o_{j}}\left(x_{i}\right)}
$$

Sendo que $m$ corresponde ao número de regras disparadas para a variável de saída desejada, e $\mu_{o_{j}}\left(x_{i}\right)$ é a pertinência do ponto $x_{i}$ ao conjunto resultante da inferência da m-ésima regra.

- Média dos Máximos: neste método considera-se a média dos valores de $x_{i}$ em que a saída nebulosa $\mu_{o}\left(x_{i}\right)$ atinge seus valores máximos. Considerando-se $n$ valores nos quais este máximo é atingido, $y$ é definido por:

$$
y=\sum_{i=1}^{n} \frac{x_{i}}{n}
$$

Formalmente, um SIN realiza um mapeamento de um vetor de entrada $\vec{X} \in \Re^{N}$ para um vetor de saída $\vec{Y} \in \Re^{M}$, representado por $\vec{Y}=f(\vec{X})$. Um SIN no qual $M=1$, ou seja, com apenas uma variável de saída, é definido na forma lingüística como um conjunto de $r$ regras do tipo (NGUYEN; WALKER, 1996):

"SE $x_{1}$ é $A_{1 i}$ E $\ldots x_{p}$ é $A_{n i}$ ENTÃO $y$ é $B i ", i=1,2, \ldots, r$

A obtenção do conjunto nebuloso $\mu_{o}(y)$ que representa a saída deste sistema pode ser obtida através dos operadores de T-Norma e de T-Conorma:

$$
\mu_{o}(y)=S_{i=1}^{r}\left(T\left(T_{j=1}^{p}\left(A_{j i}\left(x_{j}\right)\right), B_{i}(y)\right)\right)
$$


Utilizando-se um método de centro de gravidade, considerando $n$ amostras, a saída numérica $y_{0}$ será:

$$
y_{0}=\frac{\sum_{i=1}^{n} \mu_{o}\left(y_{i}\right) y_{i}}{\sum_{i=1}^{n} \mu_{o}\left(y_{i}\right)}
$$

O mapeamento entrada-saída de um SIN, conforme destacado em Nguyen e Walker (1996), depende das seguintes escolhas durante a modelagem:

- Os conjuntos nebulosos de entrada e saída.

- Os operadores de T-Norma e T-Conorma utilizados.

- O método de defuzzificação escolhido.

Um número arbitrariamente grande de SINs podem ser modelados, através da variação destes parâmetros. Uma tentativa de classificá-los em grande quatro categorias, feita por Lee (1990b), é apresentada a seguir:

1. Raciocínio Nebuloso Tipo 1 (Mamdani): a saída do SIN é obtida através de um operador de união entre os conseqüentes obtidos. Uma estratégia de defuzzificação deve ser escolhida para uma resposta numérica. Várias alternativas são possíveis, como: máximo valor, média dos máximos e centro de gravidade. Como operador de T-Norma é utilizada a função de mínimo.

2. Raciocínio Nebuloso Tipo 2 (Larsen): similar às regras de Mamdani, porém como operador de T-Norma é utilizada a operação de produto.

3. Raciocínio Nebuloso Tipo 3 (Tsukamoto): similar às regras de Mamdani, porém as funções de pertinência dos conseqüentes devem ser monotônicas e não-decrescentes.

4. Raciocínio Nebuloso Tipo 4 (Takagi e Sugeno): a saída de cada regra é uma combinação das variáveis de entrada. A saída final é obtida através da soma ponderada do peso de cada regra.

Esta classificação é apresentada de forma diferente em diferentes trabalhos. Em Cobo (2000) os sistemas do tipo 1 e 2 são agrupados sob o nome de "Conjunto de Regras Tipo Mamdani", os sistemas do tipo 3 como "Conjunto de Regras Tipo Tsukamoto" e os sistemas do tipo 4 como "Conjunto de Regras Tipo Sugeno". Já em Jang (1992) e 
(JANG, 1993) os sistemas do tipo 1 e 2 são agrupados sob a classificação de "Tipo 2", os sistemas do tipo 3 como "Tipo 1" e os sistemas do tipo 4 como "Tipo 3". Neste trabalho a nomenclatura adotada será a de Cobo (2000).

\subsubsection{Algoritmos Nebulosos}

A criação dos SINs possibilitou a construção de autômatos nebulosos e algoritmos nebulosos (ZADEH, 1968) (ZADEH, 1973). Permitem, em suma, a realização da Computação com Palavras (ZADEH, 1996). Os algoritmos nebulosos são algoritmos com algumas de suas declarações feitas sobre variáveis lingüísticas, representando mais fielmente os processos do raciocínio humano:

"- Se este objeto é leve então sua velocidade deve ser alta."

"- Enquanto a altura é pequena levante o objeto mais um pouco."

"- Diminua a velocidade do objeto lentamente até parar."

A execução de algoritmos em sistemas de computação tradicionais é, em última instância, a operação dos modelos formais conhecidos como máquinas de Turing, descritas em Lewis e Papadimitriou (2000), que são equivalentes aos modelos de autômatos chamados adaptativos (NETO, 1994) (NETO; ROCHA, 2001). Assim, a construção de autômatos é um passo importante para obter-se execução de algoritmos. Em Reyneri (1997) pode-se encontrar a proposta de autômatos nebulosos. Estes são modelos em que a transição não é realizada de maneira categórica, mas sim através de inferência nebulosa. Mais ainda, autômatos tradicionais só podem estar com um de seus estados ativos em um dado instante, enquanto autômatos nebulosos podem ter vários estados ativos com diferentes graus de confiança.

Atualmente as aplicações de CF abrangem todas as áreas do conhecimento humano em que existe a necessidade de representação imprecisa do conhecimento e tomada de decisões, chegando até ações que trabalhem com essa imprecisão, desde controle industrial, sistemas financeiros de tomada de decisão, apoio à decisão na medicina, extração de dados, entre outros (KOSKO, 1997). 


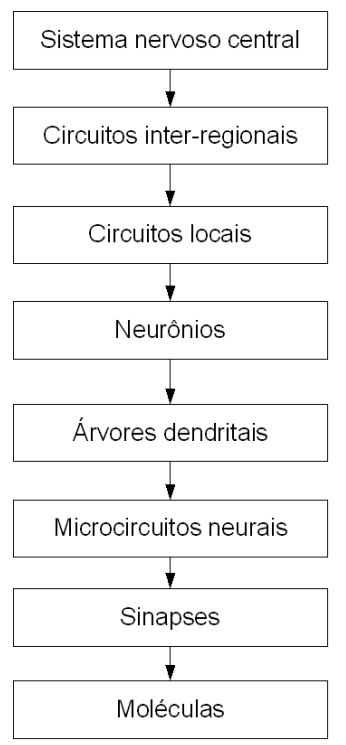

Figura 2.6: Estrutura do sistema nervoso central.

\subsection{Computação Neural (CN)}

Visando à construção do ser inteligente artificial, a abordagem da CN utiliza uma forma de programação não algorítmica, baseada em processamento distribuído paralelo de suas unidades, os neurônios artificiais. Estas unidades são inspiradas nas células que constituem o cérebro, centro do sistema nervoso central, responsável pelo comportamento inteligente, que consiste em perceber o ambiente, processar e integrar informações e atuar sobre o mesmo.

A hierarquia do sistema nervoso central é apresentada na figura 2.6. Um ser humano nasce com bilhões de neurônios, cada um deles interconectado com outros milhares, formando uma imensa rede de processamento distribuído. A criação, eliminação e modificação dessas conexões garante ao homem a capacidade de aprender, armazenar e utilizar conhecimentos através da experiência. A figura 2.7 ilustra dois neurônios biológicos conectados (CAVERSAN, 2002).

Cada célula neural possui seus receptores, os dendritos, o corpo celular e um transmissor, o axônio. A propagação de sinais entre um axônio de um neurônio e o dendrito de outro é realizada através das sinapes. As sinapses convertem o sinal elétrico do axônio em sinal químico (através de neurotransmissores). Este sinal é convertido novamente para elétrico no dendrito (através dos neuroreceptores). A sinapse pode amplificar ou atenuar o sinal que transmite. A capacidade de adaptar-se ao meio ambiente, através de aprendizado, é obtida através da criação ou modificação destas sinapses (CHURCHLAND, 2004). 


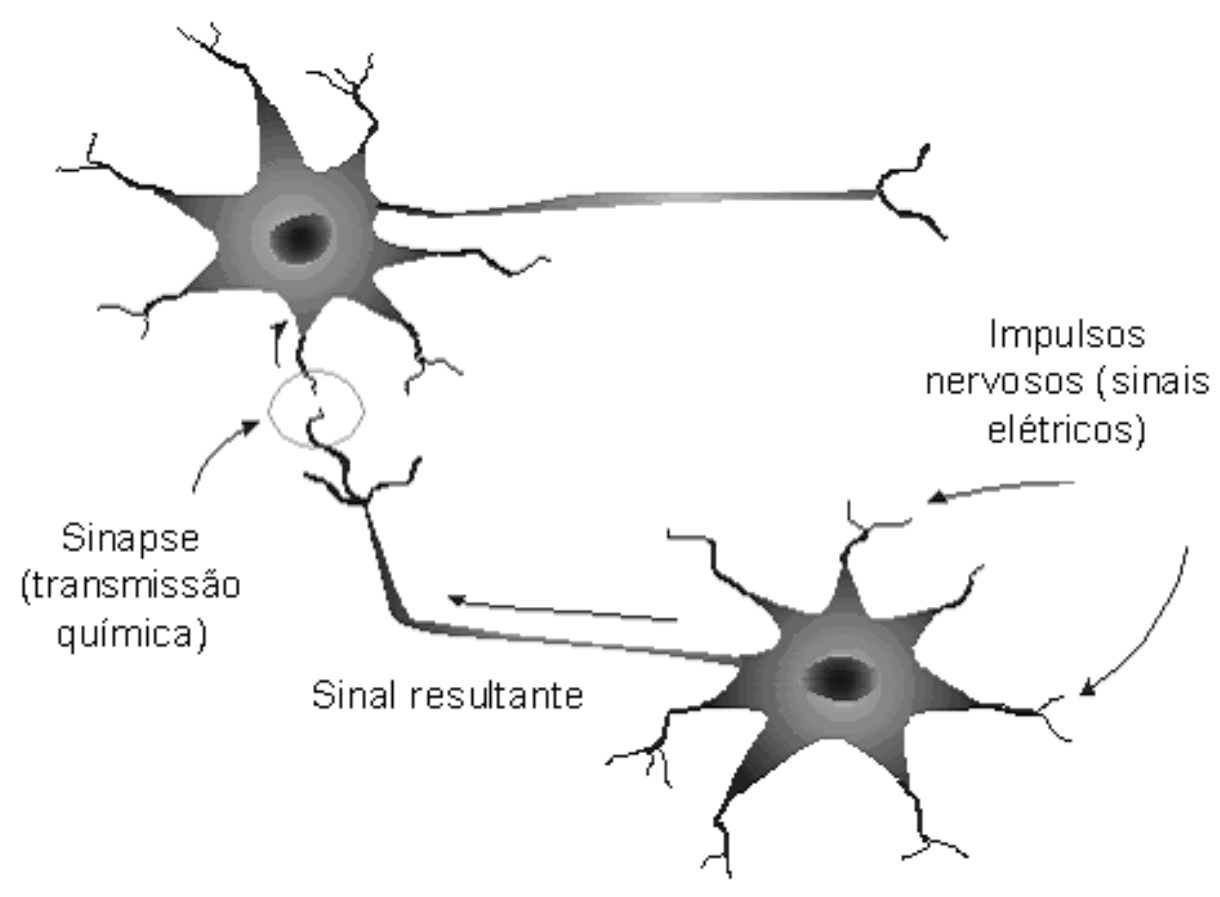

Figura 2.7: Neurônios biológicos.

As RNAs são construídas com neurônios artificiais, modelos matemáticos inspirados no comportamento dos neurônios biológicos.

\subsubsection{Neurônio Artificial}

Os modelos de neurônios são a base para a construção das RNAs. Um modelo de neurônio artificial é apresentado na figura 2.8 (HAYKIN, 2001).

Sendo que este neurônio é identificado por $k$ em um conjunto de neurônios. As entradas, correspondentes aos dendritos dos neurônios biológicos, estão representadas pelos sinais $x_{j}$. Estas entradas podem obter sinais de outros neurônios através de ligações sinápticas ou do próprio ambiente, no caso de neurônios que atuam como sensores. As ligações sinápticas entre o axônio dos outros neurônios e os dendritos do neurônio $k$ são representadas pelos pesos $w_{k, j}$, que podem assumir valores negativos ou positivos.

O cálculo da saída $y_{k}$, primeiramente, envolve uma somatória dos sinais de entrada ponderados pelos seus respectivos pesos, e adicionado o bias $b_{k}$, para obter-se o potencial de ativação $v_{k}$ :

$$
v_{k}=b_{k}+\sum_{j=1}^{m} x_{j} w_{k, j}
$$




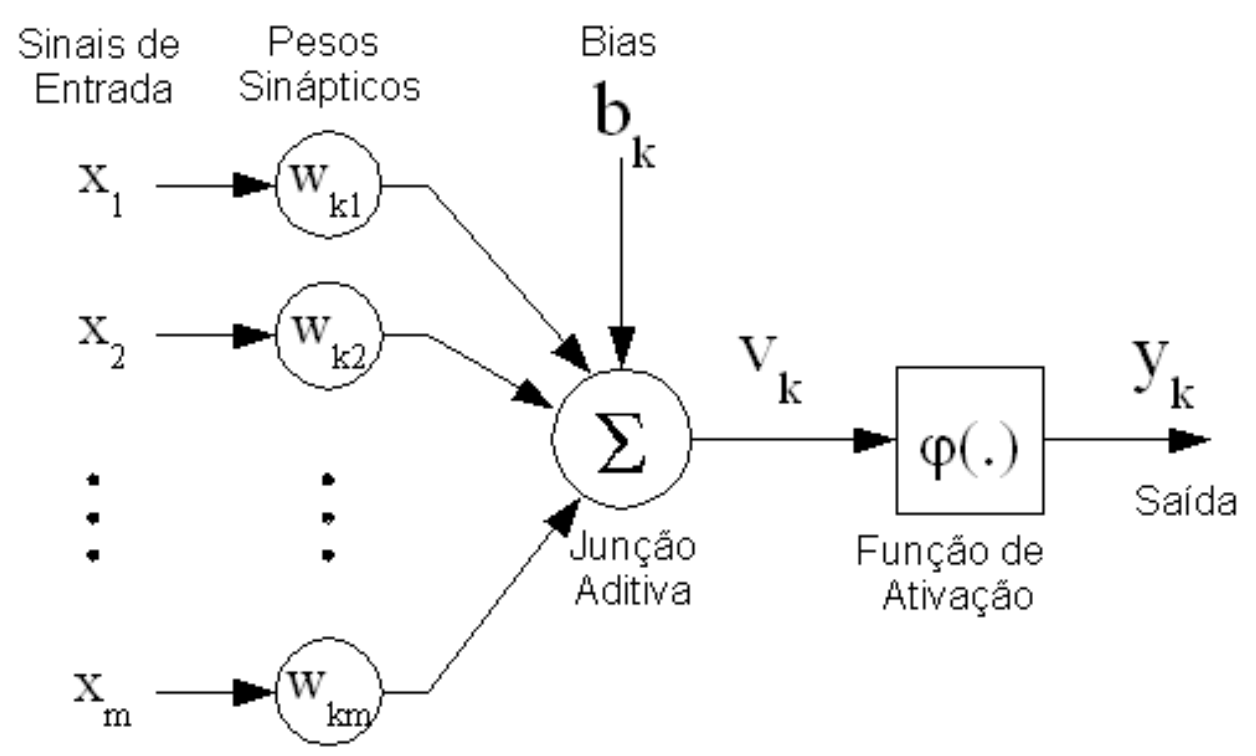

Figura 2.8: Modelo de neurônio artificial.

Neurônios com este tipo de potencial de ativação são neurônios de correlação ou neurônios de produto. Outro tipo de neurônio muito utilizado em algumas arquiteturas de RNAs é o neurônio radial, em que o potencial de ativação envolve o cálculo de uma distância entre as entradas e os pesos, que assumem a condição de centros de uma função de base radial:

$$
v_{k}=\sum_{j=1}^{m} \sqrt[n]{\left|x_{j}-w_{k, j}\right|^{n}}
$$

O parâmetro da norma para calcular a distância $(n)$, tipicamente possui o valor 2 para cálculo da distância Euclidiana (REYNERI, 1996). Embora estes sejam os modelos de neurônio mais utilizados, existem ainda outros, que realizam, por exemplo, uma operação de produto entre as entradas ponderadas (MEHROTRA; MOHAN; RANKA, 1997). Finalmente, uma função de ativação $\varphi($.$) é aplicada para restringir a saída a um valor$ finito, em geral normalizado para um intervalo $[0,1]$ ou $[-1,1]$ :

$$
y_{k}=\varphi\left(v_{k}\right)
$$

Pode-se utilizar um grande número de funções para a ativação dos neurônios. Cada modelo neural possui um conjunto de funções mais adequadas. Os modelos que utilizam aprendizado através do gradiente descendente, por exemplo, necessitam de funções de ativação continuamente diferenciáveis. Alguns exemplos de funções de ativação são 
encontrados em Mehrotra, Mohan e Ranka (1997):

- Função constante: função em que a saída é constante $C$. Exemplo:

$$
\varphi\left(v_{k}\right)=C
$$

- Função identidade: função simples que apenas transfere o sinal da somatória para a saída. Exemplo:

$$
\varphi\left(v_{k}\right)=v_{k}
$$

- Função de limiar: a saída do neurônio pode assumir valor de 0 (inativa) ou 1 (ativa) a partir de um valor de limiar $\ell$. Exemplo:

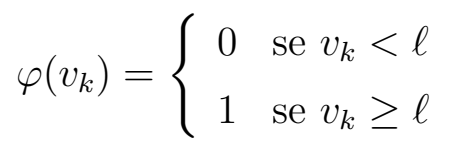

- Função linear por partes: possui uma transição mais suave que a função de limiar, da saída de inativa para ativa, no intervalo $\left[\ell_{i}, \ell_{f}\right]$. Os parâmetros $\alpha$ e $\beta$ são o coeficiente angular e linear da reta localizada no intervalo. Exemplo:

$$
\varphi\left(v_{k}\right)= \begin{cases}0 & \text { se } v_{k}<\leq \ell_{i} \\ \alpha v_{k}+\beta & \text { se } \ell_{i}<v_{k}<\ell_{f} \\ 1 & \text { se } v_{k} \geq \ell_{f}\end{cases}
$$

- Função sigmóide: função muito utilizada para a construção de RNAs. Por ser continuamente diferenciável, pode ser utilizada com os algoritmos de aprendizado que utilizam a descida do gradiente. O parâmetro $\alpha$ ajusta a suavidade a transição da saída de 0 (inativa) para 1 (ativa). Exemplo:

$$
\varphi\left(v_{k}\right)=\frac{1}{1+e^{-\alpha v_{k}}}
$$

- Função de base radial: função no formato de sino, utilizadas em neurônios que calculam a distância entre seus pesos e entradas (radiais). Exemplo:

$$
\varphi\left(v_{k}\right)=\frac{1}{\sqrt{2 \pi \sigma}} e^{-\frac{1}{2}\left(\frac{v_{k}}{\sigma}\right)^{2}}
$$




\subsubsection{Redes Neurais Artificiais (RNAs)}

As RNAs são formadas por neurônios artificiais interconectados, com o objetivo de simular a estrutura cerebral. Através deste modelo de computação, é possível obter-se:

- Processamento distribuído: o processamento realizado pelas RNAs é paralelo, cada neurônio artificial constitui uma unidade de processamento autônoma. Entretanto, cada neurônio afeta diretamente os neurônios em que está conectado. Assim, a rede se torna capaz de realizar tarefas complexas para os algoritmos tradicionais, como reconhecimento de sons e imagens.

- Representação distribuída: o conhecimento da rede se encontra distribuído entre seus neurônios. Assim, a rede se torna tolerante a ruídos e entradas parciais, bem como a falhas ou perdas de algumas de seus unidades de processamento, que influenciam suavemente as suas respostas.

- Aprendizado: a RNA pode ser construída com a capacidade de alterar os pesos das conexões entre seus neurônios, ou mesmo criar ou eliminar neurônios e conexões. Estas modificações alteram as respostas da rede. Algoritmos de aprendizado são utilizados para que estas alterações sejam feitas de tal maneira que a resposta da rede caminhe na direção da resposta desejada.

Existem diversas maneiras de classificar as RNAs existentes, de acordo com sua topologia, algoritmo de aprendizado, aplicações, entre outras. Encontra-se dificuldade, entretanto, ao tentar-se estabelecer uma classificação definitiva, tendo em vista a existência de modelos híbridos, generalizações e especializações de modelos, conforme discutido em Mehra e Wah (1992). Ainda segundo este autor, a maioria dos trabalhos evita um único critério de classificação, utilizando alguns critérios para caracterizar as redes. Estes critérios podem ser utilizados em níveis de detalhe mais específicos ou mais generalizados:

- Função de ativação: a resposta da RNA é obtida através do processamento de suas unidades, os neurônios artificiais. A forma da função de ativação destes neurônios determina a forma da função executada pela rede como um todo.

- Topologia: a maneira como os neurônios são conectados determina a capacidade da rede se comportar dinamicamente e o tipo de comportamento. Duas classes mais gerais podem ser observadas: as redes alimentadas diretamente ou acíclicas (feedforward), nas quais o sinal se propaga sempre em uma única direção, da entrada 
da rede para a saída (exceto o sinal do erro, utilizado no aprendizado); as redes recorrentes (feedback), que possuem pelo menos um laço de realimentação. Pode-se também classificá-las em redes completamente conectadas ou não, e ainda em redes de uma camada ou de múltiplas camadas.

- Algoritmo de aprendizado: o método que realiza a alteração dos parâmetros da rede, que depende diretamente da função de ativação e da topologia adotada. Os diversos métodos existentes podem ser agrupados em:

- Supervisionado: as entradas e respectivas saídas são fornecidas à rede, que utiliza o algoritmo de aprendizado para minimizar o erro entre a saída da rede no instante inicial e a saída desejada.

- Por reforço: um controle capaz de fornecer a rede uma medida de recompensa ou punição de acordo com a sua saída em um dado momento. Através deste fator de mérito a rede altera seus parâmetros, buscando maximizar a recompensa.

- Não supervisionado: neste caso a rede cria categorias internas agrupando as entradas através da detecção de padrões comuns. O tipo de padrão e o nível de agrupamento dependem dos parâmetros da rede.

- Aplicações: muitos modelos de RNAs foram propostos, e diversas especializações foram realizadas para aplicações específicas. A classificação por aplicações pode também ser adotada.

- Memórias: capazes de retornar um padrão completo dado um subconjunto ou pequena variação do mesmo.

- Classificação de padrões: uma área vasta que abrange reconhecimento de imagens, fala, diagnóstico, previsão, entre outros.

- Sistemas de redução de dimensão: capazes de aprender representações compactadas de seus padrões de entrada.

- Otimização e satisfação de restrições: a rede busca a maximizar o atendimento às restrições e às metas de otimização.

O aspecto comum entre as RNAs, além de serem constituídas de neurônios, é que são organizadas em camadas. Tipicamente, possuem uma camada de entrada, na qual os padrões de entrada são apresentados, camadas ocultas, que integram os padrões de diferentes maneiras, e camadas de saída, na qual os resultados da rede podem ser obtidos. 
Neste trabalho serão consideradas apenas redes de alimentação direta, utilizadas como classificadores. Quanto à natureza da função de ativação, RNAs representantes de dois grupos principais são apresentadas: o Perceptron de Múltipla Camada, que calcula a correlação entre as entradas de seus neurônios, e a Rede de FBR, que calcula a distâcia entre as entradas e o centro das funções radiais de seus neurônios.

\subsubsection{Perceptrons}

O Perceptron foi uma das primeiras arquiteturas de RNAs, de estrutura simples, capaz de classificar dois padrões linearmente separáveis, com apenas um neurônio com pesos ajustáveis. Adicionando-se neurônios na sua única camada, este tipo de RNA torna-se capaz de classificar mais padrões, de forma que o número de padrões corresponde ao número de neurônios (HAYKIN, 2001).

Segundo os critérios estabelecidos na seção anterior, pode-se classificar o Perceptron da seguinte maneira:

- Função de ativação: função de limiar.

- Topologia: a rede é de alimentação direta, as entradas são conectadas diretamente ao neurônio, que é responsável pela classificação.

- Algoritmo de aprendizagem: correção de erro, no qual os pesos dos neurônios (sinapses) são ajustados através do produto do erro da saída pela entrada entrada na sinapse em questão. Para o cálculo do erro, a saída esperada deve ser informada para o treinamento, ou seja, o processo de aprendizagem é supervisionado.

- Aplicações: pode ser utilizado para classificação de padrões linearmente separáveis.

O Perceptron, como as RNAs que operam como classificadores em geral, possui dois estados de operação distintos: a classificação (ou filtragem, considerando a RNA como um filtro adaptativo) e o aprendizado. Durante a classificação uma entrada é apresentada à rede e os sinais são propagados para obter-se a saída desejada. No caso do aprendizado supervisionado, esta saída é comparada com uma resposta desejada, e um sinal de erro é utilizado para ajustar os pesos das sinapses, alterando o comportamento de classificação da rede.

Conforme descrito em Haykin (2001), o aprendizado consiste, primeiramente, em inicializar todos os pesos de forma aleatória. Em seguida, classifica-se uma das entradas do 
conjunto de dados de treinamento, através da aplicação da equação 2.14 para obter-se o potencial de ativação e em seguida da equação 2.19 (com saída -1 caso $v_{k}<\ell$ ) para obter-se a saída do único neurônio da rede $y$. Considerando a saída desejada (obtida do conjunto de dados de treinamento) sendo $d$, o sinal de erro do neurônio $e$ pode ser obtido simplesmente por:

$$
e=d-y
$$

Finalmente o procedimento de ajuste dos pesos é realizado. A atualização envolve a adição de um coeficiente de ajuste $\Delta w_{j}$ ao peso:

$$
\hat{w}_{j}=w_{j}+\Delta w_{j}
$$

Sendo $\hat{w}_{j}$ o novo valor do peso $j$ da entrada após o ajuste. O cálculo do coeficiente $\Delta w_{j}$ pode ser feito de acordo com a regra:

$$
\Delta w_{j}=\eta e x_{j}
$$

Sendo $\eta$ uma constante denominada taxa de aprendizagem que regula a velocidade do ajuste dos pesos. O processo é repetido, a partir da classificação de outra entrada do conjunto de treinamento, até que não sejam necessárias mais alterações nos pesos.

Embora este modelo tenha trazido grandes expectativas na área de $\mathrm{CN}$, o trabalho histórico de (MINSKY; PAPERT, 1969) expôs as limitações do modelo e levantou dúvidas quanto a prosperidade da CN como um todo. Estas suspeitas, entretanto, mostraram-se infundadas quando a área de CN voltou a ganhar força com diversos modelos de sucesso cerca de 15 anos depois. A grande importância do Perceptron é histórica, devido ao se sucessor, o Perceptron de Múltipla Camada (PMC).

A inclusão de uma camada adicional no Perceptron de uma camada possibilita classificar padrões que estejam em regiões convexas fechadas ou abertas. Adicionando uma terceira camada, padrões em regiões arbitrárias podem ser classificados (LIPPMANN, 1987).

O PMC possui uma camada de entrada, na qual os sinais de entrada são captados, uma ou mais camadas ocultas, nas quais a integração de informações é realizada, e a camada de saída, na qual os sinais resultantes do processamento da rede podem ser obtidos. Um exemplo de PMC é apresentado na figura 2.9. Nesta figura, os neurônios estão representados de maneira simplificada: os círculos $X_{i}, Y_{j}$ e $Z_{k}$ representam neurônios 


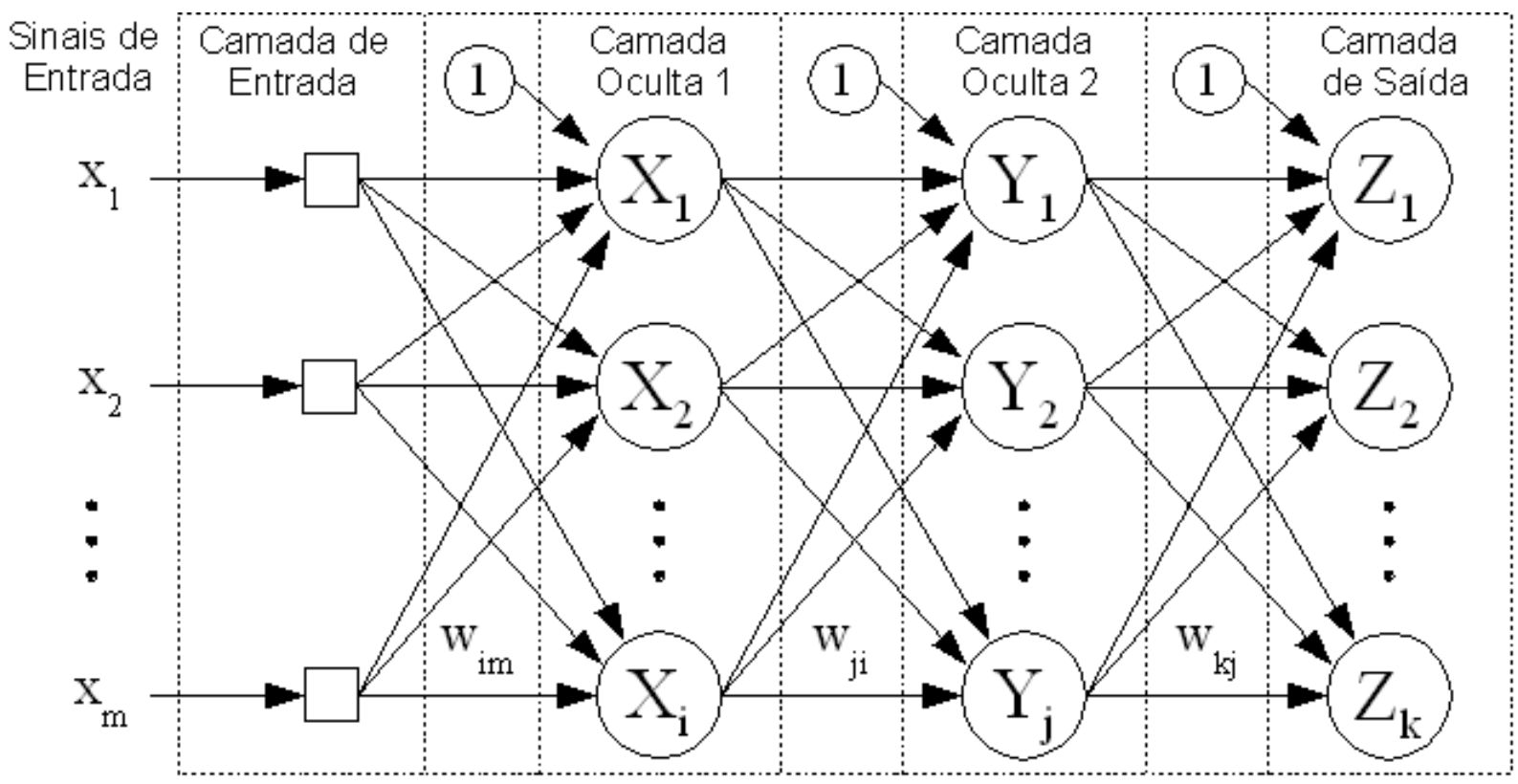

Figura 2.9: Topologia do Perceptron de Múltipla Camada.

com a junção aditiva e a função de ativação. Cada camada possui um conjunto de arcos que representam de forma simbólica as sinapses, possuindo um peso $w_{a, b}$, sendo que $a$ se refere ao número do neurônio em questão e $b$ ao número da sinapse na sua entrada.

O PMC possui características similares ao Perceptron:

- Função de ativação: função de ativação não-linear, como a função sigmóide, hiperbólica, etc.

- Topologia: a rede é de alimentação direta, multicamada (camada de entrada, ocultas e de saída) e, tipicamente, completamente conectada.

- Algoritmo de aprendizagem: retropropagação (backpropagation) ou suas variantes, em que o sinal de erro obtido na camada de saída é propagado na direção inversa das conexões dos neurônios. Do ponto de vista de uma camada, entretanto, o algoritmo é de correção de erro. A diferença essencial está na maneira pela qual as camadas ocultas obtém seus respectivos erros.

- Aplicações: classificação de padrões em geral, como reconhecimento de objetos ou letras em imagens, de fonemas ou palavras em sons, síntese de voz, previsões baseadas em dados históricos, entre outros.

A inicialização e o cálculo das saídas do PMC ocorre de maneira similar o Perceptron. A diferença é que o sinal da entrada necessita ser propagado até os neurônios da saída, 
através da aplicação da equação 2.14 seguida da função de ativação (por exemplo equação 2.21) para cada neurônio da camada de entrada, camadas ocultas e de saída, nesta ordem. Assim pode-se obter o erro $e_{k}$ de cada neurônio $k$ da saída através da equação 2.23.

A atualização dos pesos segue a equação 2.24, entretanto o cálculo de $\Delta w_{j}$ da cada neurônio é diferenciado. Esta é a principal diferença incorporada pelo algoritmo de retropropagação. A atualização dos pesos deve ser realizada na direção do gradiente descendente do erro em relação aos pesos. Os ajustes de pesos de um determinado neurônio $\left(\Delta w_{j}\right)$ seguem a equação:

$$
\Delta w_{j}=\eta \delta x_{j}
$$

Sendo que $\delta$ representa o gradiente do erro da saída do neurônio em questão. Seu cálculo é diferenciado, dependendo da camada em que se encontra o neurônio em questão. Se este estiver na camada de saída, temos:

$$
\delta=\varphi^{\prime}\left(v_{k}\right) e
$$

Sendo que $\varphi^{\prime}\left(v_{k}\right)$ é a derivada da função $\varphi(x)$ em relação ao parâmetro. Se o neurônio estiver nas camadas ocultas, ele deve utilizar os $\delta$ da camada imediatamente posterior à sua para calcular seu próprio $\delta$. Sejam $\delta_{k}$ os gradientes dos $N$ neurônios da próxima camada aos quais o neurônio se conecta, e $w_{k}$ os pesos destas conexões, temos:

$$
\delta=\varphi^{\prime}\left(v_{k}\right) \sum_{k=1}^{N} \delta_{k} w_{k}
$$

Tomando por exemplo uma função de ativação $\varphi\left(v_{k}\right)$ sigmoidal como apresentada na equação 2.21, para o cálculo da saída $y$ de um determinado neurônio, a derivada $\varphi^{\prime}\left(v_{k}\right)$ pode ser escrita em termos da própria função $\varphi\left(v_{k}\right)$ :

$$
\varphi^{\prime}\left(v_{k}\right)=\alpha y(1-y)
$$

Sendo assim, para esta função de ativação o cálculo do delta seria:

$$
\delta= \begin{cases}\alpha y(1-y) e & \text { se o neurônio está na camada de saída } \\ \alpha y(1-y) \sum_{k=1}^{N} \delta_{k} w_{k} & \text { se o neurônio está em uma camada oculta }\end{cases}
$$




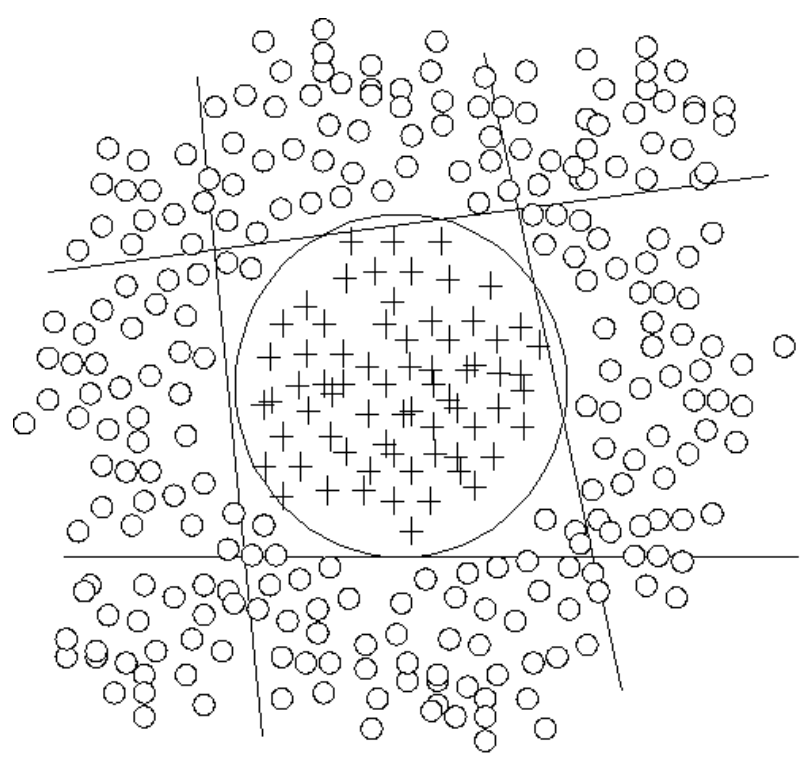

Figura 2.10: Exemplo de classificação em duas classes, adaptado de Mehrotra, Mohan e Ranka (1997, p. 142).

Como no Perceptron, este processo é repetido para todas as entradas do conjunto de treinamento, o número de vezes necessárias para atingir um erro quadrático mínimo nas saídas.

Várias heurísticas e derivações do algoritmo de retropropagação foram propostos, com o objetivo de melhorar o desempenho do PMC, como a taxa de aprendizagem adaptativa, o termo de momentum, entre outros (HAYKIN, 2001).

O PMC foi um dos modelos responsáveis pela expansão das técnicas de CN, no campo da pesquisa básica e nas aplicações. Diversas variantes deste modelo, métodos para acelerar o aprendizado e aplicações foram propostas nas últimas décadas (HAYKIN, 2001).

\subsubsection{Redes de Funções de Base Radial (FBR)}

As Redes de FBR são redes neurais que cujo aprendizado é visto como "a procura por uma superfície em um espaço multidimensional que ajuste da melhor forma o conjunto de dados de treinamento" (HAYKIN, 2001, p. 283).

Estas redes são indicadas para resolver certos problemas de classificação em que os exemplos estão agrupados como no exemplo da figura 2.10. Enquanto um PMC necessitaria de 4 a 5 neurônios na camada de oculta para classificar estes dois padões, um único neurônio oculto em uma rede FBR seria suficiente.

Tais redes são constituídas de três camadas. A camada de entrada que recebe os 


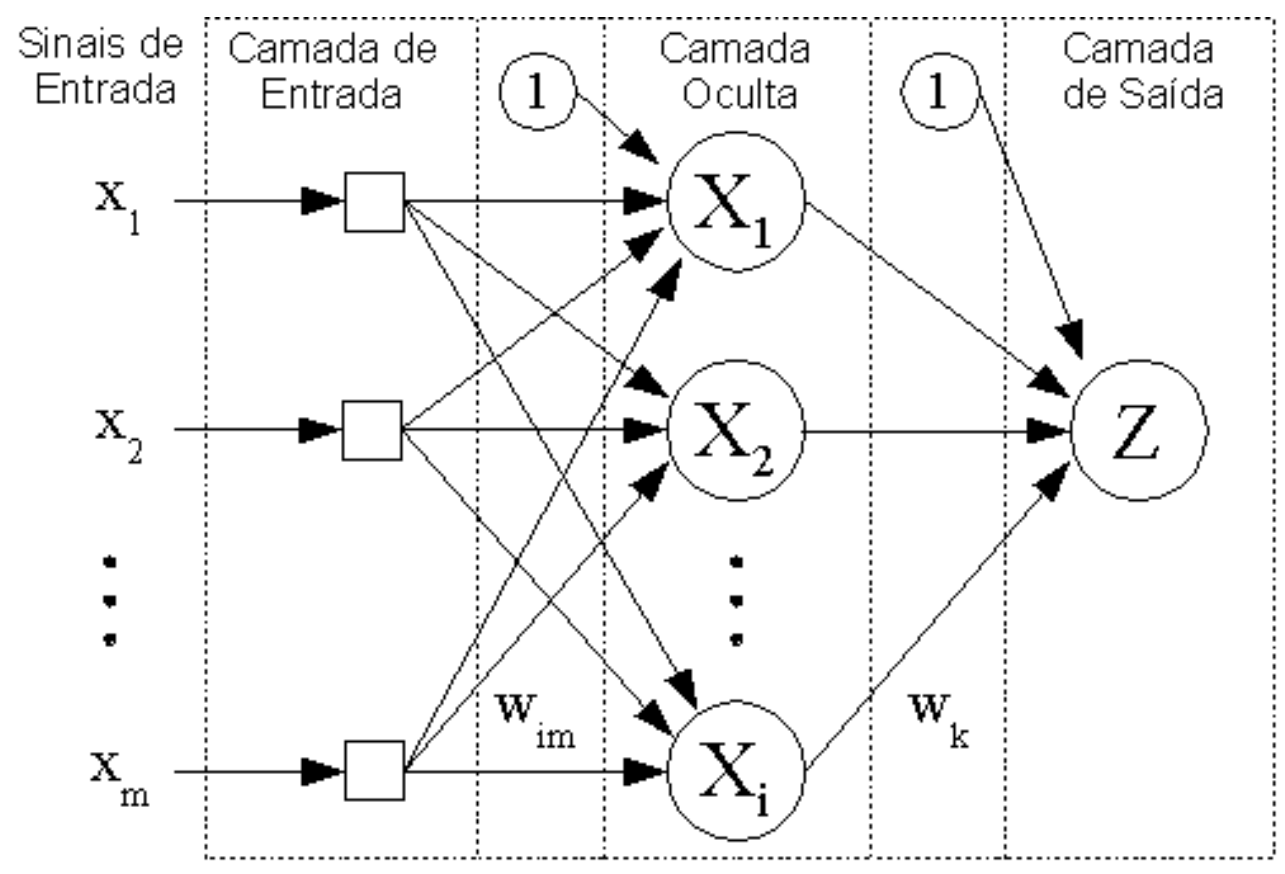

Figura 2.11: Topologia das Redes de Funções de Base Radial.

estímulos do ambiente, totalmente conectada com a única camada oculta da rede. A camada oculta, por sua vez, realiza uma transformação não-linear nos dados da entrada, e conecta-se à camada de saída. Esta última camada é linear, e fornece a resposta de rede.

A arquitetura de uma Rede de FBR é apresentada na figura 2.11. Os círculos $X_{i} Z$ representam neurônios com a junção aditiva e a função de ativação. Os pesos $w_{i m}$ são as sinapses entre os $m$ sinais de entrada e os $i$ neurônios da camada oculta. Entre a camada oculta e a saída as sinapses são representadas por um vetor de pesos $w_{k}$, que representa as sinapses de entrada do neurônio $K$. O número de neurônios da camada oculta, que possui as funções de base, é tipicamente menor que o número de pontos de dados.

Os neurônios da camada oculta são neurônios radiais, e, segundo Haykin (2001, p. 232), "calculam a distância euclidiana entre o vetor de entrada e o centro daquela unidade" . Tipicamente funções gaussianas são utilizadas para representar a ativação destes neurônios. A camada de saída, em contrapartida, é uma função linear, que realiza a soma de todas as entradas ponderadas pelos pesos $w_{k}$. A classificação das Redes de FBR é:

- Função de ativação: funções radiais na camada oculta, para calcular a distância euclidiana entre a entrada e centro, e função de ativação linear na camada de saída.

- Topologia: a rede é de alimentação direta, com duas camadas de neurônios, oculta 
e de saída (sendo esta constituída tipicamente por um neurônio), completamente conectada.

- Algoritmo de aprendizagem: diferente para cada camada. Existem várias estratégias de aprendizagem, que envolvem a escolha dos centros das funções e ajuste dos parâmetros para aproximar o conjunto de treinamento. Pode-se encontrar, por exemplo, em Haykin (2001) os métodos de Centros Fixos, Seleção Auto-Organizada de Centros e Seleção Supervisionada.

- Aplicações: pode ser aplicada nos mesmos problemas resolvidos pelo PMC, em aproximação de funções, interpolação, entre outros.

O aprendizado nas redes FBR pode ser dividido de acordo com suas camadas. Em linhas gerais, existem estratégias que envolvem o aprendizado não supervisionado para a camada oculta e supervisionado para a camada de saída, e estratégias que envolvem o aprendizado supervisionado das duas camadas (HAYKIN, 2001).

- Centros fixos selecionados ao acaso: os centros das funções radiais de cada neurônio são escolhidos aleatoriamente do conjunto de dados de treinamento. O desvio padrão das funções é calculado de forma a não permitir funções muito pontiagudas ou planas. Os pesos da camada de saída podem ser aprendidos, por exemplo, pelo algoritmo de retropropagação.

- Seleção auto-organizada de centros: os centros são selecionados através de um algoritmo de aprendizado não supervisionado de agrupamento, como por exemplo o algoritmo das k médias:

1. Inicializar os centros com valores aleatórios diferentes.

2. Apresentar uma entrada escolhida aleatóriamente à rede.

3. Escolher o neurônio vencedor, aquele cujo centro está mais próximo da entrada (menor valor na saída).

4. Atualizar os centros $w_{k}$ deste neurônio para um novo valor $\hat{w}_{k}$ :

$$
\hat{w}_{k}=w_{k}+\eta\left(x_{k}-w_{k}\right)
$$

Sendo $\eta$ a taxa de aprendizagem e $x_{k}$ as entradas do neurônio.

5. Voltar para o passo 2 até que os centros não sejam mais alterados. 
Neste caso também é possível a utilização da retropropagação para o cálculo dos pesos da camada de saída.

- Seleção Supervisionada dos Centros: nesta técnica de aprendizado os centros e as larguras das funções radiais são obtidas através dos gradientes do erro como no algoritmo de retropropagação.

Ainda segundo Haykin (2001), é possível criar uma Rede de FBR capaz de simular um PMC, e vice-versa.

\subsection{Computação Evolutiva (CE)}

Nas abordagens que podem ser classificadas como CE, a teoria da evolução das espécies de Darwin é adaptada para modelos computacionais. São consideradas populações de soluções potenciais, em que aplicam operadores genéticos para se obter novas soluções.

Conforme Rezende (2003) as três principais categorias de soluções de CE são: Algoritmos Genéticos (AGs), estratégias evolutivas e programação evolutiva.

As três técnicas compartilham muitas características comuns, conforme indicado em Fogel (1995). Todas possuem um conjunto de soluções, denominado população. Alterações aleatórias destas soluções são realizadas, e métodos de seleção determinam que soluções continuarão na população.

Os AGs utilizam operações genéticas inspiradas na natureza, operando em elementos do modelo que são considerados os cromossomos. As estratégias evolutivas e a programação evolutiva, por sua vez, possuem um foco mais voltado para a população e não para o indivíduo, mantendo relações entre o indivíduo e seus descendentes. O cruzamento pode ocorrer, mas limitado a uma determinada espécie (FOGEL, 1995).

Nas estratégias evolutivas, as soluções de uma população são vistas como comportamentos de indivíduos, e não seus genes. Assim, mutações e gerações podem alterar o comportamento de indivíduos ligados por alguma relação. Em programação evolutiva, o solução que evolui representa um algoritmo em uma determinada linguagem, resultando em um programa, para resolver determinado problema (FOGEL, 1995).

A estratégia mais utilizada, principalmente em aplicações de engenharia, segundo (REZENDE, 2003), são os algortimos genéticos. Em linhas gerais, as seguintes etapas são realizadas durante uma busca de solução através destes algoritmos: 


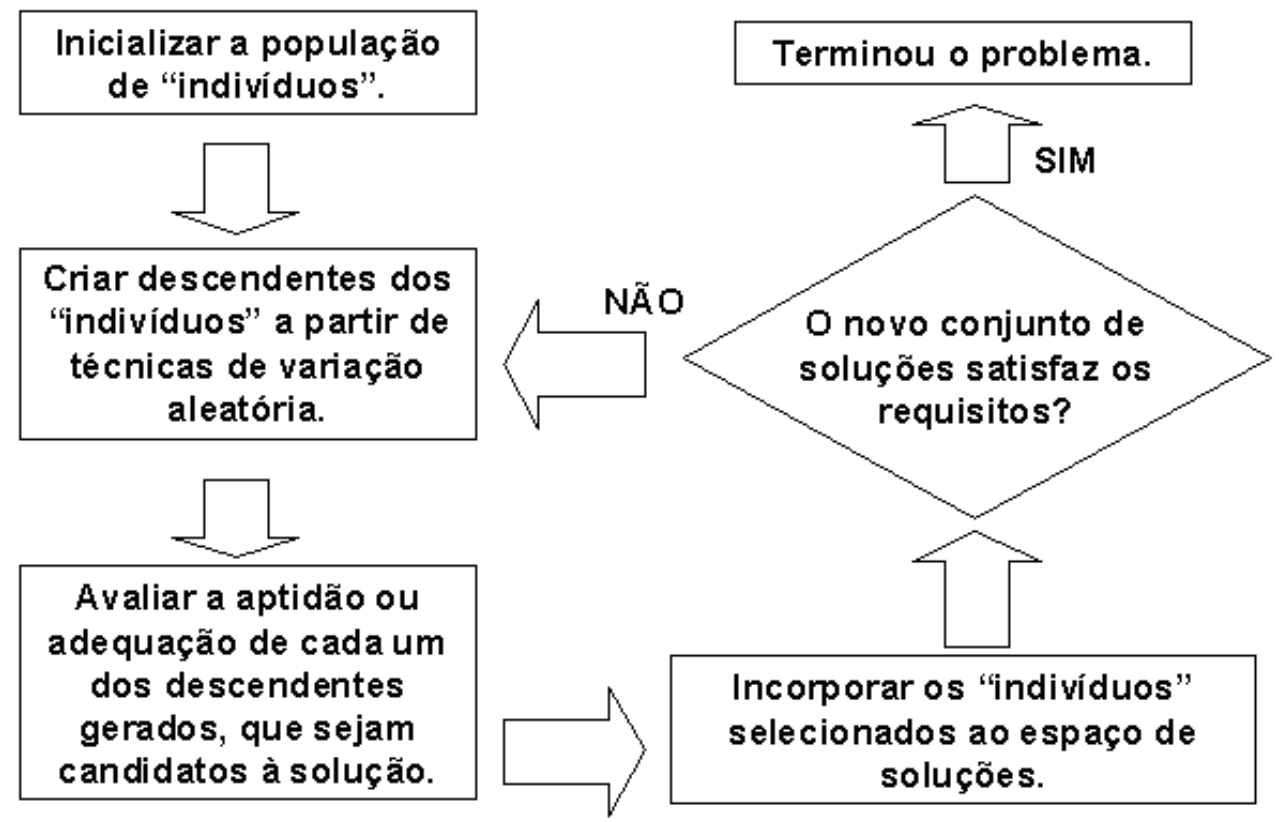

Figura 2.12: Exemplo de execução de um algoritmo em CE.

1. Gerar uma população inicial aleatoriamente.

2. Avaliar a aptidão dos indivíduos (soluções) da população através de uma função de adequação.

3. Selecionar indivíduos da população através de um mecanismo de seleção.

4. Aplicar operadores de cruzamento nestes indivíduos.

5. Aplicar operadores mutação nestes indivíduos.

6. Avaliar a aptidão destes indivíduos.

7. Caso nenhum indivíduo represente a solução desejada, voltar para passo 3.

Um diagrama que exemplifica o processo é mostrado na figura 2.12, extraído de (ANDRADE, 2002). Pode-se encontrar (REZENDE, 2003) algumas características importantes dos AGs:

- Representação: o cromossomo que representa cada indivíduo da população é uma estrutura de dados, e todas as combinações possíveis do conteúdo desta estrutura formam o espaço de busca.

- Função de adequação: uma função que avalia, de acordo com o cromossomo, o quanto um indivíduo está próximo da solução desejada. 


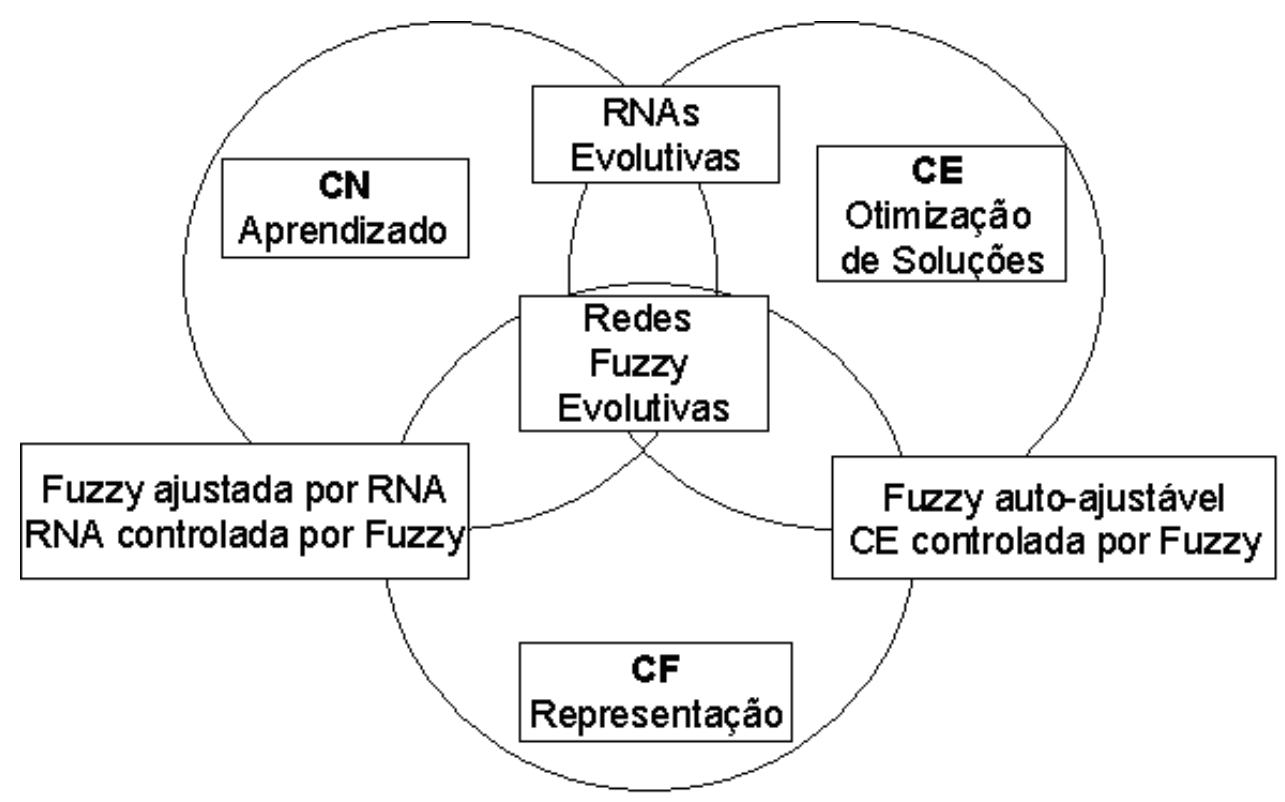

Figura 2.13: Aplicações híbridas de IC.

- Seleção: o método de seleção envolve a escolha de um subconjunto de indivíduos da população, sendo que os indivíduos com maior aptidão são favorecidos no processo.

- Operadores genéticos: cruzamento, em que indivíduos novos são gerados a partir de cruzamentos dos cromossomos dos pais, e mutação, em que um ou mais componentes da estrutura que representa o cromossomo são alterados, introduzindo diversidade genética à população.

As técnicas de CE apresentam comportamento adaptativo para tratar de problemas não lineares de muitas dimensões sem requerer conhecimento explícito sobre as estruturas associadas aos mesmos. Vêm sendo aplicados com sucesso em problemas de otimização e busca de soluções.

\subsection{Aplicações Híbridas}

Cada uma das áreas da IC apresenta características úteis para resolver certos tipos de problemas. No caso de problemas complexos, combinações das áreas podem apresentar resultados melhores que a aplicação isolada de uma determinada técnica. A figura 2.13 apresenta um esquema que ilustra a tendência de utilização de aplicações híbridas no contexto atual dos métodos de IC.

Tipicamente têm-se combinado a capacidade de representação lingüística de CF, 
aprendizado de CN e capacidade de otimização de CE. Assim, diversas combinações podem ser criadas, como as apontadas por Bonissone et al. (1999):

- CF ajustada por CN: a rede Adaptative-Network-Based Fuzzy Inference System (ANFIS) proposta por Jang (1993) pode ser vista como um exemplo de aplicação híbrida, na qual RNAs são utilizadas para ajustar um controlador nebuloso. As saídas do controlador são comparadas com dados de treinamento, e a segunda camada, composta por neurônios artificiais e responsável pelas partições nebulosas, é ajustada através do gradiente do erro.

- CF ajustada por CE: técnicas de algoritmos genéticos são utilizadas para ajustar partições primárias, ou as próprias regras, resultando em um sistema nebuloso capaz de evoluir.

- CN gerada por CE: técnicas de CE têm sido aplicadas com sucesso na síntese e ajuste de RNAs, para se encontrar valores ótimos dos pesos, substituindo o algoritmo de retropropagação, evoluindo a topologia da rede, em termos de número de camadas ocultas e neurônios em cada camada.

- CN controlada por CF: as técnicas de CF têm sido utilizadas para monitorar o desempenho de RNAs, modificando seus parâmetros como, por exemplo, a taxa de aprendizado. Outra possibilidade é a utilização de regras nebulosas no lugar da função de ativação dos neurônios, criando uma rede com maior poder de representação.

- CE controlada por CF: o potencial de CF em traduzir conhecimento especialista têm sido utilizado para gerenciar recursos de CE, como tamanho de população, rigidez de seleção, probabilidades utilizadas em mutação, entre outros.

Atualmente os modelos híbridos vêm sendo aplicados a diversos problemas complexos, com resultados interessantes, que têm levado os pesquisadores a estudos mais aprofundados sobre as três técnicas e suas potencialidades conjuntas. Esta explosão de aplicações é mais uma justificativa para a pesquisa de possíveis relações e transformações entre as técnicas.

\subsection{Unificação das Abordagens da IC}

Na história da IC, alguns trabalhos se destacaram relacionando fortemente CF e CN. O trabalho original de Jang (1992) apresenta o modelo ANFIS. Embora classificado por 


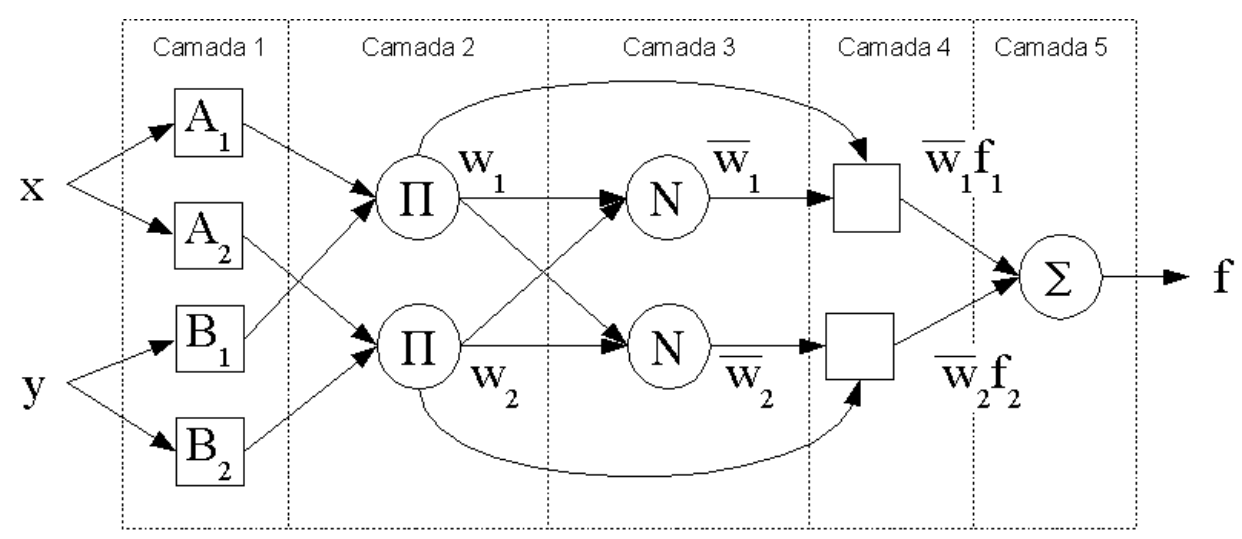

Figura 2.14: Rede ANFIS equivalente a um SIN com regras do tipo Tsukamoto, adaptado de Jang (1993, p. 668).

Bonissone et al. (1999) como um sistema híbrido, a rede ANFIS é descrita pelo seu criador como "uma classe de rede adaptativa que é equivalente a sistemas de inferência nebulosos" (JANG, 1993, p. 670).

A motivação da construção do modelo citado foram os pontos fracos das técnicas de $\mathrm{CF}$ e $\mathrm{CN}$ :

- Dificuldade de transformar conhecimento especialista humano na base de dados e de regras do SIN, e inexistência de métodos para ajustar as suas partições primárias.

- Impossibilidade de utilização de conhecimento especialista sobre o sistema na inicialização dos parâmetros de uma RNA.

Pode-se notar, que uma técnica complementa a outra, solucionando as pendências existentes. A arquitetura de uma rede ANFIS equivalente à um SIN de regras do tipo Tsukamoto, com apenas duas variáveis, é apresentada na figura 2.14. O SIN simulado possui duas variáveis de entrada, $x$ e $y$, e suas regras lingüísticas são:

"SE $x$ é $A_{1}$ E $y$ é $B_{1}$ ENTÃO $f$ é $C_{1}$

"SE $x$ é $A_{2}$ E $y$ é $B_{2}$ ENTÃO $f$ é $C_{2}$

A rede ANFIS deve ser construída da seguinte maneira (JANG, 1993):

- Camada 1: composta de unidades de transformação que avaliam o grau de pertinência de uma única entrada em relação à uma única variável lingüística. Do ponto de vista de redes adapatativas, pode ser considerado um neurônio linear com apenas 
uma entrada, com uma função de ativação similar à uma função de pertinência de conjuntos nebulosos. O resultado do processamento desta camada, portanto, são as pertinências das entradas em relação às variáveis lingüísticas, as premissas.

- Camada 2: responsável por aplicar um operador de conjunção (T-Norma) às premissas de cada regra nebulosa, esta camada é constituída de $n$ neurônios, sendo $n$ o número de regras nebulosas. Os neurônios integram as entradas, entretanto esta integração não é uma somatória das entradas ponderadas pelos pesos como em arquiteturas típicas de redes neurais, e sim dependente da T-Norma utilizada. A função de ativação é a identidade, ou seja, nenhuma transformação é aplicada no conjunto de entrada.

- Camada 3: responsável por normalizar os valores de disparo das regras, obtidos na camada anterior.

- Camada 4: composta por nós que recebem apenas uma entrada e geram uma saída, realiza o cálculo do produto dos valores normalizados das regras da camada anterior com o valor numérico da saída obtido através da sua função de pertinência. Assim, esta camada disponibiliza em sua saída, os conseqüentes.

- Camada 5: realiza a somatória de todos os sinais oriundos da camada 4, através de um neurônio linear sem pesos ajustáveis.

Ainda segundo Jang (1993) esta rede pode ser treinada através de diversos algoritmos de aprendizado propostos em CN, como os métodos que utilizam o gradiente decrescente. Neste mesmo trabalho é proposto um método híbrido de ajustes de parâmetros, derivados destes dois algoritmos, utilizando a retropropagação para propagar os erros para as camadas ocultas.

Desta maneira, o trabalho pioneiro de Jang (1992) demonstra a possibilidade de converter um conjunto de modelos nebulosos em uma rede adaptativa, um modelo mais genérico de redes neurais de alimentação direta com aprendizado supervisionado. Sendo assim, este trabalho indica que, para uma certa família de modelos nebulosos e neurais, sob determinadas condições de operações, é possível realizar transformações que traduzem exatamente um modelo em outro.

Alguns anos depois, as redes Funções de Base Radial com Peso (FBRP) foram propostas no trabalho de Reyneri (1995), como um modelo generalizado englobando as arquiteturas de redes neurais PMC e FBR. Neste modelo o potencial de ativação $v_{k}$ de um determinado neurônio é uma fusão dos neurônios de correlação e radiais: 


$$
v_{k}=b_{k}+\frac{1}{m} \sum_{j=1}^{m} D_{n}\left(x_{j}-c_{k, j}\right) w_{k, j}
$$

Sendo este neurônio identificado por $k$ em um conjunto de neurônios. A entrada é um vetor com elementos $x_{j}$. O neurônio $k$ possui um vetor de localização dos centros, de elementos $c_{k, j}$, e um vetor de pesos $w_{k, j}$. A função $D_{n}($.$) calcula a distância entre cada$ elemento $j$ do vetor de entrada e o vetor de localização dos centros:

$$
D_{n}(a, b)= \begin{cases}(a-b) & \text { se } n=0 \\ |a-b|^{n} & \text { se } n>0\end{cases}
$$

Finalmente, uma função de ativação $\varphi($.$) é aplicada obter a saída y_{k}$. Reyneri (1995) descreve a possibilidade de representar as redes PMC e FBR com este novo modelo. No caso dos PMC, basta utilizar um vetor de localização de centros com valores zero. Para representar uma rede FBR, no vetor de pesos deve ser constituído de valores um, utilizando $n=2$ para a função $D_{n}($.$) .$

O aprendizado é realizado através do gradiente decrescente no caso do vetor de pesos, e no caso do vetor de localização de centros através dos algoritmos de aprendizado autoorganizado ou mesmo supervisionado, com o método do gradiente ajustando o centro e largura das funções radiais. Além da capacidade de repsresentar estas duas arquiteturas de RNA, Reyneri (1995) aponta a possibilidade de modelagem de regras nebulosas através de uma rede FBRP. Em novo trabalho, Reyneri (1996) apresenta uma proposta de unificação entre os paradigmas nebuloso e neural, através das redes FBRP. Os modelos neurais foram divididos em dois grandes grupos:

- Redes Baseadas em Correlação: todos os paradigmas com neurônios baseados no Perceptron, cuja saída é uma correlação entre o vetor de entradas e e o vetor de pesos. Estes neurônios foram denominados P-neurons.

- Redes Baseadas em Distância: redes FBR, mapas de Kohonen, Memórias Associativas, que são baseadas em um neurônio cuja saída depende da distância entre o vetor de entradas e o vetor de localização de centro do neurônio. Estes neurônios foram chamados de $R$-neurons.

A proposta apresentada em Reyneri (1996) é que regras nebulosas podem ser aproximadas por neurônios do tipo FBRP, construídos de uma forma específica. O primeiro 
passo para avaliar uma regra nebulosa, de acordo com o modelo da equação 2.12 , é a obtenção do grau de pertinência de cada entrada $x_{j}$ aos seus respectivos conjuntos nebulosos $A_{j}$, representado por $A_{j}\left(x_{j}\right)$. Reyneri (1996) propõe uma notação para representar estes conjuntos nebulosos, válida apenas para funções de pertinência simétricas e monotônicas ao redor de um centro (muito comuns em modelos nebulosos):

$$
A(x)=H\left(\frac{|x-c|}{s}\right)
$$

Sendo que $c$ é o centro da função, $s$ é a largura da função, e $H(z)$ é o formato da função, que pode ser alguns dos formatos normalmente utilizados para modelos nebulosos:

$$
H(z)= \begin{cases}1-|z| & \text { triangular } \\ \frac{1}{1+|z|^{2 \alpha}} & \text { formato de sino } \\ e^{-z^{2}} & \text { gaussiana }\end{cases}
$$

A avaliação do potencial de ativação de uma regra $i$, dada por $T_{j=1}^{p}\left(A_{j i}\left(x_{j}\right)\right)$ conforme a equação 2.12, caso o operador de T-Norma escolhido seja o mínimo (equação 2.3), pode ser descrita conforme a notação descrita:

$$
y_{i}=M I N_{j=1}^{p}\left[H\left(\frac{\left|x_{j}-c_{j i}\right|}{s_{j i}}\right)\right]
$$

Como as funções $H($.$) são decrescentes ao redor do eixo, o cálculo do mínimo entre os$ valores da função pode ser transformado no cálculo dos máximos dos parâmetros, seguido da aplicação da função:

$$
y_{i}=H\left[M A X_{j=1}^{p}\left(\frac{\left|x_{j}-c_{j i}\right|}{s_{j i}}\right)\right]
$$

Que pode ser escrita na sua forma final apresentada em Reyneri (1996):

$$
y_{i}=\lim _{n \rightarrow \infty} H\left[\sqrt[n]{\sum_{j=1}^{p}\left(\frac{\left|x_{j}-c_{j i}\right|}{s_{j i}}\right)^{n}}\right]
$$

Uma regra nebulosa computada desta maneira pode ser implementada através de um 
neurônio FBRP. O centro das funções seriam os parâmetros $c_{j i}$, os pesos seriam $1 / w_{j i}$. A somatória realizada entre estes fatores é característica comum nos neurônios, e o a função $H($.$) seria a função de transferência. O equacionamento equivalente para o operador$ produto como T-Norma pode ser encontrado em Reyneri (1996).

Calculando-se o potencial de ativação de cada regra, resta somente a questão do cálculo da saída numérica através da defuzzificação. Reyneri (1996) apresenta em seu trabalho a sugestão da utilização de mais duas camadas de neurônios para a defuzzificação, embora não detalhe o procedimento par realizar esta transformação.

Sendo assim, um SIN poderia ser aproximado a partir de elementos neurais. Mais ainda, poderia ser treinado com os algoritmos de aprendizado de RNAs. As principais vantagens apontadas por Reyneri (1996) na utilização de redes FBRP como um modelo genérico para computação neural e nebulosa são:

- Interpretação lingüística de pesos neurais: a extração de conhecimento de uma determinada RNA treinada para resolver um determinado problema, no formato de regras nebulosas e variáveis lingüísticas.

- Computação numérica de regras nebulosas: operação numérica das regras nebulosas, permintindo o ajuste de parâmetros (aprendizado), ou execução de regras nebulosas em processadores neurais.

A plataforma proposta por Reyneri (1996) foi utilizada na construção de um modelo de robô autoguiado com seis pernas, como exemplo de aplicação de controle nebuloso em sistemas dinâmicos complexos (BERARDI et al., 1997).

Estes trabalhos mostram de que existem elementos equivalentes entre CF e CN. No caso do modelo ANFIS, a transformação é isomórfica, mas muitas restrições são feitas na construção do modelo neural. No caso das redes FBRP, a transformação realiza uma aproximação, mas os modelos de neurônios utilizados são mais próximos dos modelos neurais mais comuns.

Embora a abrangência das transformações não seja completa, e também não seja nas duas direções (como, por exemplo, um Perceptron ser transportado para o domínio nebuloso), estas propostas podem ser utilizadas como um importante ponto de partida para a obtenção de novas relações entre as técnicas. 


\subsection{Considerações Finais do Capítulo}

A área de IA vêm ganhando força nos últimos anos, em termos de pesquisa básica, no estudo da inteligência e, mais ainda, em aplicações de sucesso em diversos campos. Atualmente algumas classes de problemas só possuem solução prática através destas técnicas. Pode-se particionar a IA em dois grandes grupos, a criação de artefatos que contenham racionalidade, por um lado, e a simulação das características da inteligência biológica, por outro.

As técnicas de IA centradas em agentes inteligentes, que envolvem a modelagem da racionalidade, são descritas e exploradas detalhadamente em Russel e Norvig (2004). As abordagens da IC representam o segundo grande conjunto de técnicas de IA, envolvendo $\mathrm{CF}, \mathrm{CN}$ e $\mathrm{CE}$.

Nguyen e Walker (1996) possui uma completa abordagem formal dos modelos nebulosos. No caso dos modelos neurais, Haykin (2001) é uma referência que abrange os principais modelos, de maneira formal, demonstrando casos de aplicação e realizando análises comparativas. Uma leitura introdutória sobre CE pode ser encontrada em Fogel (1995).

Estas três áreas são responsáveis por parte consideráveldo crescimento das aplicações de IA. Utilizadas inicialmente de forma isolada, hoje são vistas como complementares e aplicadas em sistemas híbridos. Pode-se encontrar em Chen (1996) e Tsoukalas e Uhrig (1997) aplicações envolvendo as duas técnicas que são foco deste trabalho, CF e CN, com detalhes da construção dos projetos e exemplos práticos.

Mais recentemente, nos trabalhos descritos neste capítulo e em outros citados na introdução, a convicção de que as técnicas são complementares evolui para a possibilidade de serem, pelo menos em parte, equivalentes. Estas propostas servem de base para a pesquisa mais aprofundada e realização de experimentos que possibilitem aprimorar as técnicas e, talvez, compreender melhor o que elas pretendem simular: o conjunto de atributos que denominamos inteligência. 


\title{
3 Modelos para Exploração de Relações da IC
}

\author{
Neste capitulo são apresentados o diagrama Gajski-Kuhn original \\ e o diagrama Andrade-Caversan, adaptação daquela forma de \\ representação para a IC. Com a proposta de seus pontos notáveis \\ e níveis de abstração, este modelo pode ser utilizado como base \\ para a exploração de relações da IC. Novos modelos, que surgiram \\ como propostas alternativas durante a pesquisa, também são \\ apresentados.
}

A exploração de relações entre as técnicas da IC envolve o estudo de modelos e sistemas que auxiliem a representação de seus elementos e a experimentação de instâncias de alguns modelos, realizando simulações e coleta de dados empíricos que permitem reforçar intuições ou comprovar a validade de modelos propostos.

Foi construído um modelo para representação das duas técnicas de IC envolvidas neste trabalho, o diagrama Andrade-Caversan (AC), com o objetivo de representar e sistematizar a busca por relações de forma estratificada.

Do ponto de vista dos possíveis translados entre os domínios das duas técnicas, duas abordagens podem ser levadas em consideração. O estabelecimento de uma relação umpara-um entre os elementos das técnicas, um isomorfismo, caracteriza uma relação muito forte entre elas. Outra abordagem é a aproximação de elementos de uma técnica para elementos da outra, uma relação mais fraca porém muito interessante, visto que as duas técnicas se caracterizam também como aproximadores de funções.

A evolução do modelo e dos experimentos resultou em novas idéias e propostas. A idéia de um isomorfismo completo atenua-se gradativamente, dando lugar à idéia de um sistema de representação em que as técnicas possuem não só intersecções, mas também elementos complementares. 


\subsection{Isomorfismos entre Sistemas}

A definição de isomorfismo remete à teoria dos conjuntos. Conforme Kolmogorov e Fomin (1975) um isomorfismo é um mapeamento de um-para-um entre dois conjuntos, sendo que a função de mapeamento preserva a ordem dos elementos. Em suma, esta relação entre conjuntos é extremamente forte, tornando os conjuntos praticamente iguais, apenas vistos sob óticas diferentes.

Sabe-se que a teoria clássica de conjuntos, a álgebra booleana e a lógica proposicional são isomórficas, e suas equivalências são apresentadas na tabela 3.1, segundo Andrade (2002):

\begin{tabular}{|c|c|c|}
\hline Teoria de conjuntos & Álgebra Booleana & Lógica proposicional \\
\hline$\wp(X)$ & $B$ & $\Im(V)$ \\
\hline$\cup$ & + & $\vee$ \\
\hline$\cap$ & $\sim$ & $\sim$ \\
\hline$\sim$ & 1 & 1 \\
\hline$X$ & 0 & 0 \\
\hline$\oslash$ & $\leq$ & $\Rightarrow$ \\
\hline$\subseteq$ & & \\
\hline
\end{tabular}

Tabela 3.1: Isomorfismos entre sistemas lógicos formais

Qualquer teorema válido em um dos sistemas isomórficos deve encontrar um correspondente no outro. Sendo assim, existe a possibilidade de transportar um problema de um domínio para outro, isomórfico, tratá-lo com os teoremas existentes neste outro domínio, e trazê-lo novamente para o domínio original.

Em uma área relativamente nova como a IC, na qual muitos teoremas e modelagens diferentes ainda estão sendo propostos, o estabelecimento de relações isomórficas entre suas principais estruturas auxiliaria muito o processo de pesquisa. Existem, ainda, muitas divergências nas definições constituintes dessa área e da própria área de IA. A existência desses isomorfismos poderia ajudar a esclarecer algumas dessas indefinições, indicando que as técnicas existentes poderiam ser casos particulares de um modelo unificado, que representaria de maneira generalizada o que seria exatamente o escopo e a própria definição de IC. 


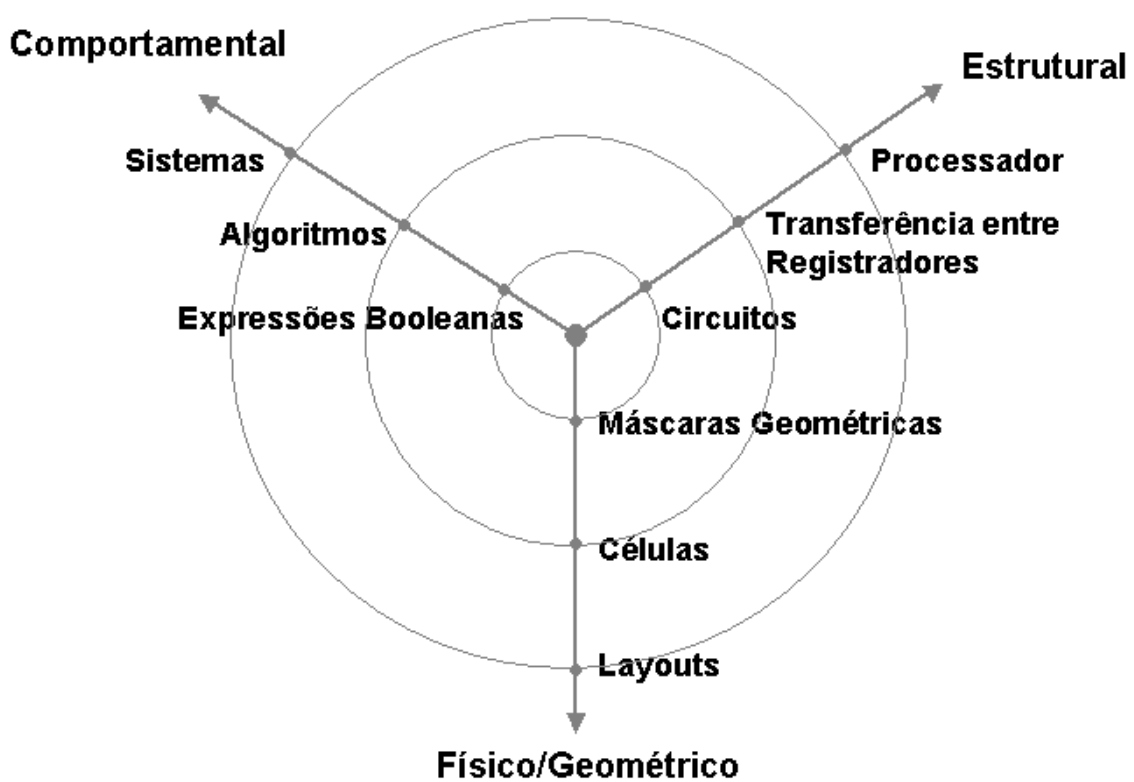

Figura 3.1: Diagrama Gajski-Kuhn.

\subsection{O Diagrama Gajski-Kuhn (GK)}

Para realizar a exploração das relações entre as três técnicas de IC, estabeleceu-se primeiro uma metodologia de pesquisa. Em Andrade (2002) foi feita a proposta da utilização do diagrama GK, devido à analogia que pode ser feita entre seus eixos e as técnicas de IC.

O diagrama GK (GAJSKI; KUHN, 1983) é uma ferramenta utilizada para representação de sistemas digitais, que consiste de um diagrama com três eixos, conforme apresentado na figura 3.1, que representam três maneiras diferentes de se analisar um sistema digital:

- Funcional (comportamental): o que um determinado circuito faz. Pode ser representado, por exemplo, utilizando-se expressões booleanas que indicam o comportamento do circuito.

- Estrutural: a ponte que liga a representação funcional e a geométrica. Apresenta os componentes (lógicos) através dos quais o circuito pode ser descrito sem os detalhes físicos, como portas lógicas, por exemplo. A representação estrutural pode ser utilizada como funcional, em alguns casos simples em que aquela descreve o comportamento do sistema de forma satisfatória.

- Geométrica: a representação física que ignora, na medida do possível, a funciona- 


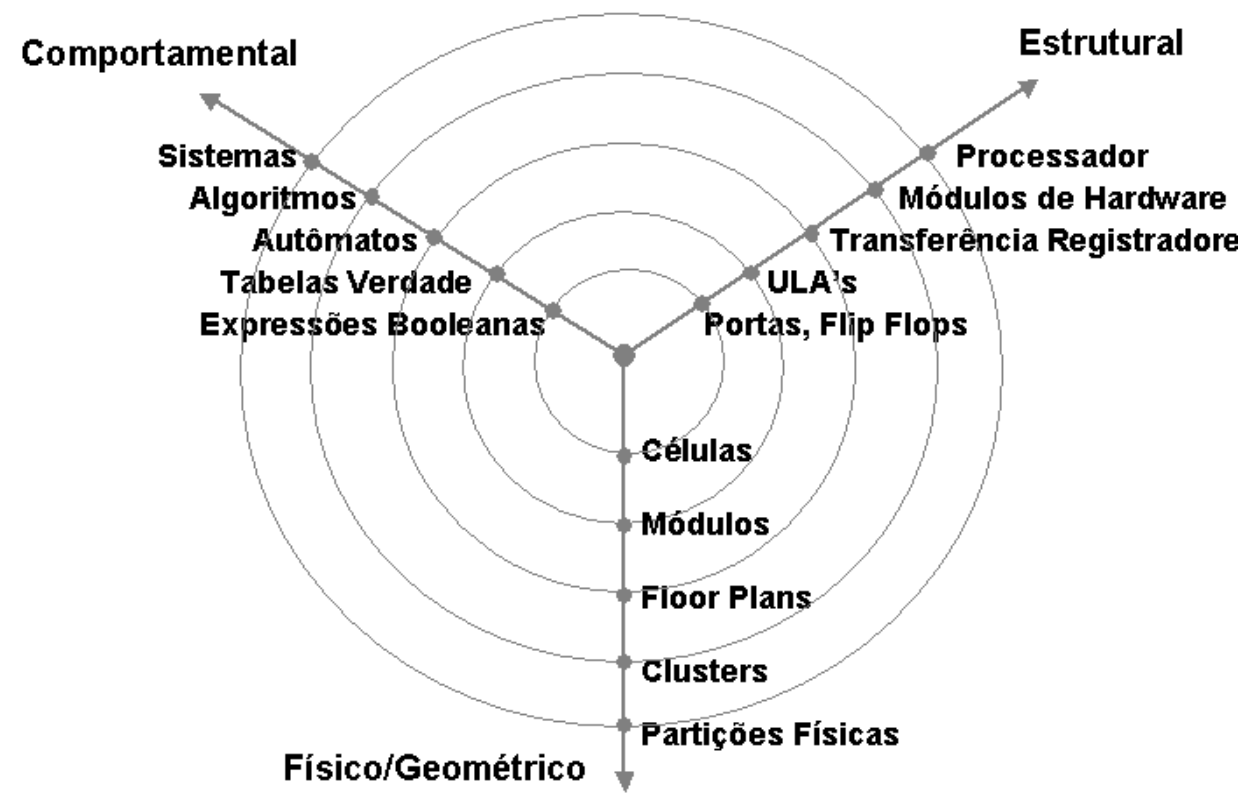

Figura 3.2: Diagrama GK base para pesquisa das técnicas de IC.

lidade desejada e concentra-se na estrutura espacial que será montada através da especificação estrutural.

O centro do diagrama representa um nível mais baixo de abstração, chegando aos componentes fundamentais de cada eixo. O nível de abstração aumenta conforme se afasta do centro, chegando-se à representação de um sistema completo. Sendo assim, os círculos concêntricos representam níveis equivalentes de abstração, partindo do centro (mais concretos) até os círculos mais externos (mais abstratos).

Os pontos indicados no diagrama são chamados de pontos notáveis, representando pontos discretos bem definidas dos sistemas digitais, servindo como base para definir os níveis de abstração equivalentes.

Uma característica importante do diagrama é a existência de operações que levam de um ponto notável para outro, que pode ou não estar em um mesmo eixo. Um exemplo indicado em Wagner, Jansh-Pôrto e Weber (1988) é a síntese funcional, que propõe transportar o projeto do eixo comportamental, representado através de algoritmos, para o próprio eixo comportamental, representado em níveis de abstração inferiores, como máquinas de estados ou equações lógicas, ou ainda para o eixo estrutural, no nível de transferência de registradores ou portas lógicas. 
O trabalho de Gajski e Kuhn (1983) propôs alguns poucos pontos notáveis, e desde então várias outras propostas foram feitas, como em Wagner, Jansh-Pôrto e Weber (1988). A definição dos pontos notáveis pode ser diferente dependendo do problema a ser tratado, pois cada problema tem características relevantes diferentes. Deve-se, entretanto, manter a idéia principal do diagrama GK quanto ao conteúdo de cada eixo e aos níveis de abstração. Baseando-se nos dois trabalhos citados, e levando-se em consideração o problema de representação de sistemas de IC, foi considerado o diagrama GK apresentado na figura 3.2. Este diagrama foi utilizado como apoio para a definição de níveis de abstração e pesquisa das características das técnicas de IC, apresentados a seguir.

\subsection{O Diagrama Andrade-Caversan (AC)}

Conforme proposto em Andrade (2002), o diagrama GK pode ser adaptado para a área de IC, observando-se as seguintes similaridades:

- Eixo comportamental: pode ser associado à $\mathrm{CF}$, pois os sistemas que utilizam este tipo de modelagem tem o foco em expressões lingüísticas obtidas através da extração de conhecimento especialista sobre o comportamento do sistema. Estes sistemas podem ser vistos como uma caixa preta, na qual o comportamento é conhecido, mas a estrutura interna do sistema e suas propriedades estão ocultas.

- Eixo estrutural: pode ser associado aos sistemas de CN, que são modelados utilizando uma estrutura baseada no cérebro humano, de maneira explícita, mas cujo comportamento é implícito. Por sua vez, esses sistemas podem ser observados como uma caixa branca, na qual a estrutura está exposta, mas o comportamento e as propriedades estão ocultos.

- Eixo geométrico: pode ser associado à técnicas de CE, pois esses sistemas são baseados em representações matemáticas das propriedades biológicas dos indivíduos. Assim sendo, as propriedades desses sistemas são expostas, mas seu comportamento e estrutura, ocultos, possibilitando a associação com uma caixa cinza.

Com base nestas observações propostas em Andrade (2002) pôde-se obter um diagrama GK estendido para a IC, mostrado na figura 3.3.

Ao representar os sistemas de IC dessa maneira, as funcionalidades do diagrama GK original podem auxiliar na exploração das relações, através do estabelecimento de pontos 


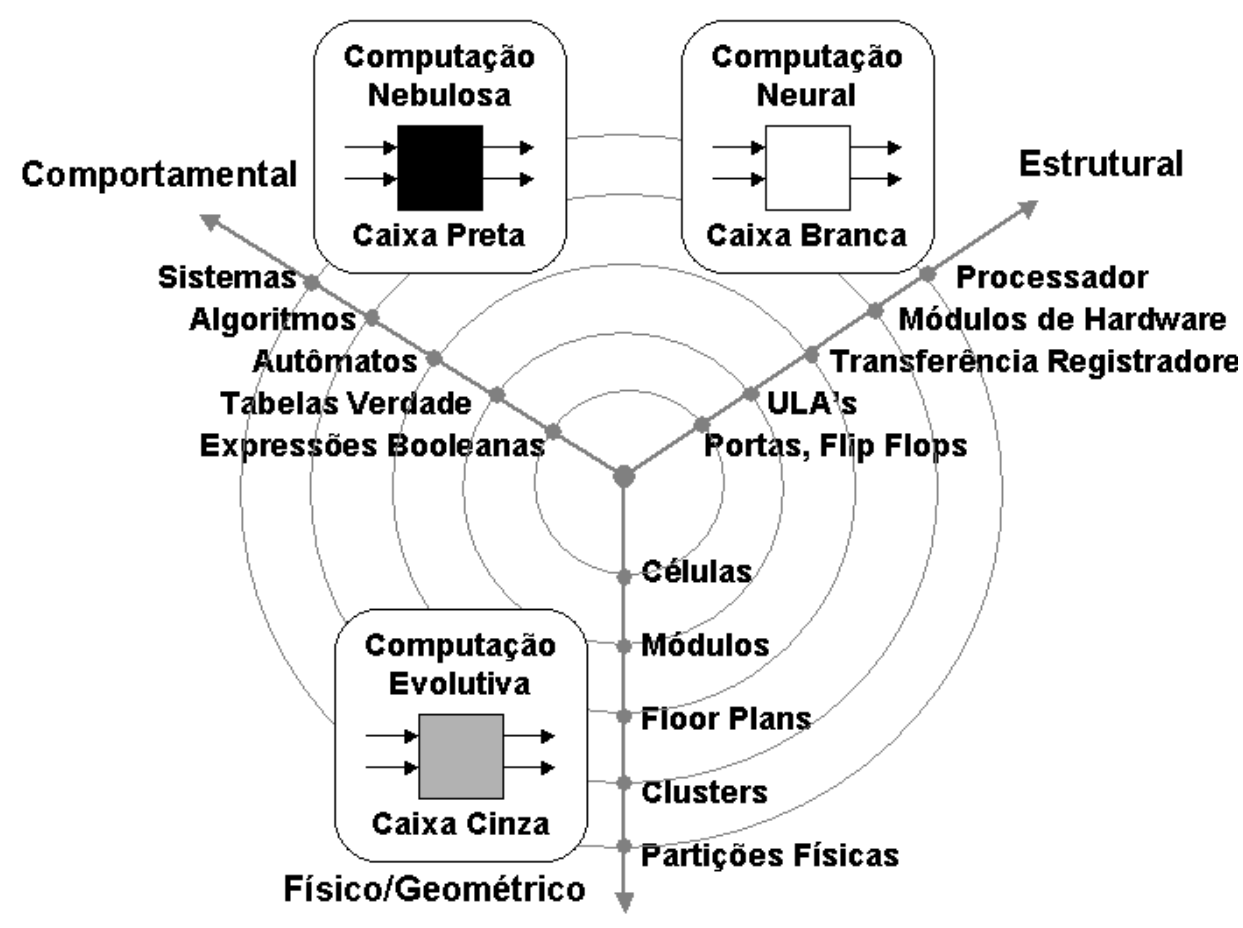

Figura 3.3: Diagrama GK estendido para a IC.

notáveis mais compatíveis com as técnicas de IC, e de operações que transportem o problema de um ponto notável para outro, para um mesmo nível de abstração ou para outro, como é possível no diagrama original.

A próxima etapa para o estabelecimento de um modelo para explorar as relações da IC, que resultaram no diagrama denominado diagrama $\mathrm{AC}$, é a proposta dos pontos notáveis específicos das técnicas de $\mathrm{CF}, \mathrm{CN}$ e CE.

Para estabelecer-se os pontos notáveis das técnicas de IC, e posteriormente pesquisar as relações entre os mesmos, a primeira abordagem partiu do diagrama GK original. Durante o processo de pesquisa, entretanto, surgiram novas propostas de modelagem para o diagrama.

As duas propostas mais próximas do diagrama GK, foco principal desse trabalho, são apresentadas nessa seção. A primeira proposta está mais presa aos pontos notáveis existentes no diagrama GK original, enquanto a segunda sugere pontos completamente novos mais aderentes às técnicas de IC. Além destas propostas, duas abordagens que modificam estruturalmente o diagrama GK original foram sugeridas, e são abordadas na próxima seção. 


\subsubsection{Pontos Notáveis Baseados no diagrama GK original}

Esta abordagem consiste em encontrar nas técnicas de IC pontos que sejam equivalentes aos pontos notáveis utilizados no diagrama GK, sendo que para cada técnica seu eixo correspondente no diagrama é utilizado.

O primeiro eixo analisado foi o comportamental, bem como sua técnica correspondente, a CF. Seguindo os pontos notáveis indicados na figura 3.1, podemos traçar alguns paralelos com alguns elementos da CF:

- Sistemas: um sistema digital consiste de um conjunto de componentes com o objetivo comum, que para tal fim possui entradas, que são processadas, e saídas. Pode-se atribui à este ponto, em termos de CF, um SIN. O SIN possui as características do sistema digital e, adicionalmente, a capacidade de representação e processamento de conhecimento na forma lingüística, característica do comportamento inteligente.

- Algoritmos: um algoritmo é uma seqüencia de ações executadas para alcançar um determinado objetivo. Os algoritmos de sistemas digitais trabalham com valores categóricos. Conforme proposto em Zadeh (1973) é possível, com a teoria de conjuntos nebulosos, a criação de algoritmos nebulosos.

- Autômatos: Já foram propostos autômatos nebulosos, como citado em Reyneri (1997), que são autômatos que não trabalham com transições bruscas entre estados, e sim com transições nebulosas. O estado atual do autômato nebuloso pode, também, ser um conjunto de estados com graus de pertinência

- Tabelas Verdade: a tabela verdade em lógica nebulosa pode ser vista como uma tabela N-dimensional, pois um conjunto de variáveis de entrada e saída são linguísticas e portanto assumem valores lingüísticos.

- Expressões Booleanas: existem as expressões nebulosas que podem ser alocadas neste nível, com seus operadores e relacionamentos bem definidos pela teoria dos conjuntos nebulosos (ZADEH, 1965).

Durante o estabelecimento dos pontos notáveis através da utilização do diagrama GK original, notou-se que pontos de grande relevância para a área de IC não foram considerados, por não possuírem equivalente direto no diagrama GK que é utilizado com sistemas digitais. Desta maneira, foram propostos novos pontos notáveis, com componentes típicos da modelagem de sistemas de IC. 


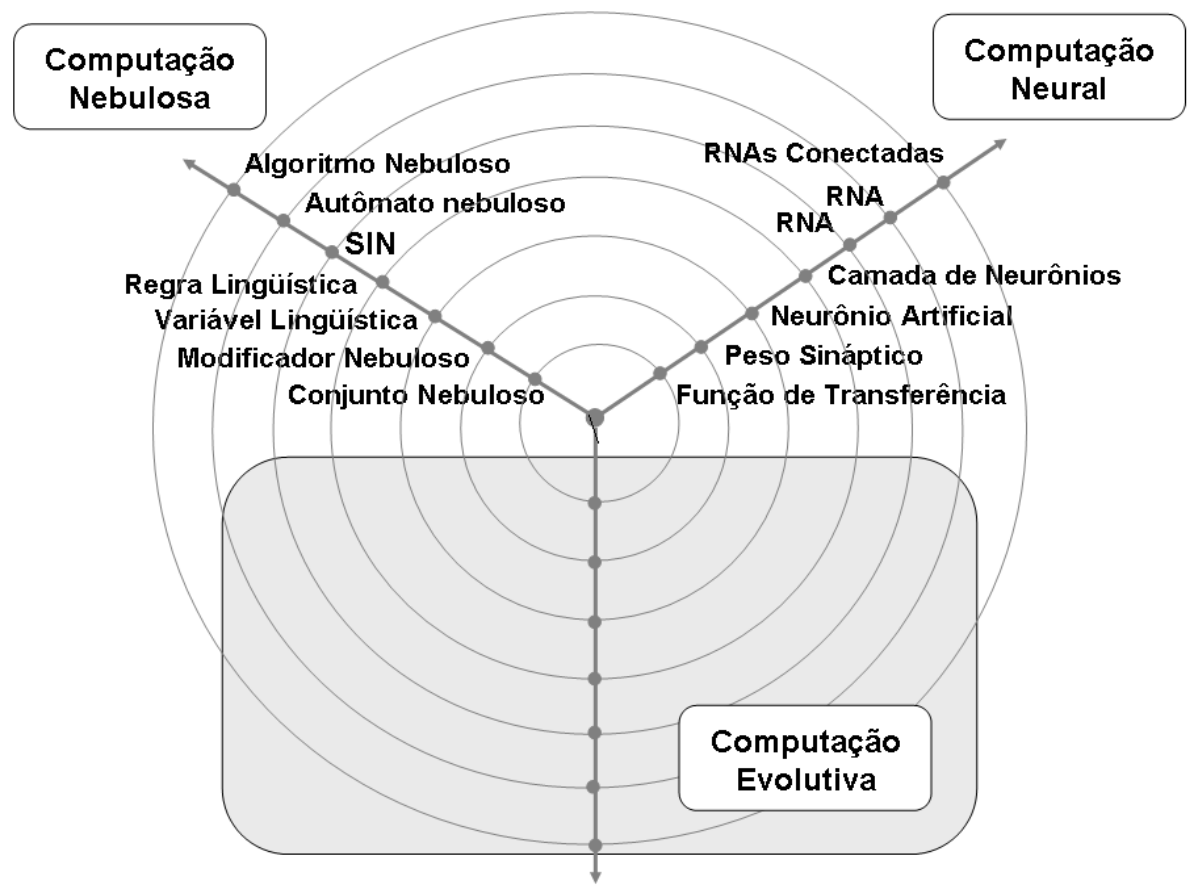

Figura 3.4: Diagrama AC.

\subsubsection{Pontos Notáveis Baseados na IC}

Uma nova abordagem, que utiliza-se apenas da arquitetura do diagrama GK, com três eixos, níveis de abstração e pontos notáveis, foi proposta. Neste caso, procurou-se estabelecer como pontos notáveis elementos relevantes na modelagem de sistemas que utilizam IC, sem a preocupação da equivalência com o diagrama GK original. Vale notar que o eixo da CE não foi considerado neste diagrama, visto que não é foco deste trabalho. Este diagrama, finalmente, foi escolhido para servir como base no trabalho, e denominado diagrama Andrade-Caversan (AC).

Os pontos notáveis escolhidos, relevantes para cada uma das técnicas são apresentados na figura 3.4. No caso de CF, os seguintes elementos foram considerados:

- Conjunto Nebuloso: pode ser visto como o elemento primário, baseado na teoria dos conjuntos nebulosos, para a criação dos sistemas nebulosos. É constituído de uma função de pertinência que indica o grau de associação de cada valor ao seu conjunto nebuloso.

- Modificador Nebuloso: pode ser aplicado à um número nebuloso, modificando a sua função de pertinência, e, portanto, o comportamento do número nebuloso. 
- Variável Lingüística: é uma variável que pode assumir valores de números nebulosos, utilizada para a modelagem lingüística dos sistemas nebulosos.

- Regra Lingüística: é uma regra utilizada para realizar a inferência nebulosa, normalmente no formato "SE..ENTÃO" com antecedentes e/ou conseqüentes lingüísticos.

- SIN: sistema completo de inferência nebulosa, com capacidade de representação e processamento de conhecimento na forma lingüística.

- Autômato Nebuloso: autômatos que trabalham com transições nebulosas entre os estados, cujo estado ativo não é necessariamente um, mas sim diversos estados com graus de pertinência diferentes.

- Algoritmo Nebuloso: algoritmos criados com declarações lingüísticas.

Para as técnicas de CN, os elementos escolhidos foram:

- Função de Transferência: função utilizada para integrar e propagar os sinais das entradas dos neurônios para sua saída; sua forma influencia diretamente o comportamento de uma rede da qual faça parte.

- Peso Sináptico: influencia a entrada do neurônio de maneira a atenuar ou amplificar o sinal; no processo de aprendizado pode ser modificado para alterar as respostas da rede.

- Neurônio Artificial: elemento básico na construção de uma RNA, integra suas entradas influenciadas pelos pesos, através de uma função de transferência, gerando uma determinada saída.

- Camada de Neurônios: conjunto de neurônios formando uma camada, que é responsável por mapear um conjunto de entradas em um conjunto de saídas, de acordo com a função desejada para a rede.

- RNA: rede neural completa, com várias camadas; redes com uma ou várias camadas, com um ou vários neurônios por camada, podem ser construídas; para este modelo, supõe-se que uma RNA mais simples está no nível de abstração correspondente ao SIN, e uma RNA mais complexa (com mais neurônios e mais camadas) está no nível de abstração do autômato nebuloso.

- RNAs Conectadas: para a execução de algoritmos completos, um conjunto de RNAs interconectadas pode ser utilizado, sendo cada uma responsável pela execução de uma determinada porção do algoritmo (autômato). 
A definição dos pontos notáveis do eixo de CE não faz parte do escopo deste trabalho. Um grupo de estudo do Laboratório de Engenharia de Conhecimento da Escola Politécnica da Universidade de São Paulo (KNOMA, 2005) têm trabalhado com o eixo evolutivo da IC. Embora o posicionamento dos pontos esteja fora do escopo, sabe-se que alguns elementos são importantes na modelagem evolutiva:

- Genes: elementos básicos dos modelos evolutivos, são a codificação de parâmetros dos problemas para cadeias genéticas.

- Cromossomo: conjuntos de genes, que caracterizam um indivíduo de uma determinada população.

- Operador Genético: operações que atuam sobre os indivíduos, alterando propriedades ou gerando novos indivíduos, como mutação e crossover.

- Função de Adequação: realiza o cálculo da adequação de um determinado indivíduo em relação a um critério de aceitação para a solução do problema.

- Indivíduo: resultado do código genético (cromossomos) e das operações genéticas que atuaram sobre o mesmo.

- População: conjunto de indivíduos que contém os candidatos à solução do problema, da qual será gerada uma nova população com novos indivíduos.

O diagrama AC serviu como ponto de partida para os estudos das relações entre CF e CN, bem como base para a construção do modelo de plataforma computacional para as explorações de relações apresentada no capítulo 4.

Durante a pesquisa surgiu, entretanto, também a hipótese da inexistência de relações entre todos os pontos notáveis. Neste caso, existiria somente um ou alguns pontos notáveis que permitiriam o transporte de problemas entre os diferentes domínios. Ainda assim o diagrama AC é uma ferramenta útil para o estudo e análise dessas relações. Finalmente, outras hipóteses foram surgindo e, embora não utilizadas no trabalho, são apresentadas aqui para que se possa registrar o estudo e, eventualmente, estudas a possibilidade de que algumas delas seja mais adequada para representar a IC que o diagrama AC.

\subsection{Modelos Alternativos de Diagramas da IC}

A definição e análise dos pontos notáveis das técnicas de IC resultaram em duas novas propostas de modelos de diagramas, que podem ser mais aderentes às características das 


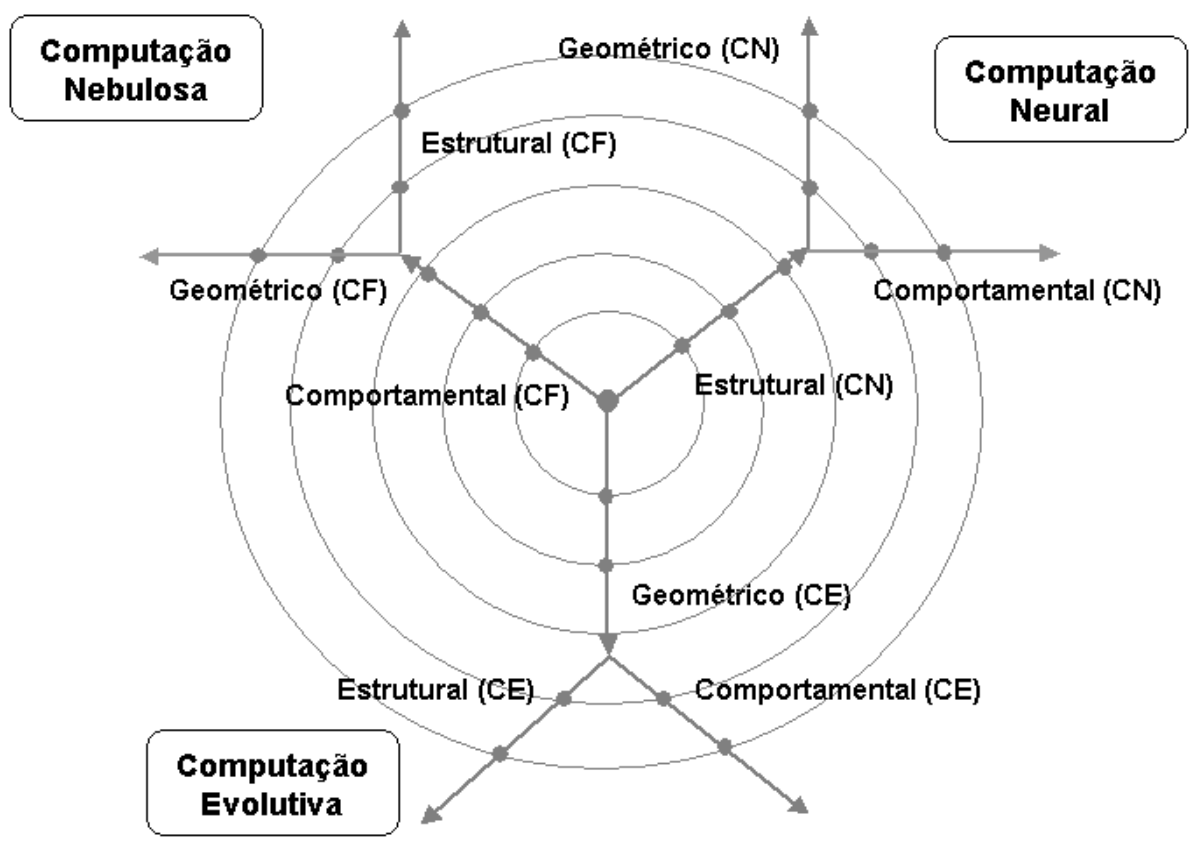

Figura 3.5: Diagrama da IC com eixos adicionais para representação das técnicas.

técnicas, podendo ser estudadas como possibilidades alternativas da linha de pesquisa principal.

\subsubsection{Os Eixos Segmentados}

Uma proposta idealizada sugere que cada técnica da IC possui, individualmente, as características comportamentais, estruturais e geométricas. Em cada uma das técnicas, uma destas características está exposta, o que não indica necessariamente a inexistência das outras. Sendo assim, um diagrama modificado foi proposto para representar de melhor maneira este comportamento, conforme mostrado na figura 3.5.

Neste modelo a abordagem para se obter as transformações entre os domínios é um pouco diferente. A busca nos modelos anteriores se concentrava no transporte de um ponto notável em um eixo para outro, como por exemplo do eixo comportamental (CF) para o eixo estrutural (CN). Este modelo sugere que as técnicas com comportamento oculto (CN e CE), por exemplo, possuem um comportamento próprio diferente da técnica com comportamento exposto (CF). Sendo assim, no exemplo citado, seria possível transportar o problema de um ponto notável de comportamento da CF para um ponto de comportamento da $\mathrm{CN}$ antes de converter efetivamente para o eixo estrutural, que é exposto nesta 
técnica.

Embora tenha surgido como modelo de exploração, esta proposta não foi seguida para o desenvolvimento deste trabalho.

\subsubsection{A Proposta do Quarto Eixo}

A segunda idéia formulada sugere que as técnicas de IC possam levar à um quarto eixo, que representa melhor o comportamento inteligente que as outras três técnicas procuram simular. Sendo assim, não seria possível realizar transformações entre as técnicas diretamente pois elas seriam casos particulares de uma técnica mais generalizada, e não apenas visões diferentes desta mesma técnica.

Para realizar o transporte entre dois paradigmas, seria necessário o mapeamento para o quarto eixo (genérico) primeiramente, e posterior transformação para o paradigma desejado. O mapeamento de alguns elementos (em particular nebulosos e neurais) para este eixo mais geral levariam para um ponto (ou região) comum. Entretanto, existe a possibilidade que algumas das características dos paradigmas levassem para pontos do quarto eixo que não possuem equivalentes em outros paradigmas. A hipótese de isomorfismo não existiria para o conjunto completo de elementos do paradigma. A ilustração desta possibilidade é apresentada na figura 3.6.

Os recentes avanços na linha de pesquisa indicam que, no caso do modelo de diagrama de três eixos mostrar-se ineficaz, este modelo pode ser adotado. A idéia de pontos da IC que só podem ser representados por uma das três técnicas é aderente à crença atual da comunidade científica de que as técnicas são complementares. Entretanto, além de complementares, as técnicas possuiriam intersecções em alguns se seus pontos, que permitiriam o transporte de elementos. Estes fatores levaram para uma outra possibilidade de representação, deixando o diagrama GK e focando na área de expressividade de linguagens.

\subsubsection{Expressividade das Linguagens da IC}

Conforme Sebesta (2003), a expressividade de uma linguagem de programação está relacionada com sua capacidade de especificar computações de forma mais ou menos conveniente, ou ainda com a capacidade de escrita de uma linguagem. Uma linguagem mais expressiva, dado um certo domínio, possui estruturas simples e claras para resolver os problemas deste domínio. A expressividade pode ser vista, de modo subjetivo, como aquilo que a 


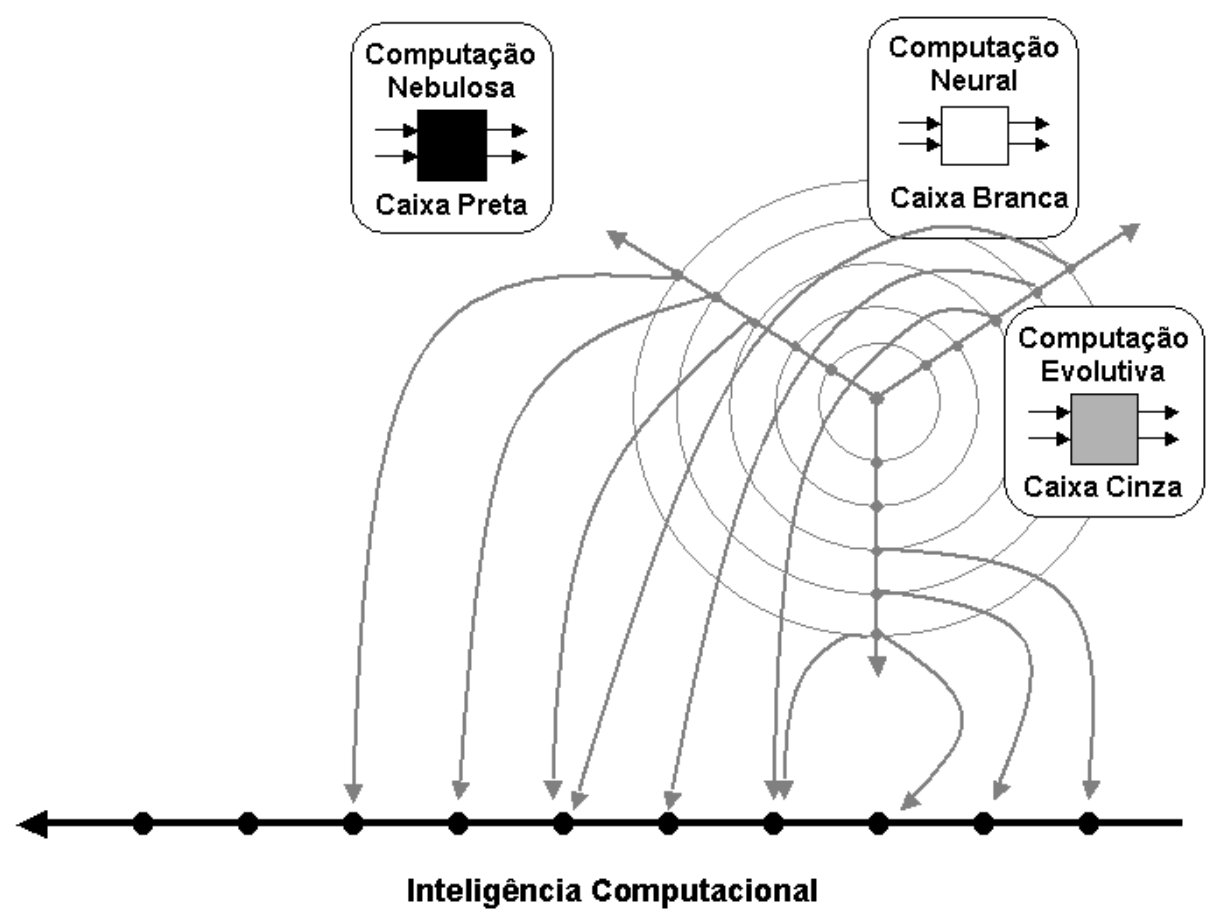

Figura 3.6: Diagrama da IC com eixo único da IC.

linguagem pode ser usada para descrever, ou seja, a semântica de um dado problema.

O estudo de linguagens é dividido em duas grandes classes: a sintaxe e a semântica. A sintaxe é a forma em que ela expressa algo, as estruturas e elementos que utiliza para descrever um problema. A semântica é justamente o significado do problema descrito (SEBESTA, 2003). Podem existir muitas sintaxes para se descrever uma mesma semântica. A expressividade pode ser vista como a capacidade de uma determinada sintaxe em cobrir, de forma mais ou menos simples, uma determinada semântica.

Assim, algumas linguagens podem ser ótimas para descrever parte de uma determinada semântica, mas péssimas ou incapazes de descrever outras partes. Nestes casos, a simbiose de algumas sintaxes, cada uma descrevendo a parte da semântica (a parte que descreve de forma mais adequada) pode ser uma alternativa interessante para modelos de semântica complexa. Os modelos de IC, tipicamente, possuem este tipo de semântica.

Uma abordagem diferente para o tratamento das relações existentes entre as técnicas de IC pode ser baseado na teoria das linguagens. Cada técnica pode ser visto como uma sintaxe para se descrever uma determinada semântica. A figura 3.7 ilustra esta idéia. Uma metáfora com o padrão de representação de cores $\mathrm{RGB}^{1}$ foi feita para facilitar a

\footnotetext{
${ }^{1}$ Padrão de representação de cores Red-Green-Blue, em que todas as cores podem ser obtidas com a mistura da luminosidade das três cores básicas: vermelho, verde e azul.
} 


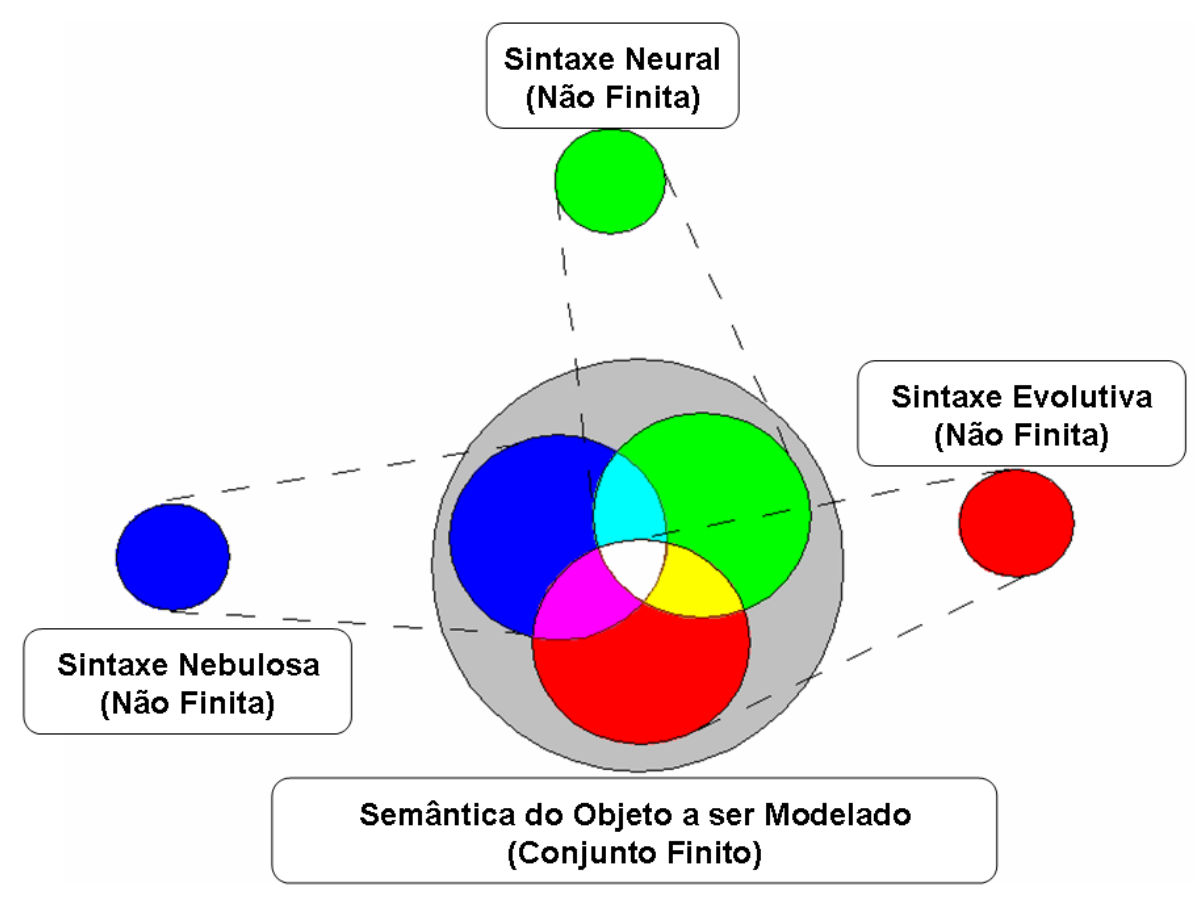

Figura 3.7: Diagrama das linguagens da IC e sua expressividade.

explicação.

Desta maneira, um determinado problema de interesse da área de IC, com sua respectiva semântica, pode envolver as três técnicas para ser representado. Cada cor representa no diagrama uma parte da semântica descrita por uma ou mais técnicas (sintaxes):

- Azul: elementos que só podem ser descritos pela sintaxe dos modelos nebulosos.

- Verde: elementos que só podem ser descritos pela sintaxe dos modelos neurais.

- Vermelho: elementos que só podem ser descritos pela sintaxe dos modelos evolutivos.

- Ciano: elementos podem ser descritos pelas sintaxes nebulosa e neural; ocorre uma intersecção das duas técnicas, embora uma possa ser mais expressiva que a outra, as duas são capazes de representar o problema.

- Amarelo: elementos descritos pelas sintaxes neural e evolutiva.

- Magenta: elementos descritos pelas sintaxes nebulosa e evolutiva.

- Branca: neste subdomínio, as três sintaxes poderiam ser utilizadas para representar a semântica. 
- Cinza: Partes do problema que não poderiam ser representadas pelas sintaxes da IC.

As diversas aplicações de IC indicam que as áreas azul, verde e vermelha existem e não são nulas. As relações entre CF e CN destacadas neste trabalho indicam, também, que a região de cor ciano não é nula. As demais áreas dependem do estudo aprofundado das técnicas de $\mathrm{CE}$, para que possam ser melhor definidas.

Embora se possa concluir que determinadas áreas não são nulas, o estabelecimento das fronteiras de cada área não é simples e envolve um estudo à parte. Esta é um apossibilidade de futuros trabalhos derivados deste.

Uma possibilidade interessante apontada pela figura 3.7 é uma maneira alternativa de se buscar as relações da IC, que seria a busca das áreas complementares das técnicas, para posteriormente obter-se as áreas equivalentes.

\subsection{Transportes no Diagrama AC}

Uma das grandes vantagens da representação derivada do diagrama GK é a possibilidade de transporte de elementos de um eixo para outro através da realização de transformações. Com base nas aproximações apresentadas na seção 2.5, alguns destes transportes, ainda que de forma aproximada, podem ser realizados.

A figura 3.8 ilustra as relações extraídas das propostas de aproximação apresentadas. Os conjuntos nebulosos influenciam nos centros das funções de ativação e no formato da função de transferência. Os centros, um para cada entrada, podem ser vistos como parte dos pesos das entradas. Assim, os conjuntos influenciam nos pesos e nas funções de transferência.

A avaliação do potencial de ativação de cada regra nebulosa pode ser realizado por um neurônio, em que as entradas, pesos e função de transferência são modelados de acordo com o antecedente da regra. Finalmente, um SIN construído por várias regras pode ser modelado como uma RNA, com um neurônio para cada regra na primeira camada e uma camada adicional para o cálculo da defuzzificação.

Esta possibilidade de conversão de um SIN para RNA foi explorada nos experimentos práticos do trabalho, apresentados no capítulo 5 . 


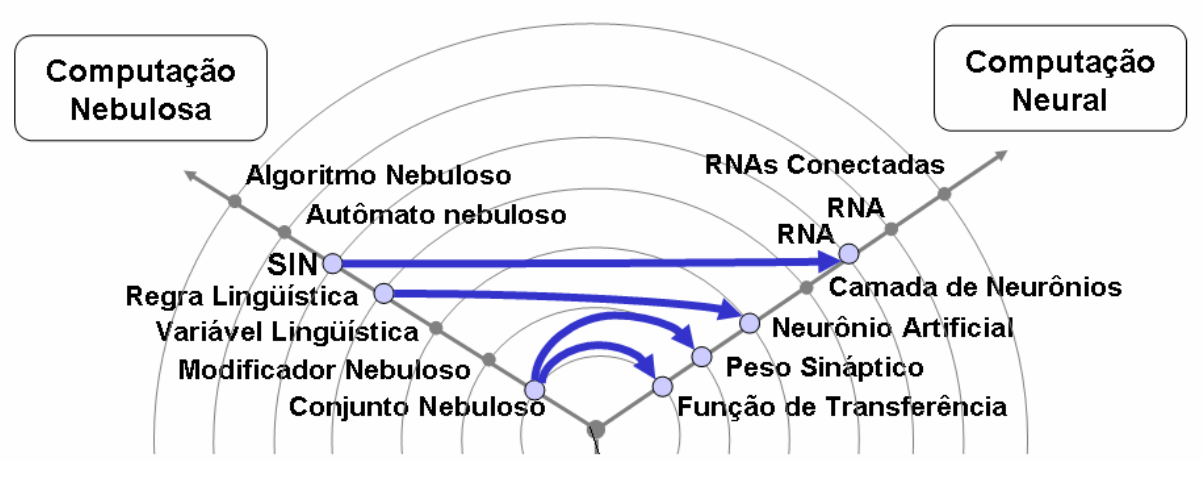

Figura 3.8: Transporte de elementos entre os eixos do diagrama AC.

\subsection{Considerações Finais do Capítulo}

Os modelos de IC surgiram e evoluíram de forma independente, em períodos e domínios de aplicações diferentes. Recentemente a combinação destes modelos geraram aplicações híbridas de sucesso. É possível que, separadamente, os pesquisadores que criaram e desenvolveram cada uma das técnicas estivessem, muitas vezes, utilizando derivações de uma técnica mais básica, ainda por descobrir.

Compreender melhor o escopo e as relações entre estas técnicas pode esclarecer estas dúvidas. A criação de modelos e sistemas, além de métodos de investigação, pode auxiliar esta busca. As propostas de modelagens que resultaram no diagrama AC, desenvolvidas neste capítulo, foram apresentadas em seu formato original em Caversan e Andrade (2004). Desde então, optou-se por deixar o eixo evolutivo de lado temporariamente.

Embora envolvam outras características, CF e CN possuem um comportamento comum no que diz respeito à representação de uma função. Um SIN e uma RNA podem ser vistos como uma aproximação de uma determinada função, uma forma de representação desta função. O objetivo principal de CE, entretanto, parece ser a busca da função e não sua representação, que acaba sendo dependente do contexto. Esta busca pode guardar alguma relação com técnicas de aprendizado, mas não com a representação da função em si.

O modelo de expressividade também foi resultado posterior ao trabalho, e parece descrever de forma mais completa as possíveis relações da IC. A proposta ainda deve ser desenvolvida, mas acaba sendo mais genérica e não invalida, mas engloba, o diagrama AC. Estabelecer o que cada região engloba, os limites das intersecções e o que cada técnica não pode fazer é uma possibilidade de trabalho futuro. 
O capítulo seguinte apresenta a proposta de uma plataforma computacional, baseada no diagrama AC aqui proposto, para realização de experimentos. A área de IA utiliza-se muito de simulações e coleta de dados empíricos para a formulação e aceitação dos seus modelos, e a idéia desta plataforma é seguir a mesma linha de pensamento.

As relações exploradas neste trabalho, entre CF e CN, são ainda alvo de polêmica, mas sem dúvida existem. Embora um isomorfismo não tenha sido obtido, as aproximações que se podem realizar são extremamente interessantes do ponto de vista prático. O valor de uma equivalência perfeita, ao invés de aproximação, deve ser questionado, também. Se as técnicas de CF, segundo o próprio princípio da incompatibilidade de Zadeh (1973), buscam resolver o problema sem preocupação com precisão numérica, visto que ele é dispensável, uma conversão para CN com precisão numérica seria necessária? Ou apenas um modelo neural que resolvesse o problema independente da precisão numérica seria suficiente? Nesta linha de pensamento, talvez um certo "isomorfismo de significado" já tenha sido obtido através das aproximações. 


\title{
4 Plataforma Computacional para Exploração das Relações da IC
}

\author{
Neste capítulo é apresentada a especificação de uma plataforma \\ computacional para realizar a exploração das relações entre $C F$, \\ $C N$ e CE, contendo os requisitos funcionais e o projeto da ferra- \\ menta e de seus componentes. A arquitetura aqui proposta segue o \\ modelo do diagrama $A C$.
}

A motivação da criação de uma ferramenta computacional é auxiliar a pesquisa das relações entre as técnicas de IC. O desenvolvimento de uma plataforma que contemple, de forma hierárquica, os componentes fundamentais (pontos notáveis) das três técnicas (CF, CN e CE), possibilita a investigação de cada componente de forma isolada, simulações de transformações entre componentes de diferentes classes e análises do comportamentos dos sistemas de forma global.

Segundo Pressman (1995, p. 222), a especificação de um software "descreve a função e o desempenho de um sistema baseado em computador e as restrições que orientarão seu desenvolvimento.". Na especificação os requisitos do software devem ser declarados. Uma análise de requisitos deve ser realizada para verificar a viabilidade do desenvolvimento em termos computacionais. Finalmente, o projeto do software deve ser especificado. As etapas posteriores, que englobam o desenvolvimento do software, a realização de testes e manutenção do sistema não foram consideradas neste trabalho. Apenas um protótipo foi desenvolvido, apresentado no capítulo 5, que deve ser aprimorado de forma incremental, resultando em alterações no projeto e até mesmo em requisitos, fechando um ciclo de desenvolvimento similar ao modelo espiral (PRESSMAN, 1995).

A especificação criada para esta plataforma computacional é uma versão simplificada dos modelos propostos por (PRESSMAN, 1995), adaptada através da utilização do Adaptable Process Model (APM) (ASSOCIATES, 2005). Visando à estratificação mais eficiente dos componentes, o paradigma de desenvolvimento orientado a objetos foi escolhido. Fo- 
ram incorporados ao modelo de especificação elementos da notação Unified Modelling Language (UML) encontrados em Booch, Rumbaugh e Jacobson (2000), desenvolvida especificamente para atender as necessidades de documentação de sistemas construídos neste paradigma.

\subsection{Especificação dos Requisitos}

\subsubsection{Introdução}

O nome utilizado para a plataforma computacional é UCIP. O objetivo principal da UCIP é possibilitar experimentos envolvendo as técnicas de $\mathrm{CF}, \mathrm{CN}$ e $\mathrm{CE}$, além das relações entre as mesmas. Para este fim, as seguintes metas intermediárias são necessárias:

- Criação de um núcleo básico de CF, construído de forma hierárquica, que permite a modelagem de soluções desta natureza através de seus componentes.

- Criação de um núcleo similar para CN.

- Criação de um núcleo similar para CE.

- Criação de um mecanismo de transporte, inicialmente abstrato, capaz de transformar componentes de cada uma das técnicas em componentes equivalentes em outras técnicas: $\mathrm{CF}$ para $\mathrm{CN}$ e $\mathrm{CE}, \mathrm{CN}$ para $\mathrm{CF}$ e $\mathrm{CE}$ e, finalmente, $\mathrm{CE}$ para $\mathrm{CF}$ e $\mathrm{CN}$.

Através desta ferramenta sistemas que realizam os três tipos de computação podem ser criados, trabalhando de forma independente. Como a proposta é de uma plataforma, um conjunto de componentes, e não de uma instância de aplicação em si, diversos modelos, inclusive híbridos, podem ser criados. Os estados que uma instância poderia assumir estão representados no diagrama de estados da figura 4.1.

Deve-se ressaltar que a criação destas aplicações utilizando a plataforma não objetiva, inicialmente, alto desempenho na computação realizada. A divisão estratégica em camadas e componentes priva a plataforma da realização de otimizações específicas de cada técnica, com o objetivo de potencializar ao máximo a investigação das relações. Um exemplo deste tipo de limitação encontra-se na modelagem de RNAs. Tipicamente, as implementações desta natureza utilizam técnicas sofisticadas de produto matricial, na propagação das sinapses, para obter alto desempenho. No caso da plataforma, cada neurônio será tratado individualmente, pois ele pode representar um componente em outra técnica e deve ser estudado isoladamente. 


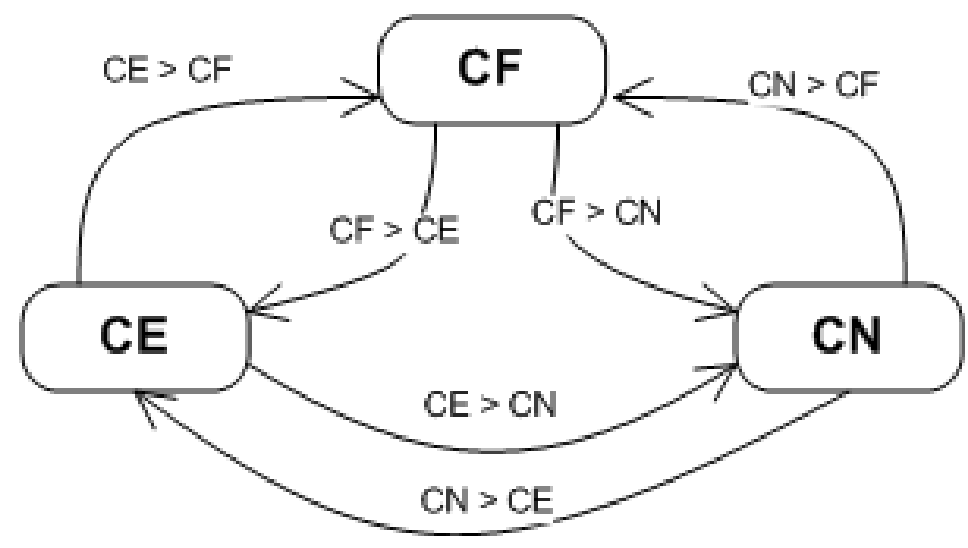

Figura 4.1: Diagrama de estados de uma instância da UCIP.

\subsubsection{Utilização}

Existem duas maneiras fundamentais de utilização da plataforma UCIP. A primeira possibilita a integração com sistemas diferentes, com uma dependência menor da implementação da própria plataforma. A segunda implica em uma integração maior com os componentes da UCIP:

- Construção do modelo através de parametrização simples: cada técnica suportada pelo UCIP deve oferecer um protocolo que permita interagir com o modelo através de dados de entrada, saída e parâmetros. Os parâmetros serão utilizados na construção do modelo, seja um SIN, uma RNA ou um Algoritmo Genético (AG), por exemplo. Após parametrizado, o sistema receberá as entradas e as fornecerá as saídas (no caso das RNAs com aprendizado supervisionado, o conjunto de treinamento deve ser considerado parte da parametrização).

- Construção do modelo através de programação: sendo a plataforma composta de um conjunto de componentes, a maneira mais natural de utilizá-la é através da construção de programas que instanciem ou até mesmo estendam estes componentes. Esta utilização é interessante pois muitos dos componentes são abstratos, com apenas alguns dos casos mais comuns de uso contemplados na plataforma. Como exemplo, pode-se citar o componente abstrato ActivationFunction, que representa uma função de ativação dos neurônios artificiais, servindo de base para dois casos particulares de funções de ativação: LinerFunction e SigmoidFunction. A utilização através de parametrização simples só possibilita a modelagem do sistema com estas duas funções de ativação. A utilização através de programação possibilita a extensão da própria plataforma, através da implementação de novas funções de ativação, de- 


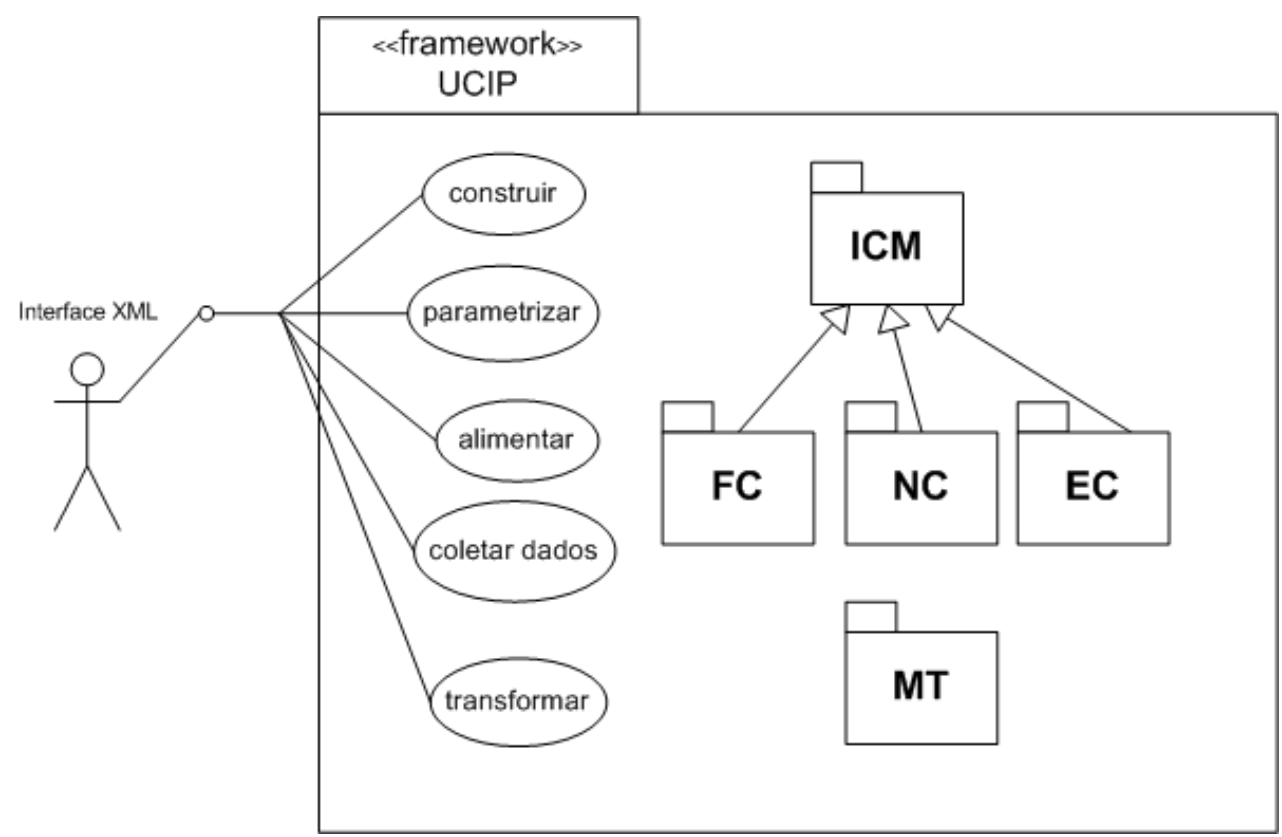

Figura 4.2: Diagrama de caso de uso e componentes da plataforma UCIP.

rivadas da classe abstrata.

\subsubsection{Descrição Funcional e de Dados}

Os componentes da plataforma UCIP devem ser criados de acordo com os pontos notáveis propostos no capítulo 3. Durante o projeto e desenvolvimento, em caso de necessidade, uma decomposição dos próprios pontos notáveis em classes menores pode ser realizada. Deve-se evitar, entretanto, agrupar pontos notáveis em classes comuns, o que pode causar perda do poder de simulação e análise da plataforma.

A plataforma deve apresentar mecanismos de persistência, ou seja, em um dado momento o modelo construído com a utilização de seus componentes pode ser gravado para posterior recuperação. Preferencialmente, o formato em que as informações serão gravadas deve permitir que este arquivo seja de fácil acesso para manipulação, seja por usuários ou por outros programas, possibilitando a integração do ambiente com outras plataformas. A escolha do padrão XML (BRAY et al., 2005) para representação dos dados é baseada nestes requisitos.

Os pacotes disponibilizados pela plataforma são apresentados na figura 4.2:

- Generalização das técnicas de IC: Intelligent Computational Model (ICM).

- FC para Computação Nebulosa. 
- NC para Computação Neural.

- EC para Computação Evolutiva.

- MT para Model Transformation.

Os componentes de cada pacote são apresentados de forma detalhada na subseção 4.2. O pacote ICM representa um possível modelo unificado de IC, do qual CF, CN e CE seriam especializações. Pode representar, por outro lado, o quarto eixo sugerido na seção 3.4.2, ou ainda a semântica de um determinado problema que deve ser descrita pelas sintaxes das três técnicas, como proposto na seção 3.4.3. Este pacote e suas especializações devem possuir as seguintes funcionalidades:

- Construção de um modelo funcional (instância) através de seus componentes.

- Parametrização do modelo de acordo com a necessidade do ICM envolvida.

- Alimentação do sistema através de entrada de dados.

- Coleta de informações através de saída de dados.

O pacote do tipo MT possui a funcionalidade de transportar um ou mais de componentes de um caso particular de pacote ICM para outro. Uma característica desejável é que cada componente de um determinado modelo possa ser transportado, e não apenas o modelo completo. Isto possibilita a investigação de equivalências entre alguns pontos notáveis, independendo do modelo completo. A implementação deste pacote deve ser realizada conforma a linha de pesquisa das relações da IC evolui como um todo.

\subsubsection{Critérios de Validação}

A validação de cada um dos pacotes do tipo ICM envolve a análise dos resultados da aplicação de suas instâncias na solução de problemas. Os pacotes devem ser desenvolvidos de maneira a possibilitar a construção dos diversos modelos que cada técnica possui, além de permitir sua própria extensão. Sendo assim, testes de modelos particulares podem verificar a validade de alguns componentes.

O pacote MT, em particular, deve ser desenvolvido conforme avança a linha de pesquisa. Propostas podem ser desenvolvidas e simuladas na plataforma. Se alguma transformação simulada atingir resultados satisfatórios, então pode ser incorporada ao pacote. 
A definição formal de um fator de mérito para os resultado, entretanto, é um trabalho à parte, que não está no escopo desta especificação. Esta questão pode levantar algumas controvérsias em relação ao método utilizado. Comparação clássicas entre sistemas, envolvendo geralmente análises numéricas, tem uma validade questionável. Os sistemas modelados através das técnicas possuem características inteligentes, e a avaliação de sucesso neste tipo de sistema muitas vezes está relacionada à solução do problema e não à precisão numérica da aproximação realizada pela técnica.

\subsection{Especificação do Projeto}

A definição do projeto da UCIP contempla os detalhes estruturais e funcionais de cada um dos pacotes especificados nos requisitos do projeto. A parte estática do projeto é representada através de diagramas de classes e a funcionalidade através de diagramas de atividades (BOOCH; RUMBAUGH; JACOBSON, 2000). Para simplificar os diagramas, apenas os elementos mais relevantes da modelagem são apresentados. Elementos de manutenção e controle internos das classes foram suprimidos.

Todas as classes que armazenam algum tipo de informação podem ser serializadas, ou seja, permitir que seus atributos sejam armazenados através de algum mecanismo de persistência, como arquivos binários ou no formato XML. Desta maneira, o estado de um determinado modelo pode ser armazenado para que possa ser utilizado em um momento posterior, ou mesmo exportado e manipulado por outro sistema qualquer.

\subsubsection{Pacote FC}

Conforme ilustrado na figura 4.3, a construção de um modelo nebuloso (FuzzyModel) envolve a escolha e combinação de determinados elementos de CF: um mecanismo de fuzzificação para converter entradas categóricas em nebulosas (Fuzzyfier), um mecanismo de inferência (InferenceSystem) capaz de inferir conhecimento utilizando uma base de dados (DataBase) e uma base de regras (RuleBase). A inferência é realizada através da escolha da regra composicional de inferência (CompositionalRule), T-Normas (Norm) e TConormas (CoNorm) utilizados para avaliar as regras. Além destes, possui um mecanismo defuzzificador (Defuzzyfier), para transformar as saídas (valores lingüísticos) em valores categóricos.

As relações entre estas classes principais e as classes necessárias para a construção de um modelo nebuloso são apresentadas na figura 4.4, o diagrama de classes do pacote FC. 


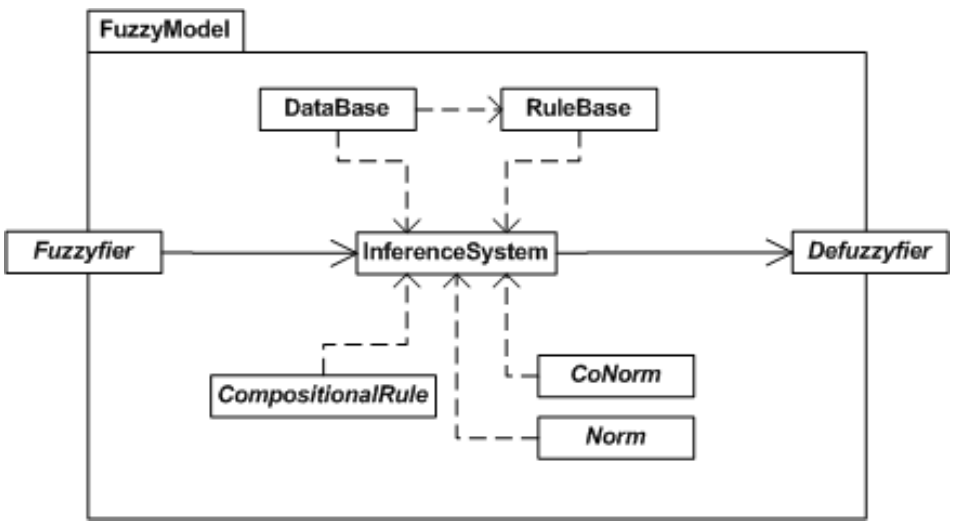

Figura 4.3: Modelo lógico do pacote para realização de CF.

A base de dados é composta de variáveis lingüísticas (Linguistic Variable). Estas por sua vez são compostas de etiquetas lingüísticas que são conjuntos nebulosos (FuzzySet), representando os valores que as variáveis podem assumir. A variável lingüística pode receber um valor categórico ou nebuloso como entrada, para calcular a respectiva pertinência em relação às suas etiquetas lingüísticas. Além de serem utilizados na composição de variáveis, os conjuntos nebulosos podem ser gerados a partir de valores categóricos, através dos fuzzificadores (Fuzzyfier).

A base de regras é composta de regras nebulosas (Rule). As regras podem ser divididas em antecedentes e conseqüentes, que são compostos de cláusulas nebulosas (Clause), que são sentenças do tipo "X is F", sendo $X$ uma variável lingüística e $F$ um valor lingüístico. Estas cláusulas podem ser unidas por operadores (Operators). Os conectivos AND (Operator $A N D)$ e OR (OperatorOR) operam, respectivamente, em duas cláusulas nebulosas através de T-Normas e T-Conormas. Um operador unário NOT (OperatorNOT) pode ser aplicado à uma cláusula, também. A composição de uma cláusula nebulosa pode utilizarse de um modificador nebuloso (Hedge), como, por exemplo, "X is very F", sendo very um modificador nebuloso. Modificadores como VERY (Very), LESS (Less), MORE OR LESS (MoreOrLess) podem ser utilizados. Para simplificar a relação entre as cláusulas nebulosas e os conjuntos nebulosos, optou-se por sempre aplicar um modificador à um conjunto pertencente à uma cláusula. Quando nenhum modificador se faz necessário, o modificador EQUAL (Equal) deve ser utilizado.

Cada regra possui um mecanismo de cálculo do seu "potencial de ativação", responsável por calcular as pertinências das proposições, agrupá-las através dos operadores, resultando na confiança da veracidade do antecedente. Esta confiança é propagada para o conseqüente através de uma regra composicional de inferência nebulosa (Compositio- 


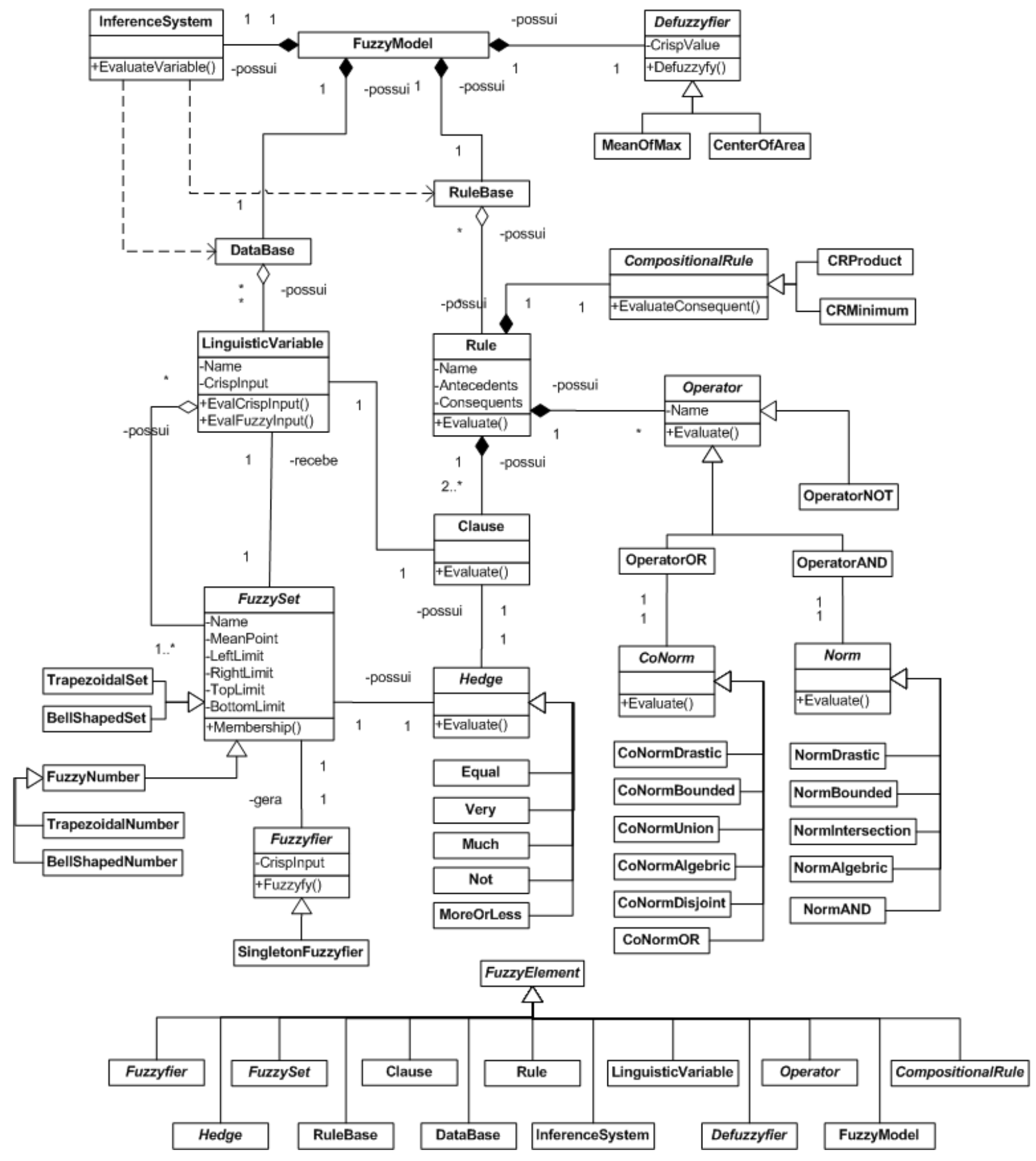

Figura 4.4: Diagrama de classes do pacote para realização de CF. 


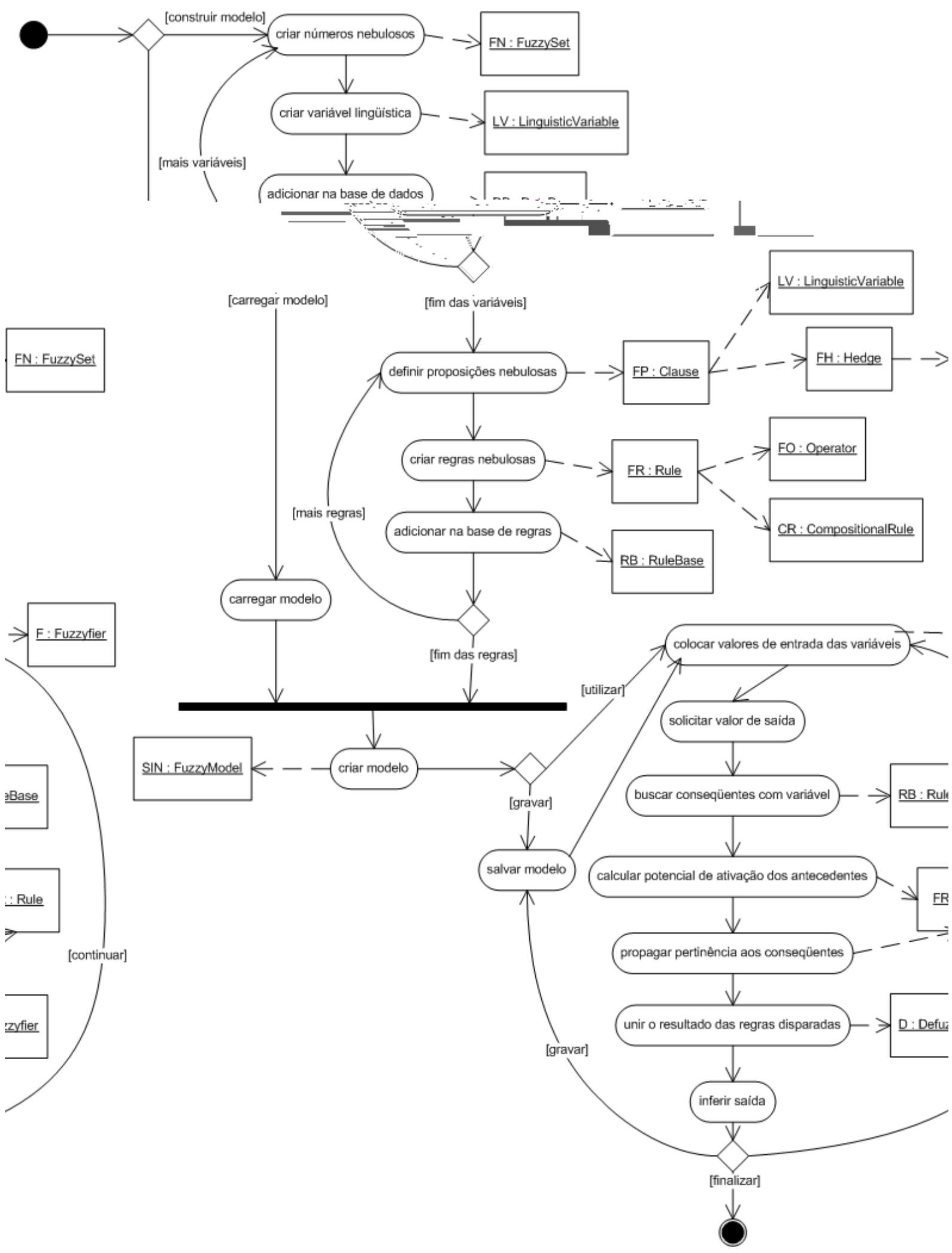

Figura 4.5: Diagrama de atividades representando a operação com CF. 
nalRule). As saídas das regras são utilizadas pelo SIN no cálculo do valor final de uma variável de saída.

O pacote permite a criação de diversos modelos nebulosos, possibilitando a extensão através dos mecanismos da orientação à objetos. Em particular, as classes abstratas FuzzySet, Fuzzyfier, (Hedge), Defuzzyfier, Norm, Conorm, Operator e CompositionalRule possibilitam a extensão natural da plataforma, utilizando herança e polimorfismo para implementar casos diferentes dos seus métodos. Todos os elementos possuem um ancestral comum, a classe FuzzyElement. Isto possibilita que toda classe pertencente ao domínio de CF seja tratada como um elemento nebuloso genérico, característica especialmente útil na especificação das trasnformações entre modelos.

A figura 4.5 ilustra a seqüência de operações realizadas para construir (ou carregar), salvar e utilizar os modelos nebulosos através dos componentes do diagrama estático.

Na etapa de construção do modelo, as variáveis lingüísticas são incorporadas à base de dados, modeladas a partir do domínio do problema. As regras são criadas através do conhecimento do especialista, utilizando estas variáveis. Feito isso, a etapa de parametrização está feita e o SIN construído pode ser utilizado. Os valores categóricos da entrada são informados, e um valor de saída é solicitado. As regras que possuem tal saída no conseqüente são então avaliadas, e um método de defuzzificação é aplicado para que se possa obter a saída numérica.

\subsubsection{Pacote NC}

A construção de um modelo neural envolve a escolha das funções de ativação dos neurônios (TransferFunction), a maneira como os neurônios (Neuron) estão dispostos em camadas (Layer), as conexões entre estes neurônios (Synapse) e, finalmente, um algoritmo de aprendizado (Learning) para a rede (NeuralNet) composta destes elementos. O diagrama que representa estes elementos constituintes do modelo neural é apresentado na figura 4.6.

O diagrama de classes do pacote NC é apresentado na figura 4.7. Uma RNA (NeuralNet) é composta por camadas (Layer) interconectadas. Para a realização do ajuste dos parâmetros da rede, um método de aprendizado é necessário (Learning). Existem diferentes métodos de aprendizado, que podem ser aplicados à algumas arquiteturas específicas de RNAs. Os dois grandes grupos são os métodos supervisionados e os métodos não-supervisionados (SupervisionType). As camadas também podem assumir diferentes formas, como as camadas típicas sem interconexões utilizadas nos Perceptrons (Forwar- 


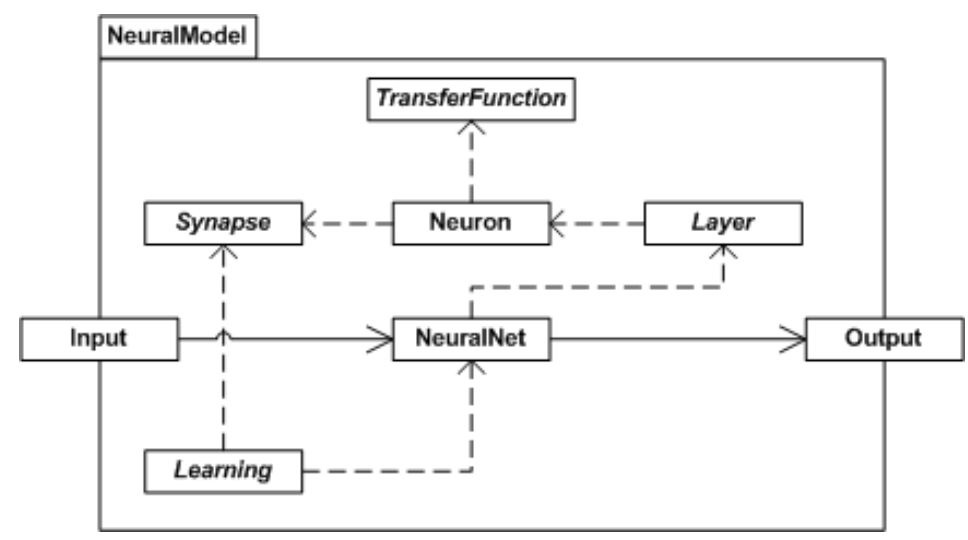

Figura 4.6: Modelo lógico do pacote para realização de CN.

dLayer), as camadas interconectadas utilizadas em aprendizado competitivo como os Mapas de Kohonen (CompetitiveLayer) ou ainda as camadas com realimentação utilizadas, por exemplo, em Redes de Hopfield (RecurrentLayer). A funcionalidade das camadas de entrada, que normalmente não possuem mecanismos de integração de sinais ou ajuste de parâmetros, servindo apenas para distribuir as entradas pela próxima camada, é representada pela camada linear (LinearLayer).

As camadas são compostas das unidades de processamento básico das RNAs, os neurônios artificiais (Neuron). Os neurônios possuem funções de transferência ou ativação (TransferFunction), que determinam a maneira pela qual os sinais de entrada são propagados para as saídas. A conexão entre as camadas é, na realidade, um conjunto de conexões entre os seus neurônios, as sinapses (Synapse). A saída de cada neurônios pode se conectar a vários outros, de maneiras diferentes. Uma conexão direta conecta apenas dois neurônios (DirectSynapse). Em vários modelos de redes neurais, como o Perceptron, um neurônio de uma camada se conecta a todos os neurônios da próxima camada (FullSynapse). Em alguns modelos, ainda, a conexão entre os neurônios é bidirecional (SymmetricSynapse). Além da capacidade de cada neurônio em integrar suas entradas propagando para as saídas (SumSignals e ForwardSignals), é necessário um mecanismo para a adaptação dos parâmetros do neurônio (AdjustWeight).

Embora as conexões sinápticas sejam realizadas entre neurônios, sua forma é normalmente definida pelas relações entre as camadas. Desta forma, pode-se definir métodos para de interconexão no nível das camadas (ConnectToLayer). Embora a conexão particular entre neurônios seja possível, a maioria dos modelos poderão ser construídos através da conexão de camadas. As entradas e saídas são utilizadas, também, pelas camadas (InputMatrix e (OutputMatrix)). 


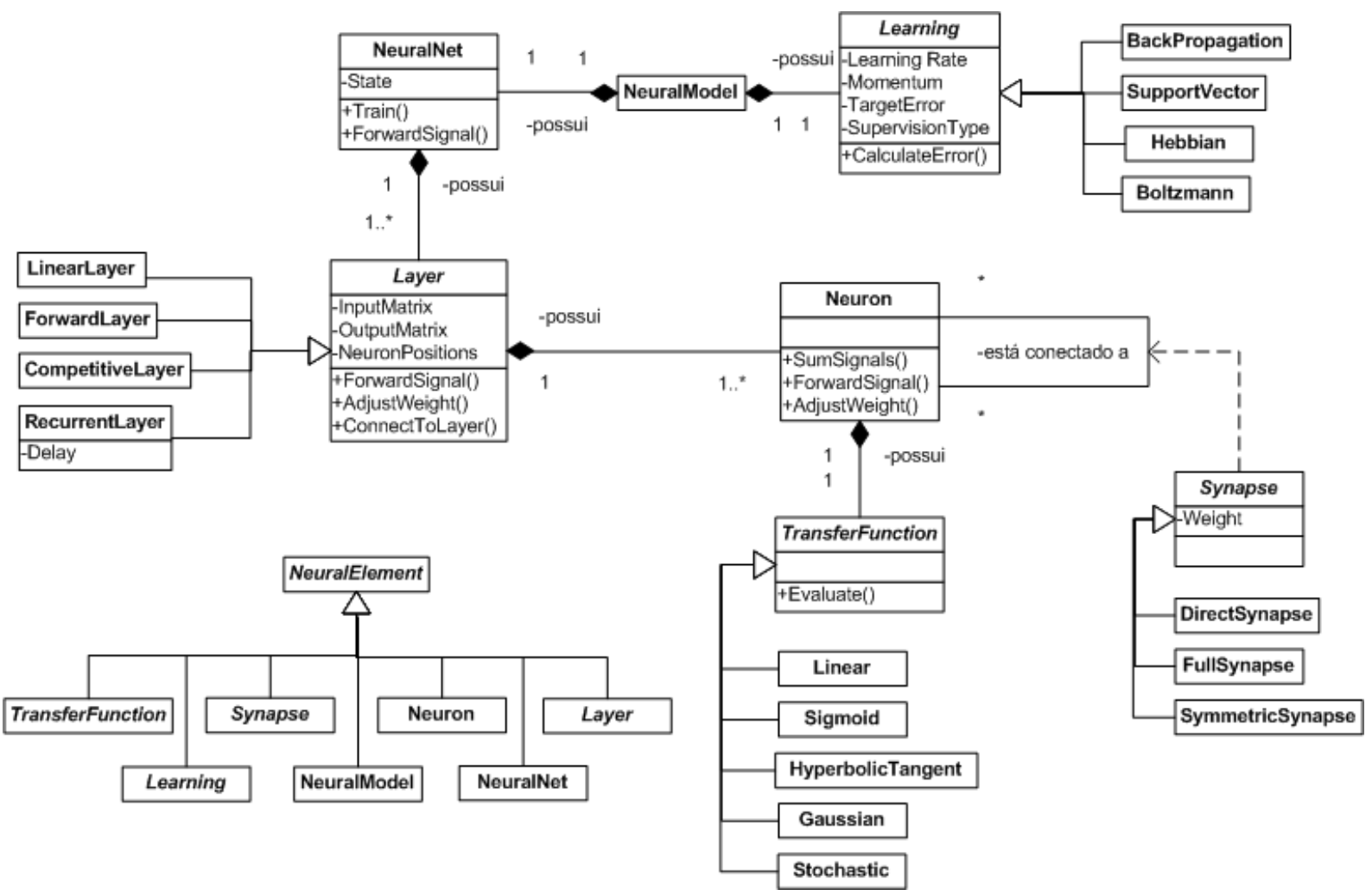

Figura 4.7: Diagrama de classes do pacote para realização de CN.

Assim como o pacote FC, a especificação visou à criação de diversos modelos neurais. A extensão pode ser realizada através dos mecanismos da orientação a objetos, através das classes abstratas TransferFunction, Synapse, Layer e Learning. Estas alterações possibilitam diferentes combinações dos neurônios e camadas, criando novas topologias de rede, utilizando os métodos existentes ou propondo novos métodos de aprendizado. O ancestral comum a todas as classes é a classe NeuralElement.

A operação típica de uma RNA genérica está ilustrada na figura 4.8. Em primeiro lugar a topologia da rede, neurônios e suas conexões, deve ser especificada, definindo um modelo neural. Tipicamente a primeira fase de operação da rede envolve algum tipo de treinamento. Este treinamento pode ocorrer apenas no início, ou de forma recorrente conforme a rede é utilizada. Finalmente, a rede é utilizada através da simples propagação dos sinais da entrada para a saída.

\subsubsection{Pacote EC}

Conforme ilustrado na figura 4.9, um modelo evolucionário necessita de um mecanismo para codificar parâmetros de um problema (Encoder) em genes (Gene), mapeando uma 


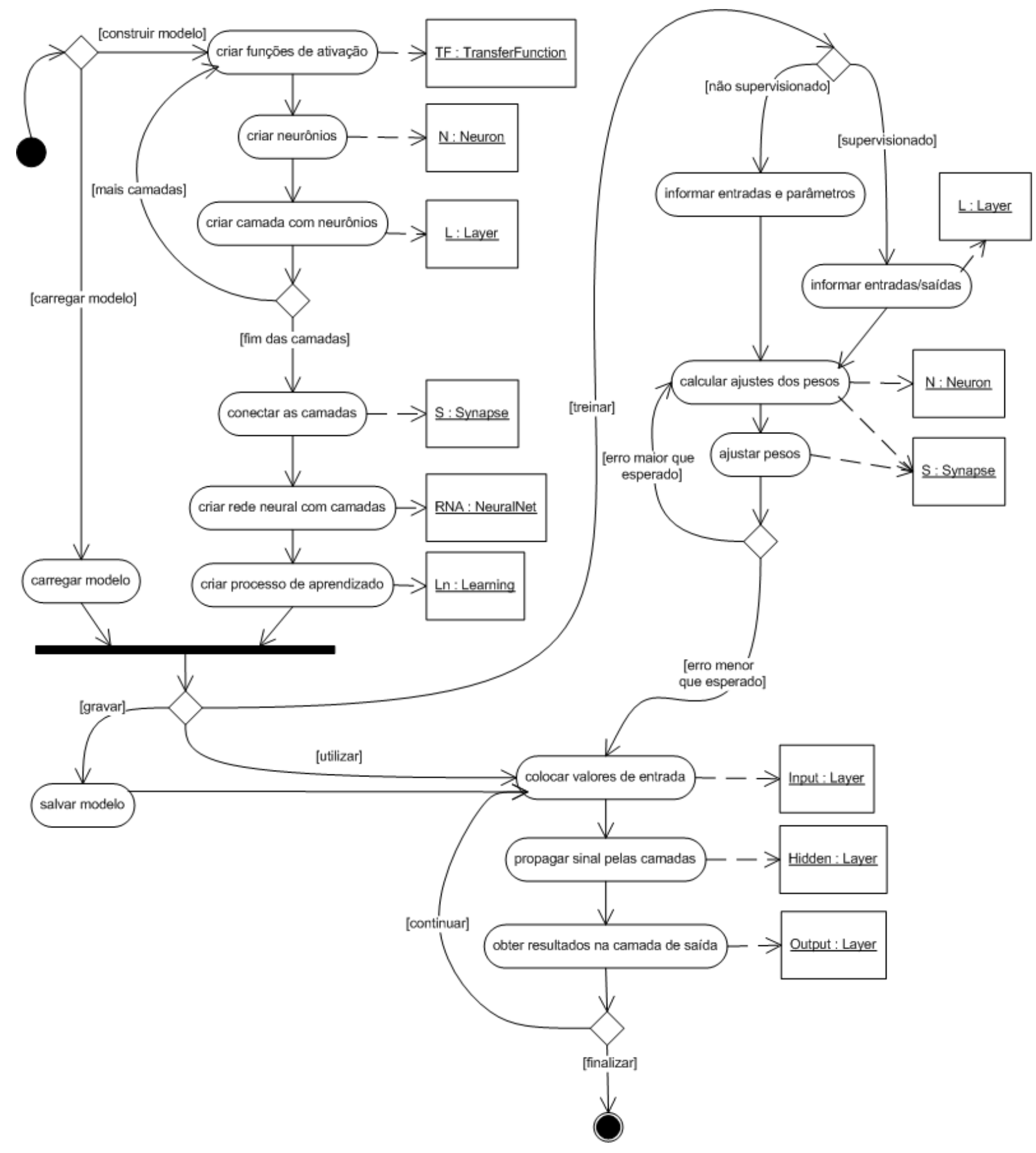

Figura 4.8: Diagrama de atividades representando a operação com CN. 


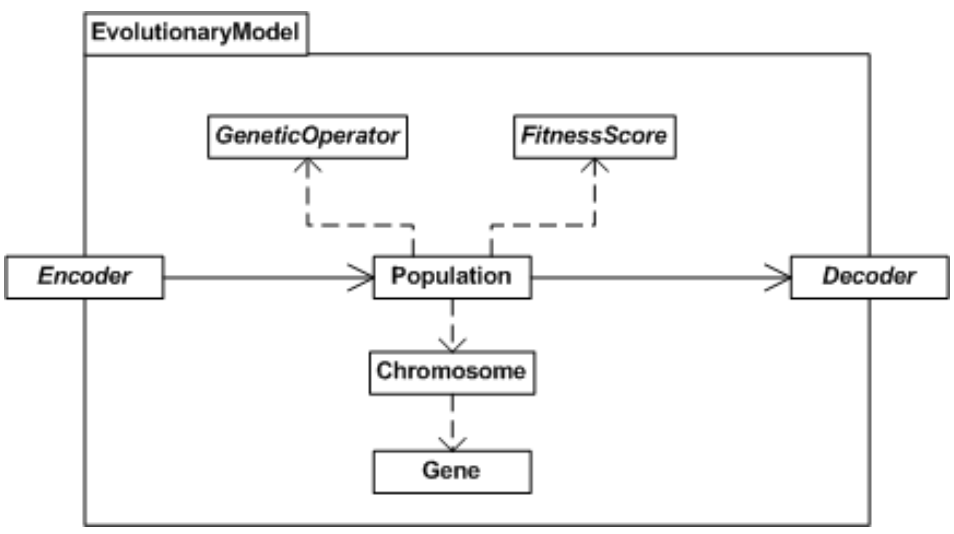

Figura 4.9: Modelo lógico do pacote para realização de CE.

determinada solução em um indivíduo (Chromossome). Vários indivíduos ou soluções formam uma população (Population), sobre a qual aplicam-se operações genéticas (GeneticOperator). Um mecanismo de avaliar a adequação da solução ao problema é necessário (FitnessScore). A utilização ou supressão destes componentes e a representação do indivíduo resultam nos diversos modelos evolucionários possíveis. Finalmente, os genes são decodificados em parâmetros do problema (Decoder). Esta terceira técnica de IC, CE, utiliza as classes e relações especificadas na figura 4.10.

A população, que representa o conjunto de soluções possíveis para um determinado problema, é representada pela classe Population. Ela é composta dos indivíduos, que representam cada uma das soluções possíveis (Chromosome). Os indivíduos carregam o seu código genético, constituído por genes (Gene). Estas cadeias genéticas que caracterizam o indivíduo são o resultado da codificação (Encoder) dos parâmetros do problema para uma cadeia de valores binários ou decimais, inteiros ou reais. As cadeias podem ser decodificadas (Decoder), para que possa ser realizada a avaliação do indivíduo em termos de adequação à solução. Esta avaliação é realizada através de uma função de adequação (FitnessScore).

Durante o processo evolutivo, operadores genéticos atuam sobre um ou mais indivíduos (GeneticOperator). Indivíduos são selecionados para sofrer este processo (Selection), e esta seleção depende diretamente da adequação do indivíduo. Outro indivíduo pode ser escolhido para realizar a troca de material genético (Crossover) ou descendentes podem ser gerados diretamente do indivíduo. Nos dois casos, algum tipo de mutação pode ocorrer com os descendentes (Mutation). Finalmente os descendentes são incorporados à população. Os descendentes gerados são comparados com a meta estabelecida (TargetSolution). 

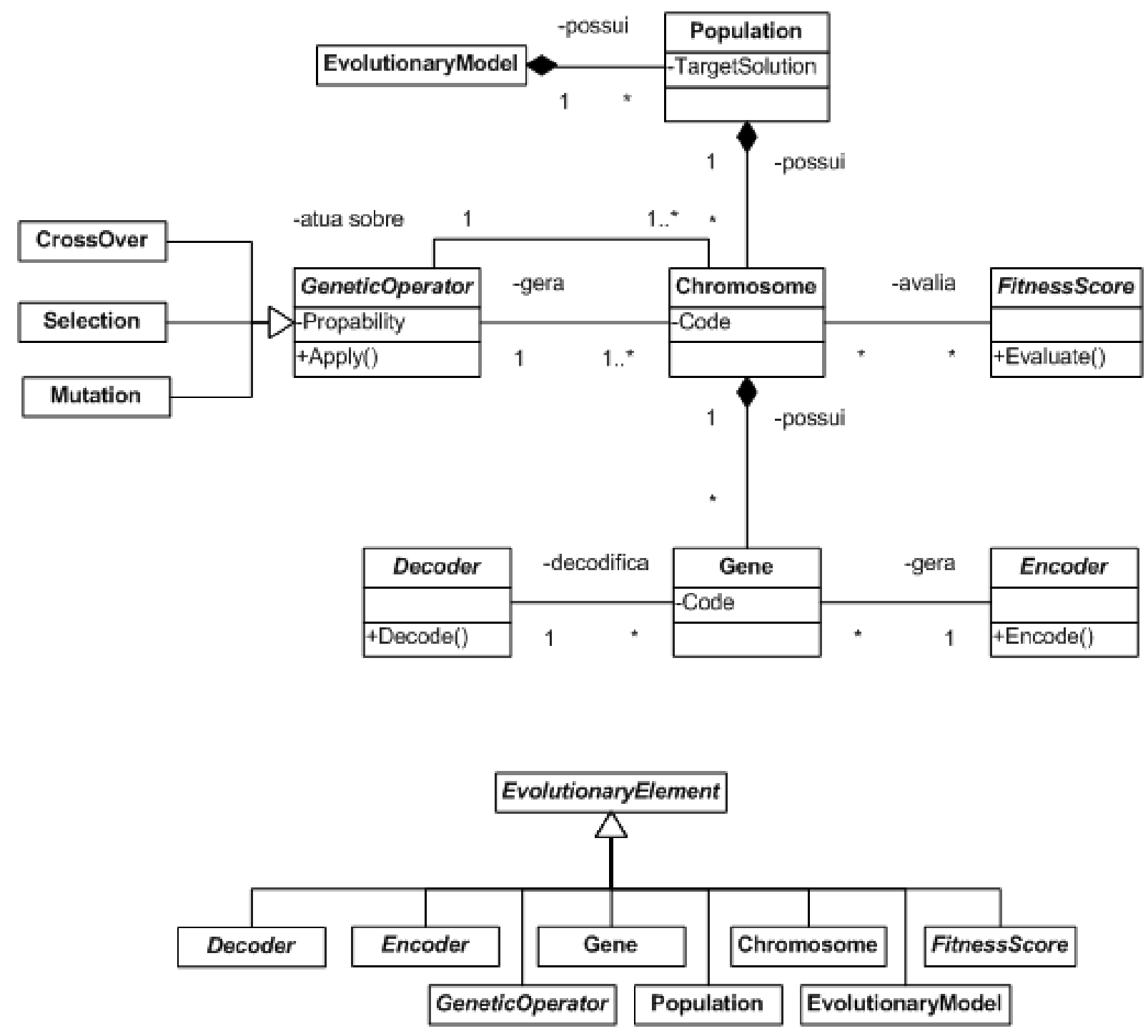

Figura 4.10: Diagrama de classes do pacote para realização de CE. 


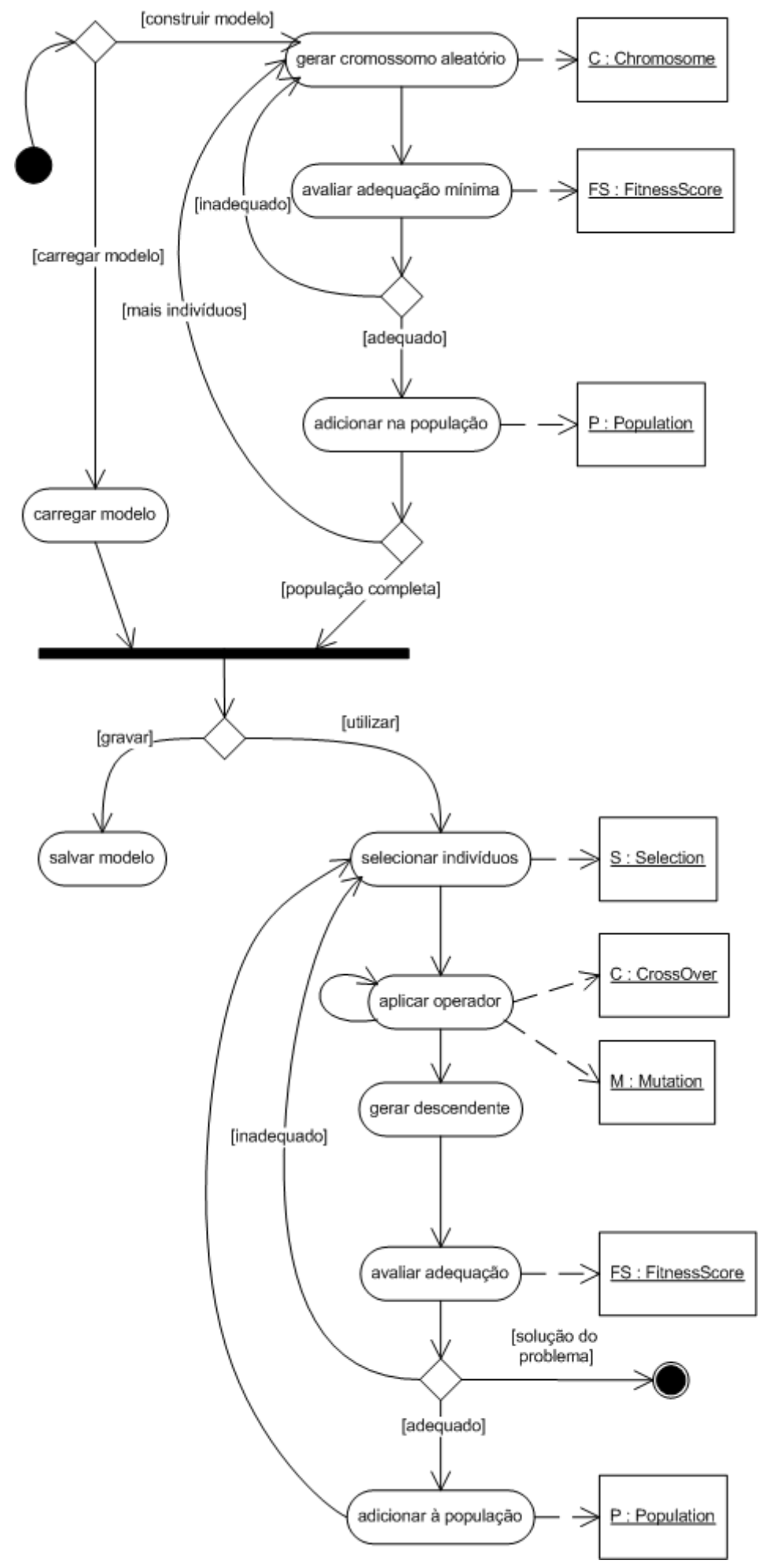

Figura 4.11: Diagrama de atividades representando a operação com CE. 
Este pacote possui os mesmos mecanismos dos pacotes $\mathrm{FC}$ e NC para expansão, como as classes abstratas Encoder, Decoder, GeneticOperator e FitnessScore. Através da combinação ou criação de novas classes derivadas destas a diversos modelos de CE podem ser desenvolvidos. O ancestral comum a todas as classes é a classe EvolutionaryElement.

O fluxo de operações típicos de um AG é representado na figura 4.11. O processo envolve normalmente a geração aleatória de individuos para compor a população inicial, que contemplem os requisitos mínimos de adequação. Uma vez definida a população inicial, o processo de busca das soluções é iniciado, através dos operadores genéticos e geração de novos indivíduos. Quando um indivíduo alcança a adequação desejada, o processo termina. A realização de investigações de isomorfismos entre os modelos nebulosos e evolucionários é foco de pesquisa atual do grupo de pesquisa do laboratório KNOMA (KNOMA, 2005).

\subsubsection{Pacote MT}

Para realizar as transformações entre os três domínios da IC, é proposta a criação de uma pacote de transformações entre modelos, apresentado na figura 4.12. As três classes representadas (FuzzyTransfom, NeuralTransform e GeneticTransform), assim como o ancestral comum ModelTransform são abstratas, devendo ser utilizadas para a criação de classes específicas para algum tipo de transformação proposta.

As classes implementadas a partir de FuzzyTransfom transformam um ou mais elementos nebulosos em um ou mais elementos neurais ( ToNeural) ou um ou mais elementos genéticos (ToGenetic). As demais classes se comportam de maneira similar, possuindo um ou mais elementos de seu domínio e podendo gerar elementos de outros domínios.

A motivação para este arquitetura é a possibilidade de se escolher partes de um determinado modelo em um pacote, seus elementos constituintes, e substituí-las por elementos de outro pacote, verificando o funcionamento do modelo posteriormente, para avaliar o impacto. Assim, um determinado elemento nebuloso, como o número nebuloso (FuzzyNumber) poderia ser modelado como um tipo de neurônio (Neuron). A exploração das relações poderia ser realizada de maneira construtiva, buscando métodos para portar cada um dos blocos dos modelos. 


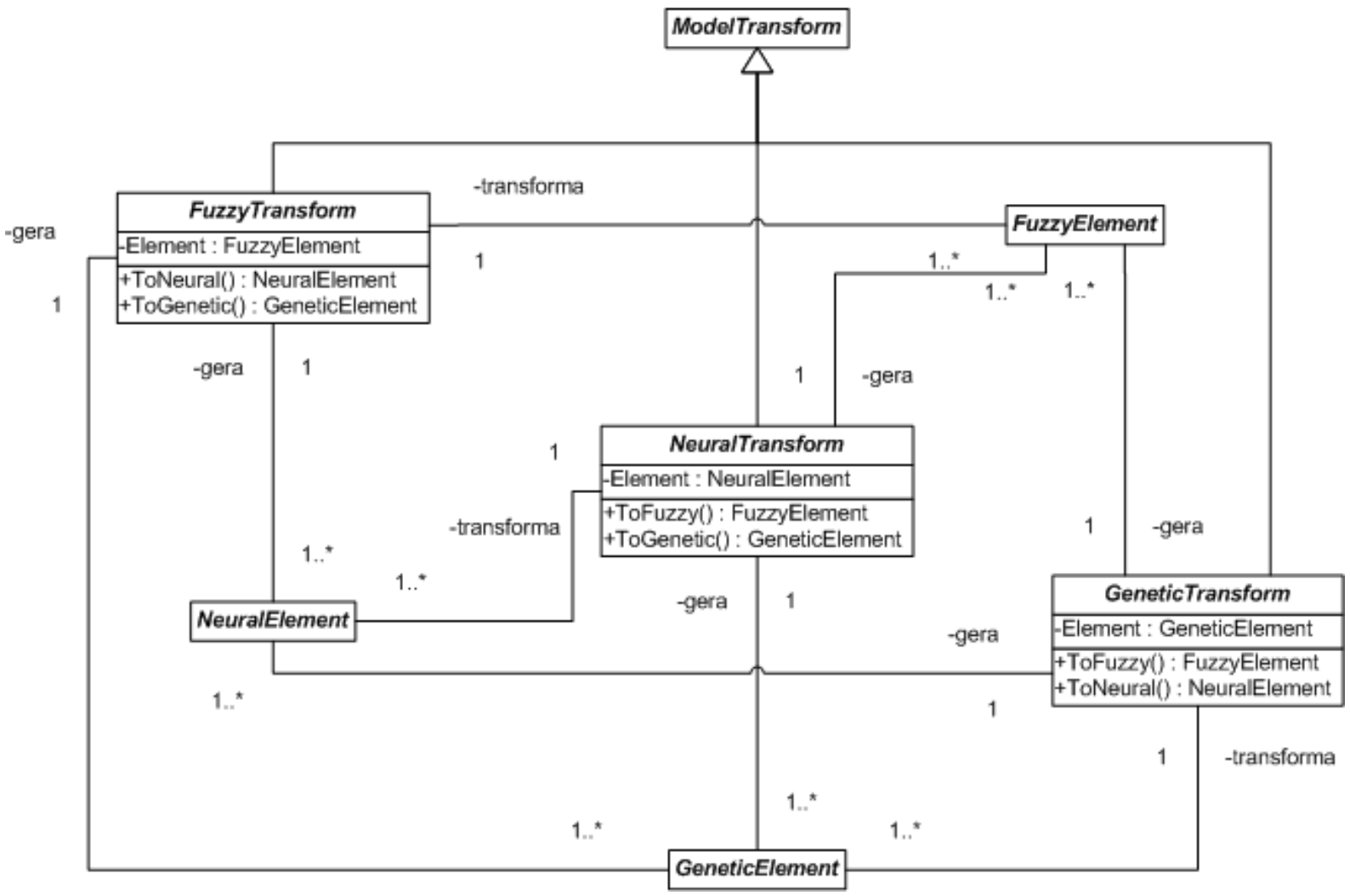

Figura 4.12: Diagrama de classes do pacote para realização de transformações da IC.

\subsection{Considerações Finais do Capítulo}

A proposta de uma plataforma computacional, ainda que muito abstrata, neste momento da pesquisa, tem um papel importante para a realização de simulações computacionais. Este tipo de teste empírico sempre foi de fundamental importância na avaliação de técnicas de IA em geral.

Uma característica importante da plataforma é estratificação dos elementos de cada tipo de modelagem, possibilitando a análise particular de cada elemento. A compreensão deste funcionamento detalhado auxilia a busca de componentes similares.

O uso das técnicas de orientação à objetos permitem que parte da plataforma fique incompleta, mas não inexistente. As características que tais elementos devem possuir são previsíveis, embora como cada um realizará suas tarefas não seja conhecido. Uma referência clássica na linha de programação orientada à objetos pode ser encontrada em Eckel (2002). Mais detalhes sobre a notação UML podem ser encontrados nos livros de Furlan (1998), Booch, Rumbaugh e Jacobson (1999) e Booch, Rumbaugh e Jacobson (2000). 
Alguns componentes derivados do pacote MT, o mais abstrato da especificação, que seguem a linha de aproximação entre CN e CF discutidas no capítulo 2, foram propostos e implementados. Os resultados de simulações com a utilização destes componentes são apresentados no capítulo 5. 


\title{
$5 \quad$ Experimentos Computacionais
}

\author{
Para a realização de algumas simulações um objeto de estudo, a \\ navegação de um robô autoguiado, foi escolhido. Tal problema \\ possui solução clássica conhecida com modelos nebulosos. Testes \\ envolvendo transformações para modelos neurais foram realiza- \\ dos. Os resultados destas simulações são apresentados e analisados.
}

A construção de veículos autoguiados, veículos capazes de movimentar-se em ambientes desconhecidos, é um antigo problema da robótica. Sistemas de CF foram utilizados para resolver este problema com sucesso, embora não de forma definitiva (para ambientes arbitrariamente complexos). Sendo assim, este problema foi escolhido para a realização de testes práticos com a plataforma.

Primeiramente um ambiente de simulação foi criado. Em seguida a solução com CF foi modelada e ajustada para resolver de forma satisfatória o problema. Visando confirmar os indícios de que SINs poderia possuir equivalências com RNAs, uma RNA foi construída e treinada para se comportar exatamente como o SIN de navegação do robô.

Em seguida componentes do pacote MT foram criados, de acordo com as aproximações propostas no capítulo 2, e algumas simulações comparativas entre os componentes transformados foram realizadas. Um algoritmo para a conversão estratificada de um SIN para RNA foi proposto.

Finalmente, a transformação foi aplicada ao problema escolhido e experimentos foram realizados com o robô nos dois domínios, buscando verificar o sucesso do método utilizado.

\subsection{Navegação de Robôs Autoguiados}

Segundo Saffiotti (1997), o objetivo da robótica autônoma móvel é a construção de sistemas físicos que podem operar sem a intervenção humana em ambientes para os quais ele não foi especificamente construído. Tal problema encontra um grande número de 
aplicações, como robôs utilitários em escritórios, hospitais, indústrias, robôs domésticos, entre outros.

Os ambientes no mundo real em que estes robôs podem operar, entretanto, estão repletos de imprecisões e incertezas. Modelos foram construídos para tentar realizar planejamento e representação dos ambientes, mas todos resultaram em sistemas de alta requisição computacional, inadequado para a maioria das aplicações de robótica móvel (MARTINEZ; TUNSTEL; JAMSHIDI, 1994).

Uma alternativa para a modelagem destes ambientes completos é o controle do comportamento conforme Saffiotti (1997). Esta idéia segue a linha de dividir-para-conquistar, criando sistemas simples para executar cada parte do comportamento esperado do robô, combinando os comportamentos inferidos para definir a linha de ação final. Uma possibilidade desta abordagem é a criação de robôs que se comportam como agentes reativos (RUSSEL; NORVIG, 2004), a cada momento percebendo o ambiente, mapeando este conjunto de entradas em saídas e atuando no ambiente em seguida.

Mesmo na modelagem orientada a comportamento, a complexidade do ambiente pode resultar em modelos complexos e de difícil tratamento computacional. As técnicas de CF podem auxiliar na abstração dos detalhes irrelevantes do ambiente, criando modelos capazes de operar com raciocínio aproximado.

Sendo assim, decidiu-se utilizar um modelo nebuloso para projetar um robô reativo autoguiado. O comportamento escolhido foi o de mover-se em terreno desconhecido evitando colisões. Na simulação foi definido também que o agente estaria sozinho no ambiente, sem outros elementos se movimentando. Esta restrição permite resolver o problema com um número mínimo de sensores.

Um diagrama que ilustra o modelo escolhido é apresentado na figura 5.1. O robô possui simplesmente três sensores de distância. Um de distância frontal $(F)$, um de distância da lateral esquerda $(L)$ e outro de distância lateral direita $(R)$. Para simplificar o modelo, a única ação possível é uma alteração na direção do robô, através de um ângulo $\theta$. A velocidade é mantida constante.

Um ambiente foi desenvolvido para tal fim, visto que a construção de um robô e de mapas de percurso, além de já ter sido amplamente discutido na literatura, foge ao escopo deste trabalho. O objetivo é de fato verificar como transportar um problema classicamente resolvido com $\mathrm{CF}$ para $\mathrm{CN}$. 


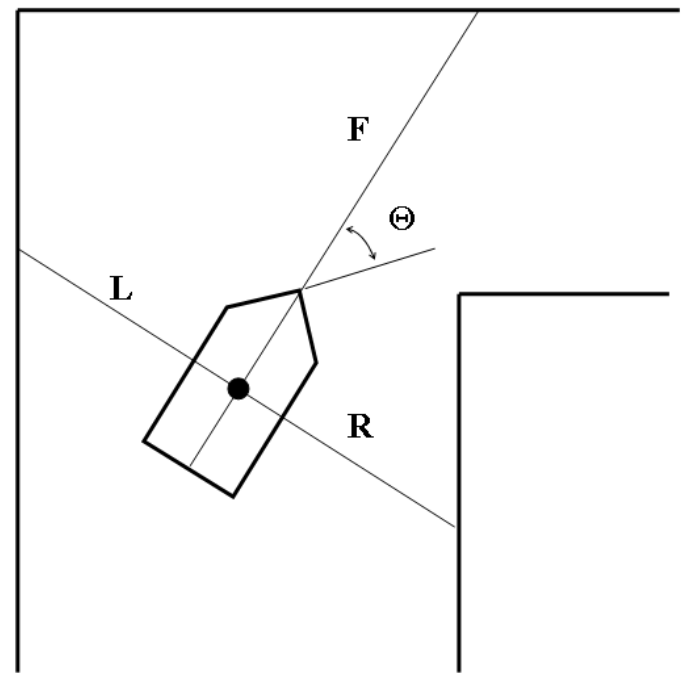

Figura 5.1: Veículo Autoguiado (F, L e R: distância frontal, esquerda e direita; $\theta$ : variação na direção.

\subsubsection{O Ambiente de Simulação}

Foi desenvolvida uma interface visual para a simulação do problema de navegação do robô autoguiado. A janela principal do ambiente é apresentada na figura 5.2. Esta janela é composta dos seguintes dos seguintes setores:

- Menu: Possibilita acessar as funções de salvar e carregar um mapa, acessar a janela de modelagem do sistema nebuloso e as informações de ajuda e autoria da ferramenta.

- Medidas dos Sensores: a distância dos obstáculos frontais e laterais é apresentada. Por ser uma ferramenta de simulação, nenhuma unidade foi adotada. A medida da distância foi obtida em pixels e pode ser considerada como metros, centímetros, entre outros.

- Ângulo de saída: o ângulo em graus que o robô deve virar no próximo passo (resultado a ação reativa aos sensores de entrada). O valor zero indica nenhuma rotação, valores negativos indicam movimentação para a esquerda e positivos, para a direita.

- Comandos: operação do robô. Permite mostrar ou não uma linha que marca a trajetória, as linhas coloridas que simulam o sinal dos sensores (lasers), alterar o 


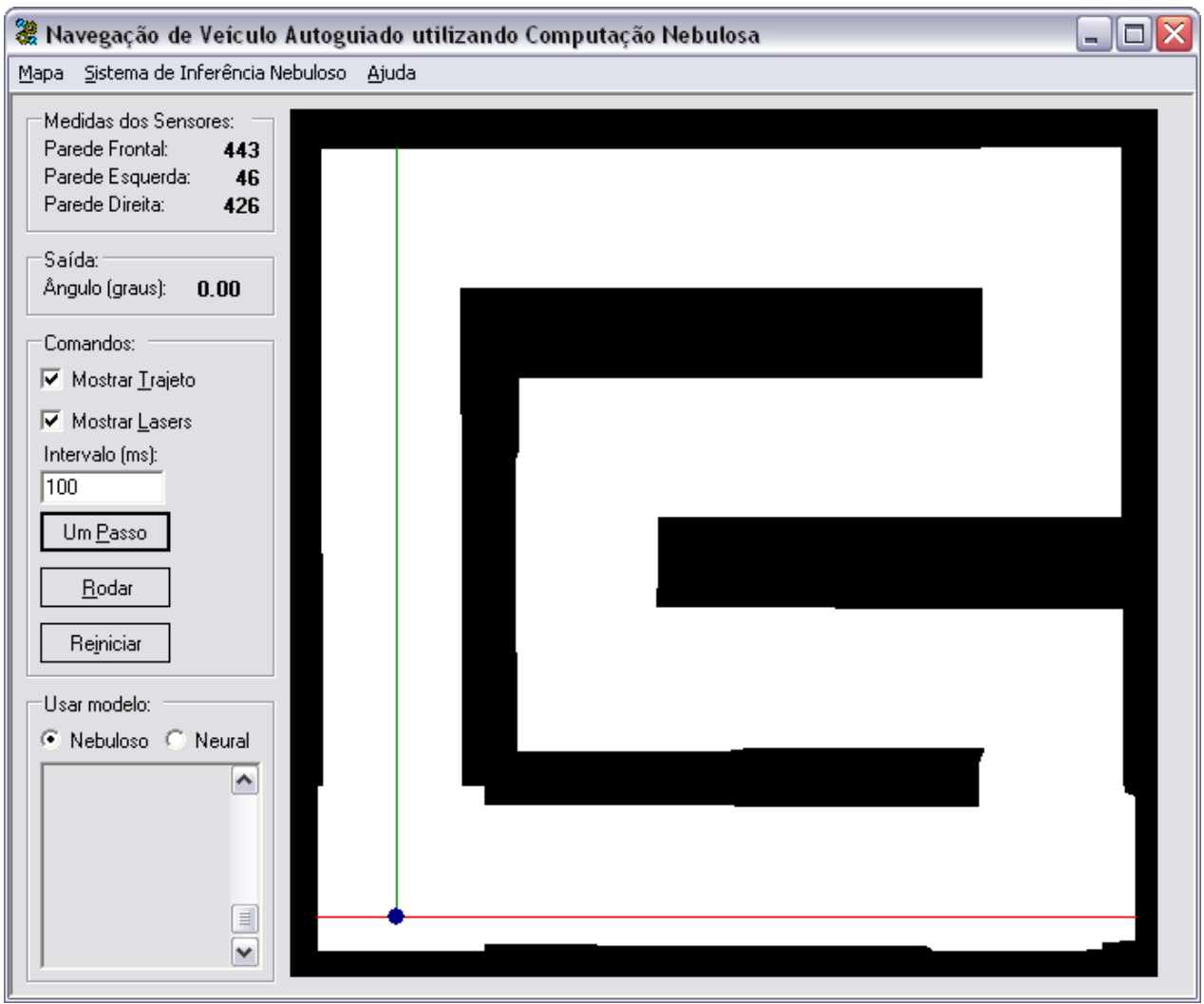

Figura 5.2: Ferramenta de simulação de navegação de veículo autoguiado.

intervalo entre cada passo da simulação, iniciar, parar e reiniciar o processo de simulação.

- Usar modelo: possibilita a escolha entre o modelo nebuloso ou neural. Possui uma área de texto para a geração de informações para depuração ou análise do processo de navegação.

- Mapa: o ambiente simulado; possui o robô, representado como um círculo azul, as áreas livres para movimentação indicadas como branco e as áreas com obstáculos (ou paredes) indicadas como preto. O usuário é livre para desenhar o mapa que desejar, bem como para carregá-lo a partir de um arquivo gravado previamente. Esta funcionalidade possibilita a simulação de ambientes desconhecidos. Outro exemplo de mapa pode ser observado na figura 5.3.

Para facilitar experimentos com modelos nebulosos diferentes, foi criada uma ferramenta visual para modelagem deste problema do robô com estes sensores em particular. A versão final do SIN que possibilita a navegação autônoma do robô em diversos ambientes foi obtida através de ajustes sucessivos nas variáveis lingüísticas e no conjunto de regras. 


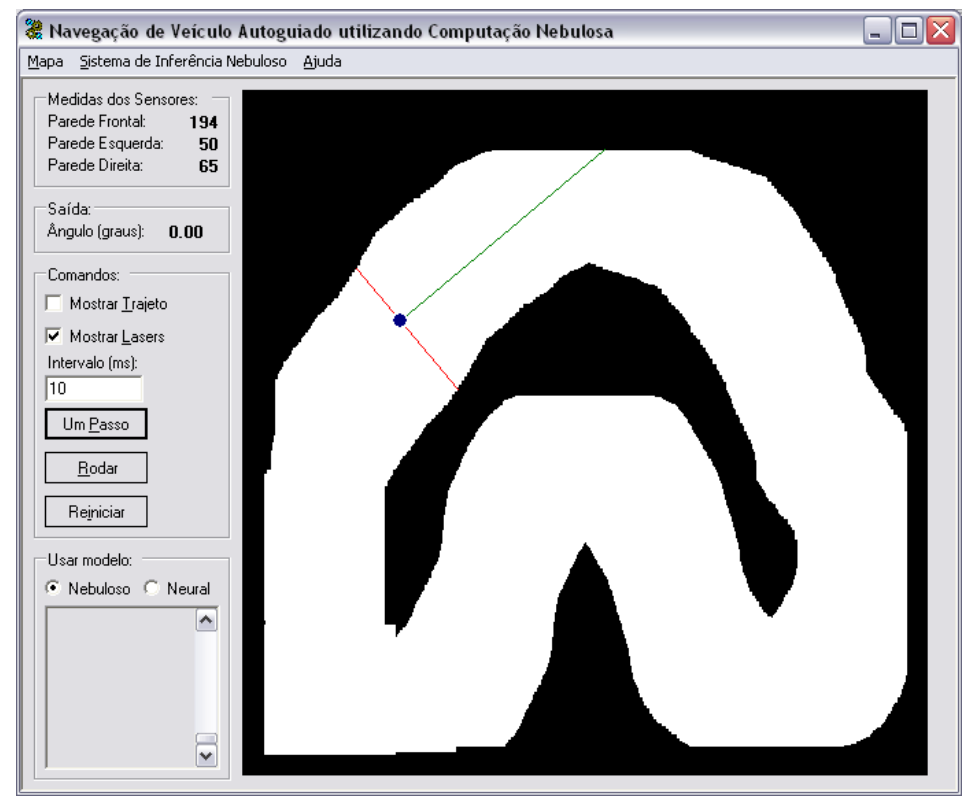

Figura 5.3: Exemplo de mapa arbitrário para navegação do robô.

Esta interface visual instancia classes do pacote FC da plataforma computacional, abstraindo os detalhes de programação do usuário. Ela é acessada através da opção "Sistema de Inferência Nebuloso" do menu. A janela principal que possibilita criar, editar, excluir e visualizar variáveis lingüísticas (base de dados) e regras lingüística (base de regras) é apresentada na figura 5.4.

A parte superior representa a base de dados. Para adicionar uma nova variável basta digitar um nome na caixa de texto superior e clicar em "Nova". Se a variável já estiver na base de regras, pode ser excluída ou editada. A edição das etiquetas nebulosas é facilitada pela representação visual dos conjuntos nebulosos, conforme apresentado no exemplo da figura 5.5, referente à uma variável ângulo.

De forma similar as regras podem ser editadas a partir da parte inferior da janela. Um exemplo da edição de uma regra pode ser visto na figura 5.6. Esta interface permite, também, a gravação do modelo criado em um arquivo no formato XML, para posterior utilização nesta ferramenta ou em outras que possam trabalhar com este formato. Este ambiente de simulação foi utilizado, em primeiro momento, para solução do problema de navegação do robô através da modelagem nebulosa. 


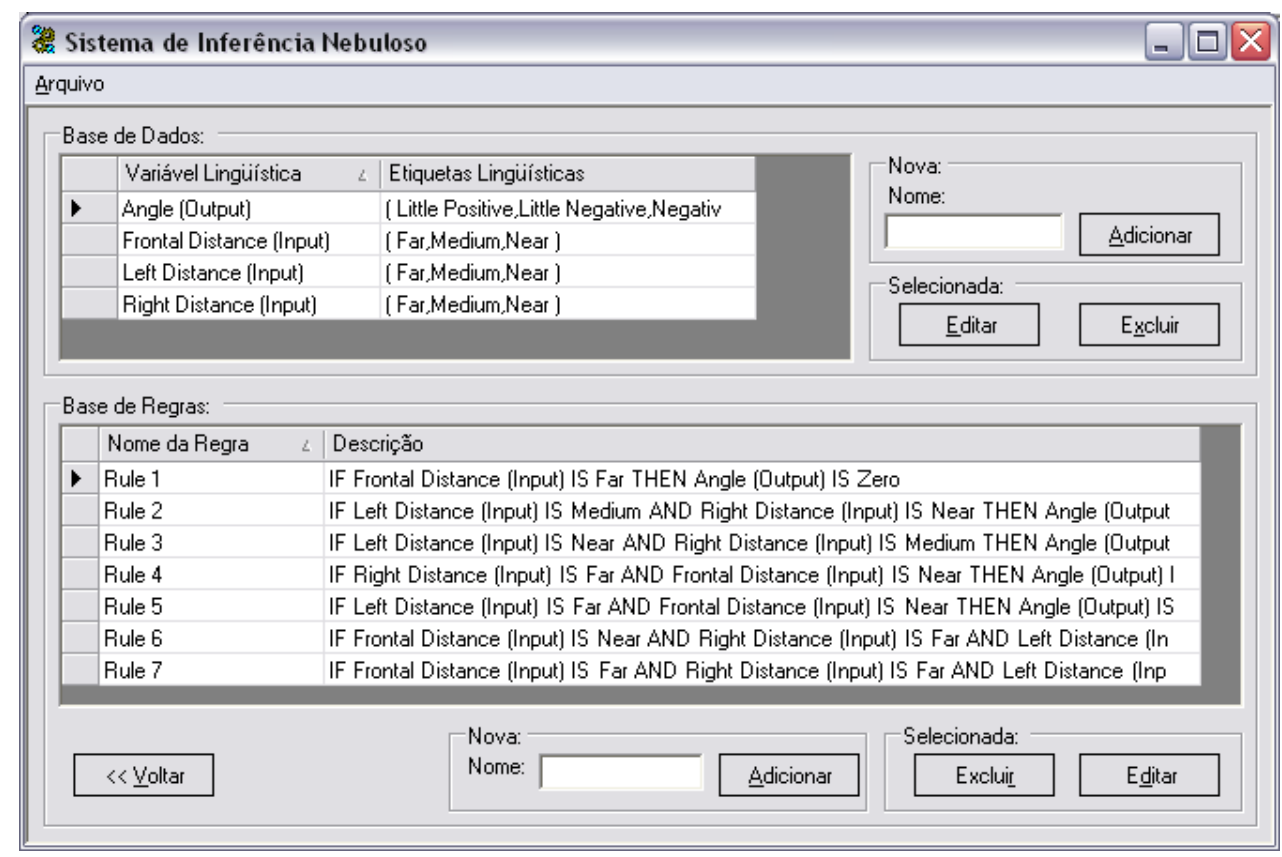

Figura 5.4: Interface para criação e manipulação do SIN.

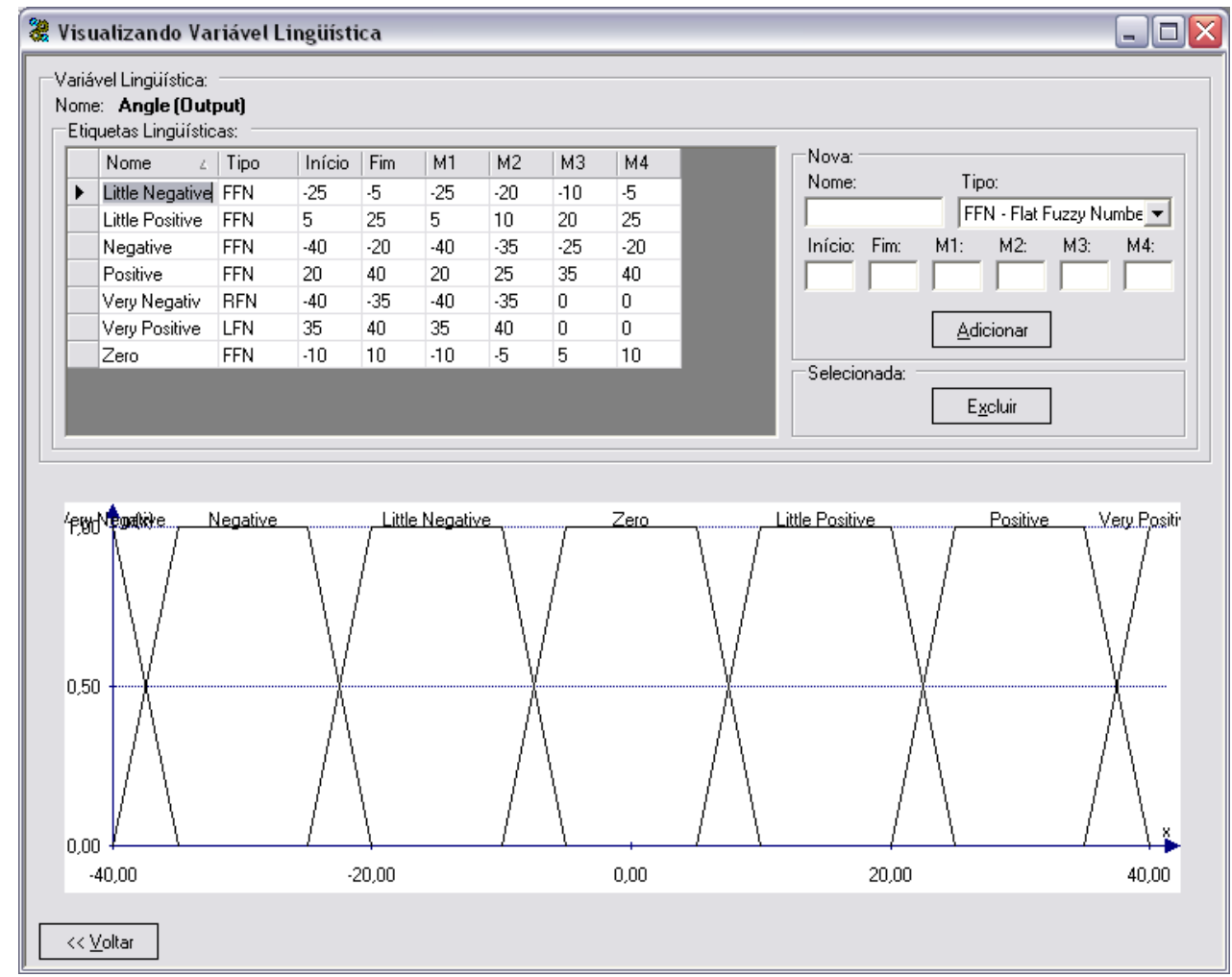

Figura 5.5: Exemplo de visualização de variável lingüística. 


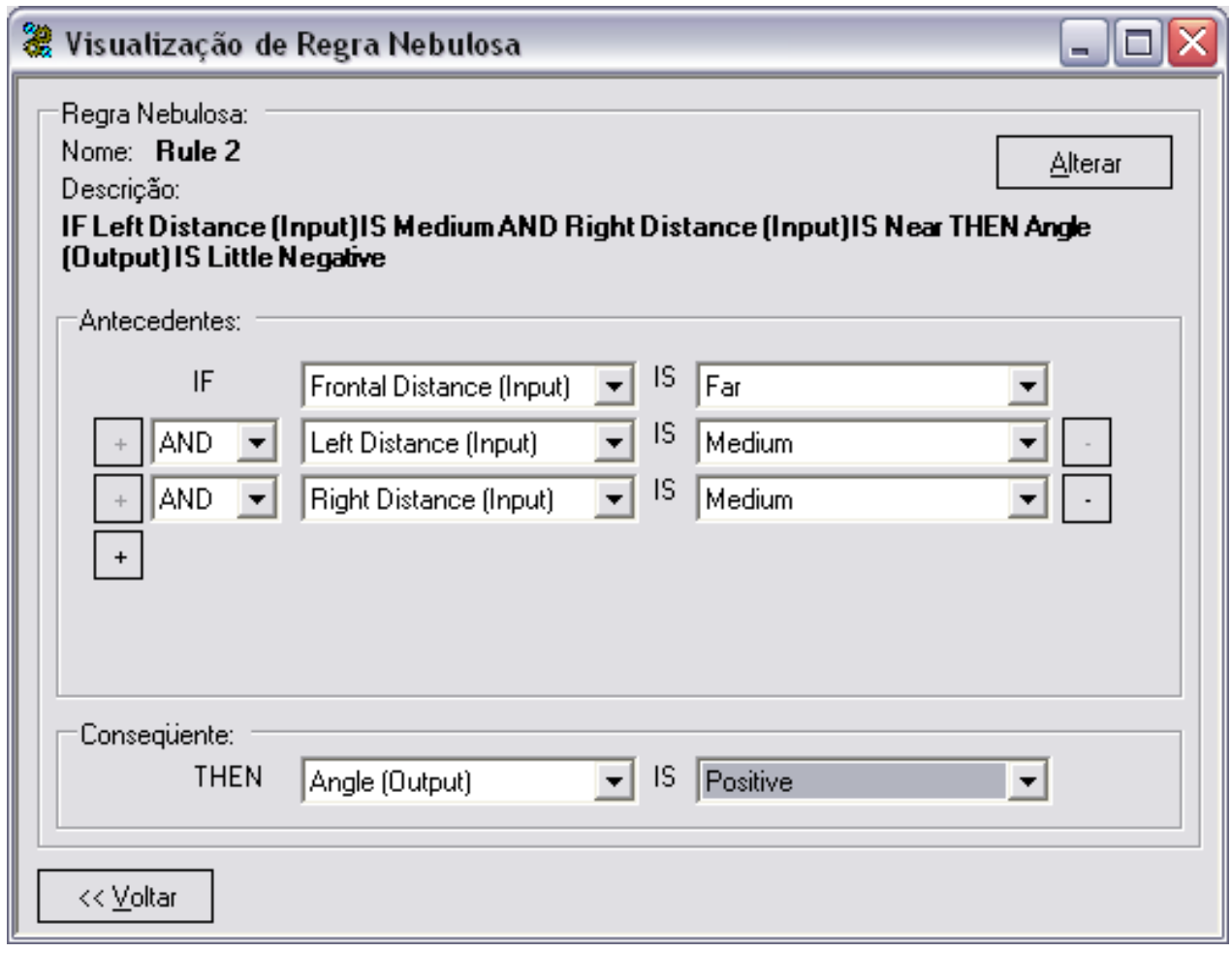

Figura 5.6: Exemplo de visualização de regra lingüística.

\subsubsection{A Implementação da Solução com CF}

Um modelo para orientar a navegação do robô foi criado e sucessivamente refinado através de testes do percurso do robô em mapas arbitrários. Um modelo final foi obtido, capaz de evitar as colisões na maioria dos mapas testados. Ainda sim, colisões ocorreram, quando o tamanho do corredor ou o espaço de manobras do robô foi diminuído de forma drástica.

As variáveis lingüísticas que compõe a base de dados do modelo final obtido são apresentadas na figura 5.7. A variável de saída é o ângulo (Angle), e as variáveis de entrada são as distâncias frontal, esquerda e direita (Frontal, Left e Right). Com estas variáveis foram construídas as regras para compor a base de regras, apresentadas na tabela 5.1 .

Finalmente, o mecanismo de inferência escolhido foi o mínimo de Mamdani e o método de defuzzificação foi o cálculo do centro de gravidade (LEE, 1990b). Todos estes elementos agrupados compõe o SIN para navegação do robô. O modelo foi construído e utilizado através do pacote FC da UCIP, e, conforme especificação da plataforma, o modelo pode ser gravado em um arquivo XML para que possa ser utilizado posteriormente ou exportado para outros sistemas. O arquivo XML com este modelo foi inserido no apêndice A.

O sucesso do modelo foi avaliado apenas através do teste de mapas arbitrários, com 

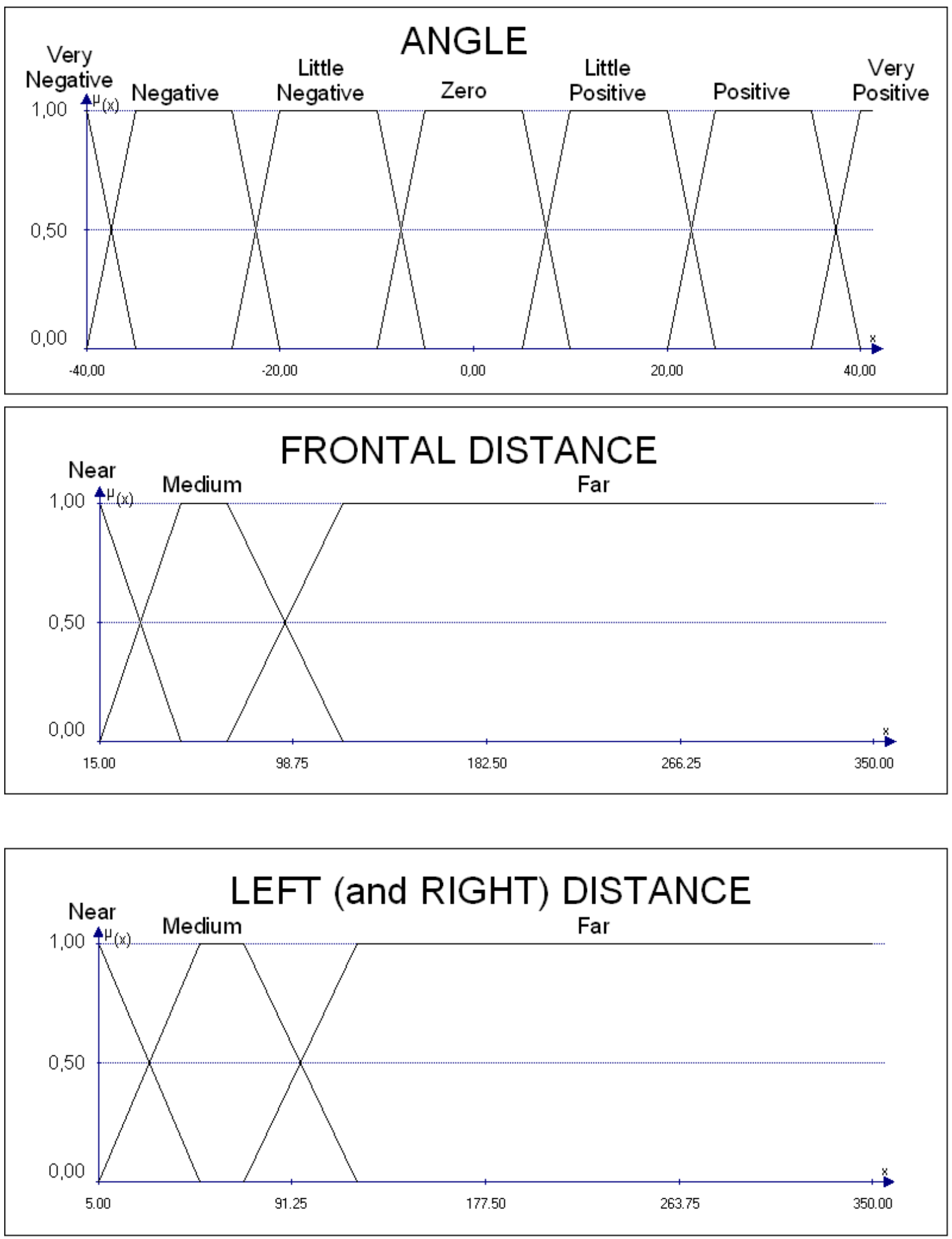

Figura 5.7: Variáveis lingüísticas para navegação do robô autoguiado. 


\begin{tabular}{|l|l|}
\hline Nome & Descrição \\
\hline Regra 1 & IF Frontal Distance IS Far THEN Angle IS Zero \\
\hline Regra 2 & $\begin{array}{l}\text { IF Left Distance IS Medium AND Right Distance IS Near } \\
\text { THEN Angle IS Little Negative }\end{array}$ \\
\hline Regra 3 & $\begin{array}{l}\text { IF Left Distance IS Near AND Right Distance IS Medium } \\
\text { THEN Angle IS Little Positive }\end{array}$ \\
\hline Regra 4 & $\begin{array}{l}\text { IF Right Distance IS Far AND Frontal Distance IS Near } \\
\text { THEN Angle IS Very Positive }\end{array}$ \\
\hline Regra 5 & $\begin{array}{l}\text { IF Left Distance IS Far AND Frontal Distance IS Near } \\
\text { THEN Angle IS Very Negative }\end{array}$ \\
\hline Regra 6 & $\begin{array}{l}\text { IF Frontal Distance IS Near AND Right Distance IS Far } \\
\text { AND Left Distance IS Far THEN Angle IS Positive }\end{array}$ \\
\hline Regra 7 & $\begin{array}{l}\text { IF Frontal Distance IS Far AND Right Distance IS Far } \\
\text { AND Left Distance IS Far THEN Angle IS Zero }\end{array}$ \\
\hline
\end{tabular}

Tabela 5.1: Regras lingüísticas para navegação do robô autoguiado

corredores curvos ou retangulares. O percurso do robô em dois mapas diferentes é apresentado na figura 5.8. Embora tenha sido cogitada uma avaliação numérica baseada em distâncias médias de obstáculos, observou-se o princípio da incompatibilidade e a filosofia dos modelos nebulosos, que buscam significado ao contrário de precisão. O significado do problema, neste caso, foi de evitar obstáculos em terrenos desconhecidos. Tal objetivo foi, de fato, alcançado.

\subsubsection{A Implementação da Solução com CN}

Para confirmar os indícios de equivalência entre alguns tipos de SINs e alguns tipos de RNAs, um experimento simples foi realizado. Foi implementada parte do pacote NC, apenas os elementos necessários para construir um PMC e treiná-lo através de retropropagação de erro.

Em seguida, foi adicionada à ferramenta de simulação a capacidade de registrar todas as inferências realizadas, as entradas e a saída obtida a cada passo. Foram registrados os passos do robô para diversos mapas, utilizando o modelo nebuloso, totalizando um conjunto de aproximadamente duzentos registros do mapeamento entrada/saída realizado pelo SIN.

Este conjunto foi utilizado para treinar um PMC com três neurônios na camada de entrada, dez neurônios na camada oculta e um neurônio na camada de saída. Após o treinamento, as simulações realizadas com o modelo nebuloso foram repetidas com o modelo neural. 

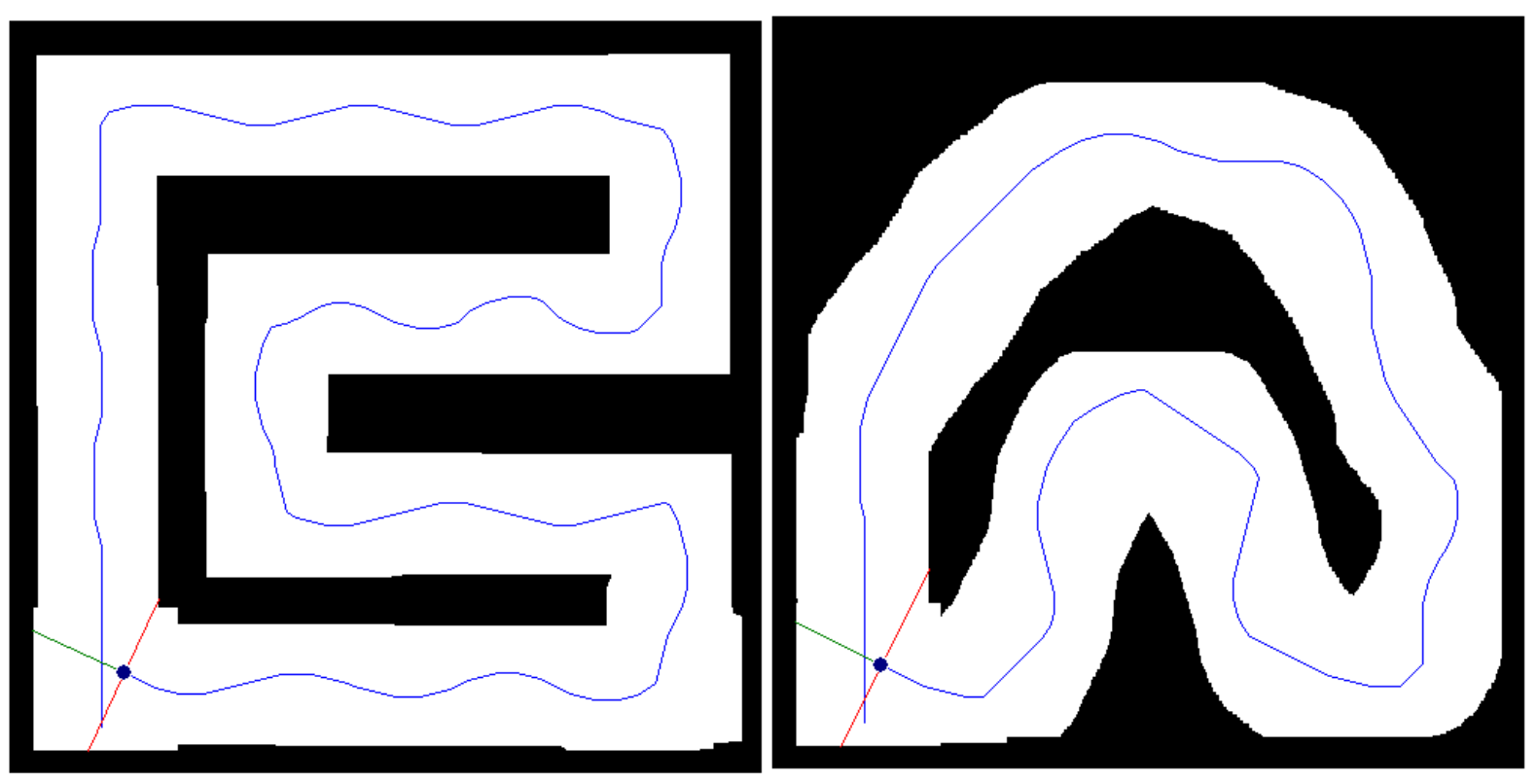

Figura 5.8: Trajeto do robô utilizando o SIN em dois mapas diferentes.
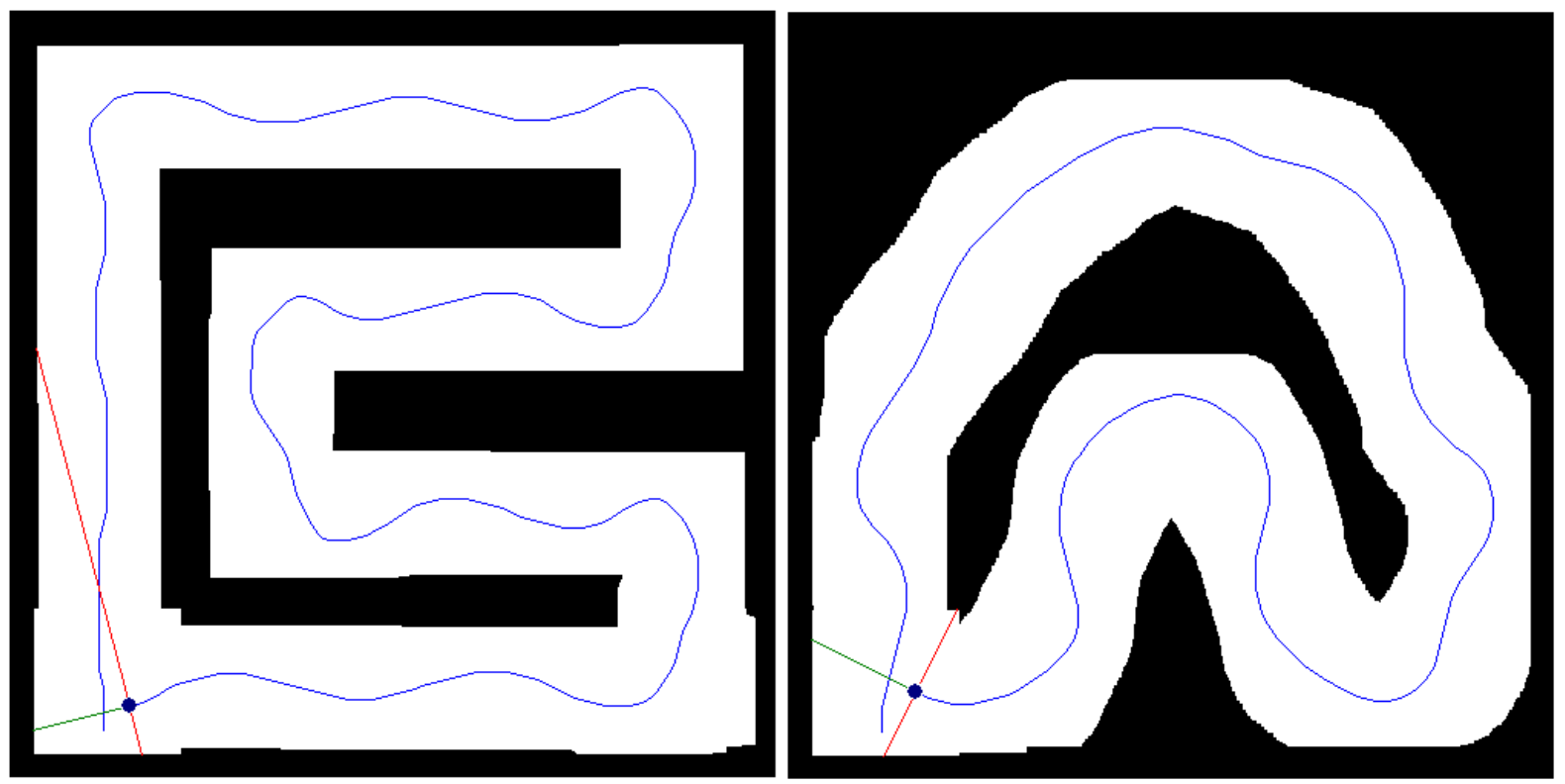

Figura 5.9: Trajeto do robô utilizando o RNA em dois mapas diferentes. 
Através do mesmo critério aplicado ao modelo nebuloso, o modelo neural obteve êxito. O robô foi capaz de movimentar-se sem colidir com obstáculos em diversos tipos de mapas. O trajeto do robô nos dois mapas utilizados para ilustrar o modelo nebuloso, agora com o modelo neural, é apresentado na figura 5.9.

Embora a idéia de que uma RNA possa simular um sistema que mapeia dados de entrada em dados de saída seja bastante óbvia, e que portanto este seria de fato o resultado, este experimento teve o objetivo de comprovar que uma RNA pode ter o comportamento igual ao de um SIN. Sendo assim, é possível que alguns de seus elementos constituintes possuem relações e sejam, até mesmo, equivalentes.

\subsection{Desenvolvimento do Pacote MT}

Com base no levantamento realizado no capítulo 2, no diagrama $\mathrm{AC}$ e na especificação da UCIP, foi desenvolvido um método para a transformação de um SIN em uma RNA aproximadamente equivalente. Para realizar a transformação total do SIN, os seguintes elementos deveriam ser transformados:

- Conjunto Nebuloso: pode ser convertido para uma Sinapse de um neurônio de base radial com peso. Seu centro é o centro da função radial, e através de base pode-se calcular a largura da função radial.

- Regra Nebulosa: convertida para um Neurônio de base radial. A função de transferência do neurônio deve ter formato de sino, para aproximar os conjuntos nebulosos.

- Conjunto de Regras: convertida para a Camada Oculta da RNA.

- SIN: convertida para RNA, as entradas e saídas definem a Camada de Entrada e de Saída da rede. O método de defuzzificação define os pesos da Camada de Saída.

A transformação foi implementada em etapas e simulações foram realizadas para verificar o resultado de etapas intermediárias. As primeiras simulações envolveram um SIN simplificado, com o objetivo de verificar o potencial de ativação das regras e a etapa de defuzzificação. 

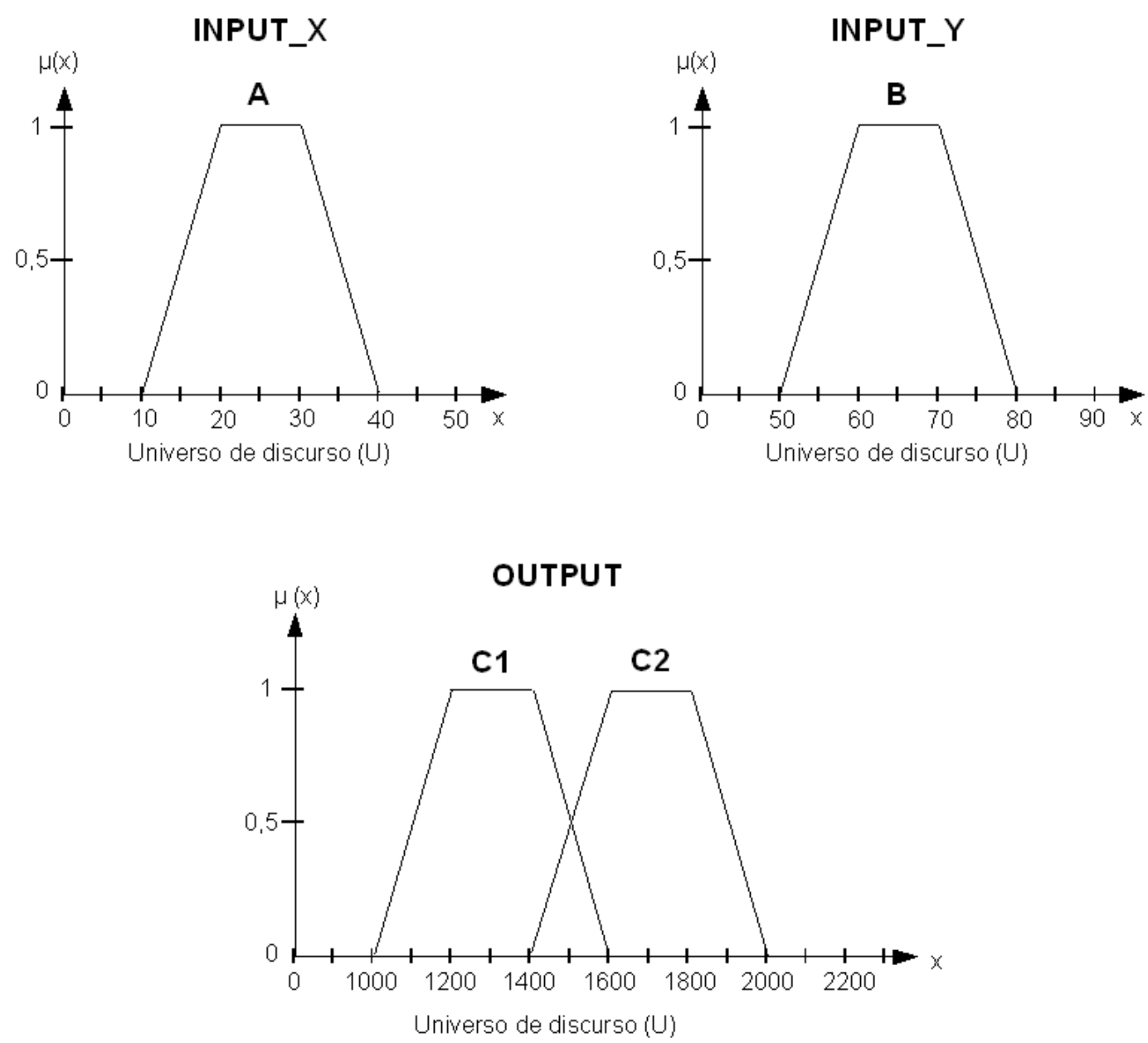

Figura 5.10: Variáveis lingüísticas simples para simulação de transformação.

\subsubsection{Resultados das Transformações por Aproximação}

Considerou-se inicialmente um SIN com as variáveis lingüísticas apresentadas na figura 5.10 e duas regras simples:

REGRA 1: IF INPUT_X IS A AND INPUT_Y IS B THEN OUTPUT IS C1 REGRA 2: IF INPUT_X IS A THEN OUTPUT IS C2

O método de inferência de Mamdani e a defuzzificação por centro de área foram utilizados. Em um primeiro momento, o objetivo foi avaliar o potencial de ativação da regra 1, se aplicada a transformação de regra nebulosa em neurônio de base radial proposta. Foram coletadas várias amostras de entradas e saídas para a regra e o neurônio obtido a partir dela, apresentados na forma de gráfico de superfície na figura 5.11. 


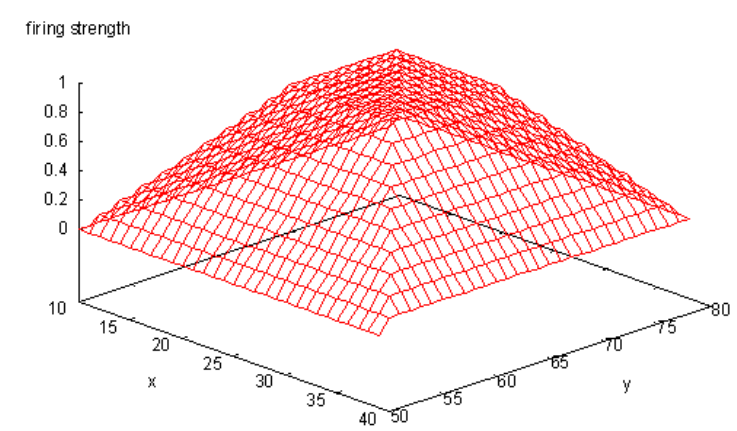

(a)

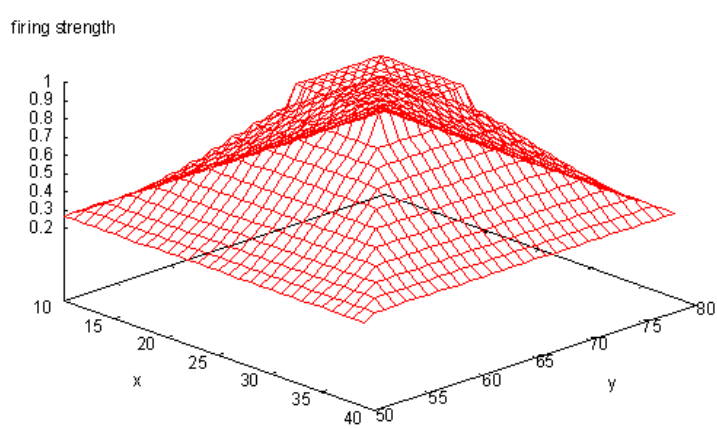

(b)

Figura 5.11: Potencial de ativação da (a) regra nebulosa e do (b) neurônio radial obtido a partir dela.

Pode-se observar que a aproximação realizada é razoável para a maioria dos pontos. Quando a pertinência dos conjuntos nebulosos se aproxima de zero, entretanto, podese observar que a pertinência do neurônio tende a zero de forma mais suave, atingindo aproximadamente o valor de dois décimos. O neurônio também parece atingir o ápice de forma mais brusca que o conjunto nebuloso. Ainda sim, decidiu-se seguir em frente com a simulação da etapa de defuzzificação, esperando que as diferenças de aproximação fossem atenuadas pelo método de centro de áreas.

Uma RNA com dois neurônios, cada um representando uma das regras, foi criada. Uma camada de saída foi construída para realizar a ponderação dos potenciais de ativação. A saída do neurônio da rede deveria, finalmente, ser dividida pela soma dos potenciais de ativação para completar o processo de defuzzificação. Os resultados de diversos testes de entrada e saída do SIN simples e da RNA construída para simulá-lo estão apresentados na figura 5.12.

A diferença entre as duas saídas é quase imperceptível. Neste caso em particular realizou-se uma breve análise numérica verificando uma diferença total das saídas de menos de meio ponto percentual. Este resultado motivou a proposta de um algoritmo genérico para transformação, que foi aplicado ao modelo nebuloso do robô autoguiado.

\subsubsection{Algoritmo Proposto para Conversão de um SIN em RNA}

A primeira etapa para a conversão é a aproximação de um conjunto nebuloso para uma sinapse. A sinapse de um neurônio radial, na verdade, armazena apenas duas informações: o centro e a largura da função. A função de ativação é aplicada posteriormente no nível 


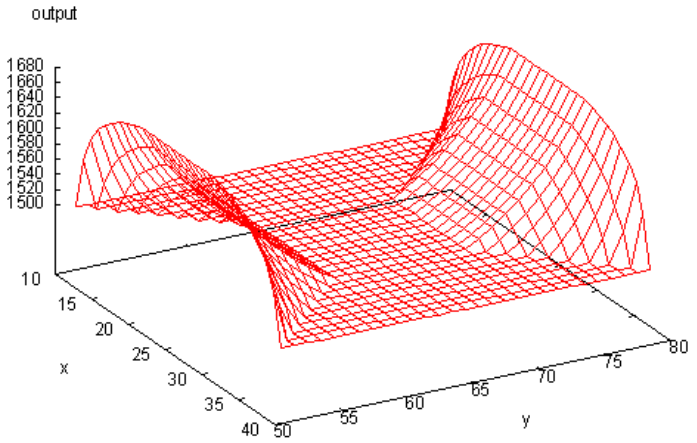

(a)

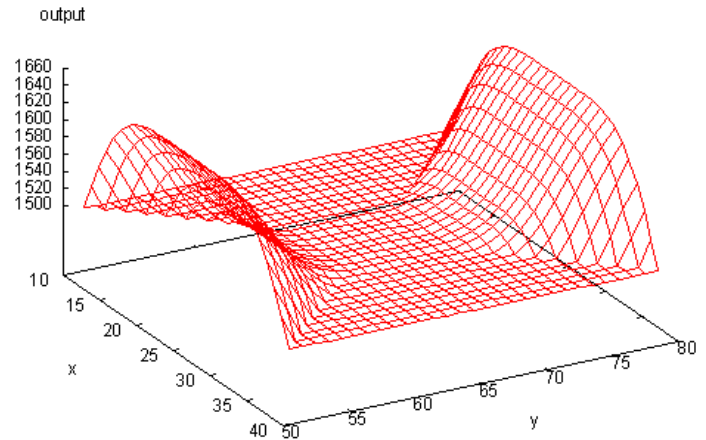

(b)

Figura 5.12: Saída obtida do (a) SIN simples e da (b) RNA obtida a partir dele.

do neurônio, com as entradas já integradas. No pacote MT foi criada uma classe FuzzyTransform com um método para realizar a conversão de um elemento FuzzyNumber em um elemento Synapse. O algoritmo em pseudocódigo é apresentado no algoritmo 1.

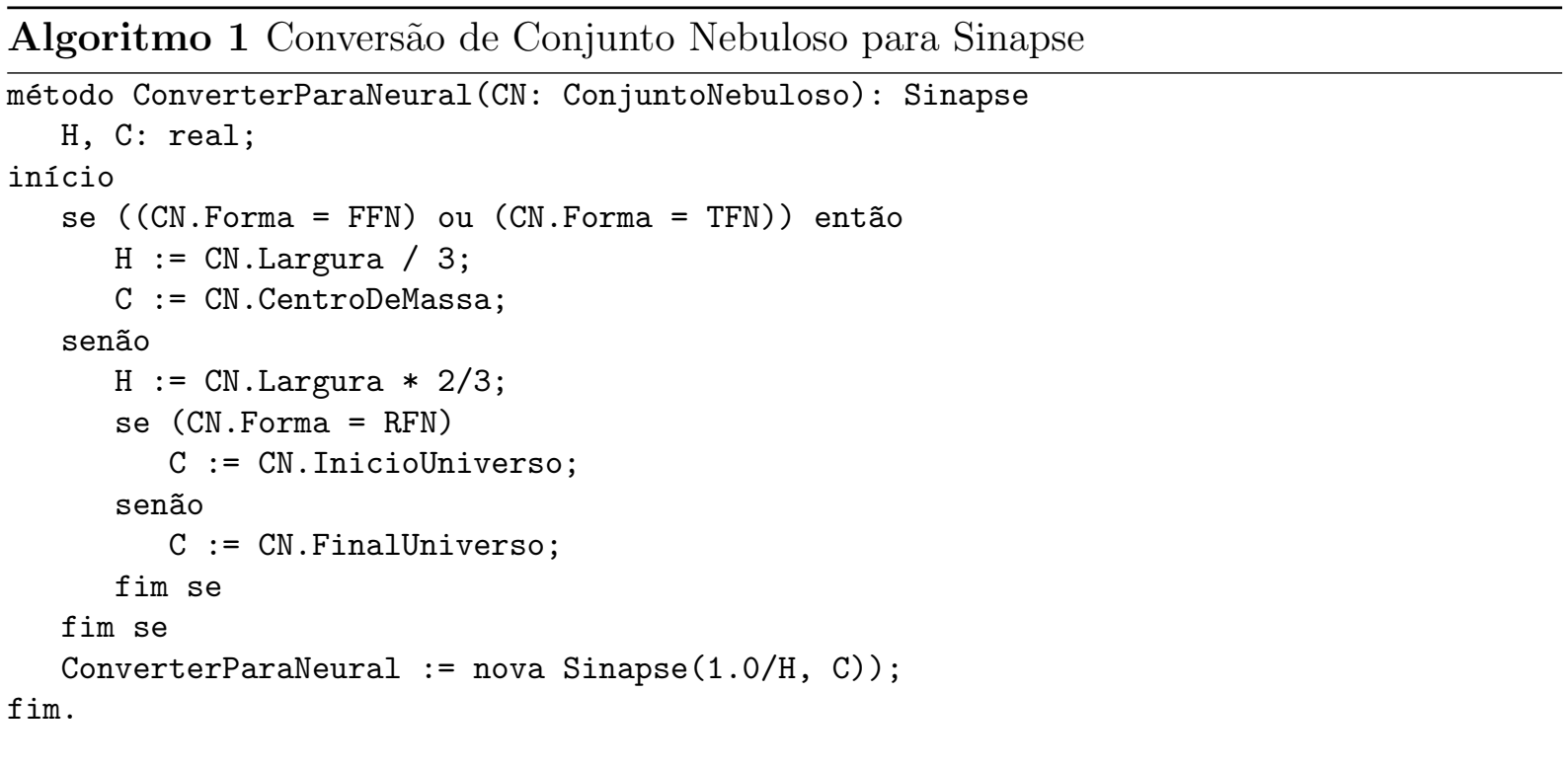

Sendo que $C$ e $H$ corresponde, respectivamente, ao centro e largura das funções radiais, codificados nas sinapses. Considerou-se no algoritmo 1 os casos de números nebulosos trapezoidais clássicos: Triangular Fuzzy Number (TFN), Flat Fuzzy Number (FFN), Left Fuzzy Number (LFN) e Right Fuzzy Number (RFN). Alguns métodos de um conjunto nebuloso são utilizados:

- Largura: retorna a largura da base do trapézio.

- CentrodeMassa: retorna o centro de massa do trapézio. 
- InicioUniverso: retorna o início do universo de discurso.

- FinalUniverso: retorna o final do universo de discurso.

Através de diversos testes empíricos e simulações das curvas das funções, obteve-se uma relação entre a base do trapézio e o fator que determina a largura da função radial. O parâmetro de largura equivalente à um terço da base do trapézio foi utilizado.

Nos casos de trapézios completos, o centro de massa pode ser o centro da função radial e o largura foi obtida diretamente pela divisão por três. Os casos de meios-trapézios como RFN e LFN representaram inicialmente um problema. Uma nova aproximação foi idealizada: foi realizado um espelhamento do meio-trapézio para criar um trapézio inteiro. Assim, o centro passa a ser o início ou fim do universo e a largura é dobrada.

Uma vez realizada a transformação de uma sinapse, o próximo passo foi a transformação de uma regra em um neurônio radial com peso. Foi adicionado à classe FuzzyTransform um método para realizar a conversão de um elemento Rule em um elemento Neuron, que utiliza o método que converte números nebulosos para sinapses, descrito no algoritmo 2 .

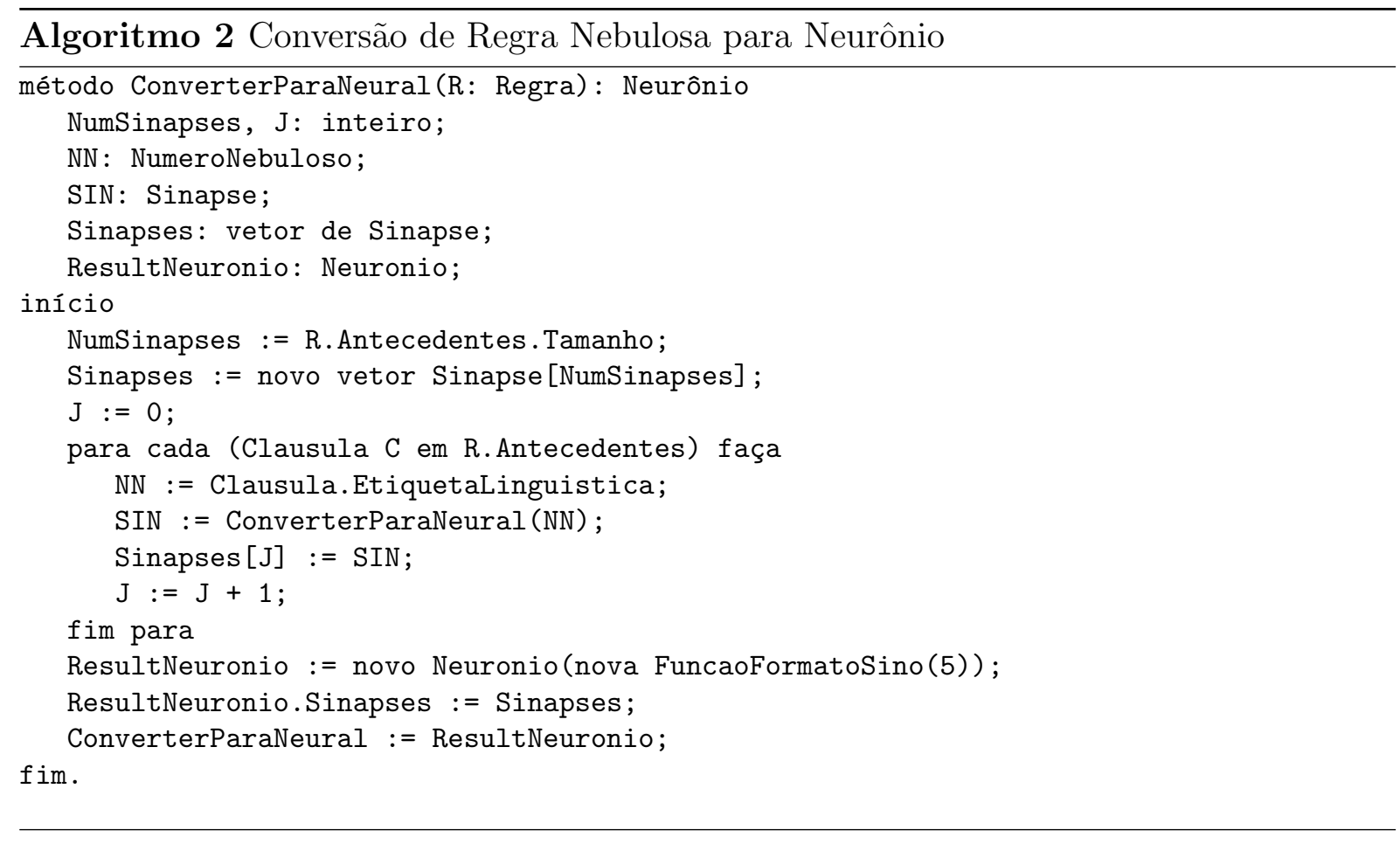

Alguns métodos de algumas classes utilizados no algoritmo 2 são:

- Regra.Antecedentes: um conjunto de cláusulas nebulosas que compõe os antecedentes de uma regra. 
- Clausula.EtiquetaLinguistica: retorna a etiqueta lingüística (conjunto nebuloso) que compõe uma cláusula ("Variável É Etiqueta").

Para construir um neurônio a partir de uma regra são construídas suas sinapses a partir das cláusulas nebulosas do antecedente da rega. Finalmente, a função de transferência precisa ser definida. A função escolhida foi a função em formato de sino:

$$
f(x)=\frac{1}{1+\left(\frac{x-C}{H}\right)^{2 L}}
$$

Sendo que $C$ e $H$ corresponde, respectivamente, ao centro e largura das funções radiais, codificados nas sinapses. Para o parâmetro $L$, que é justamente passado na criação de uma função deste tipo (FuncaoFormatoSino(5)), foi escolhido um valor 5 que aproxima razoavelmente as funções trapeizoidais. A partir deste método pode-se realizar a transformação de um conjunto de regras completas (RuleBase) em uma camada de neurônios radiais com peso (Layer), descrita no algoritmo 3.

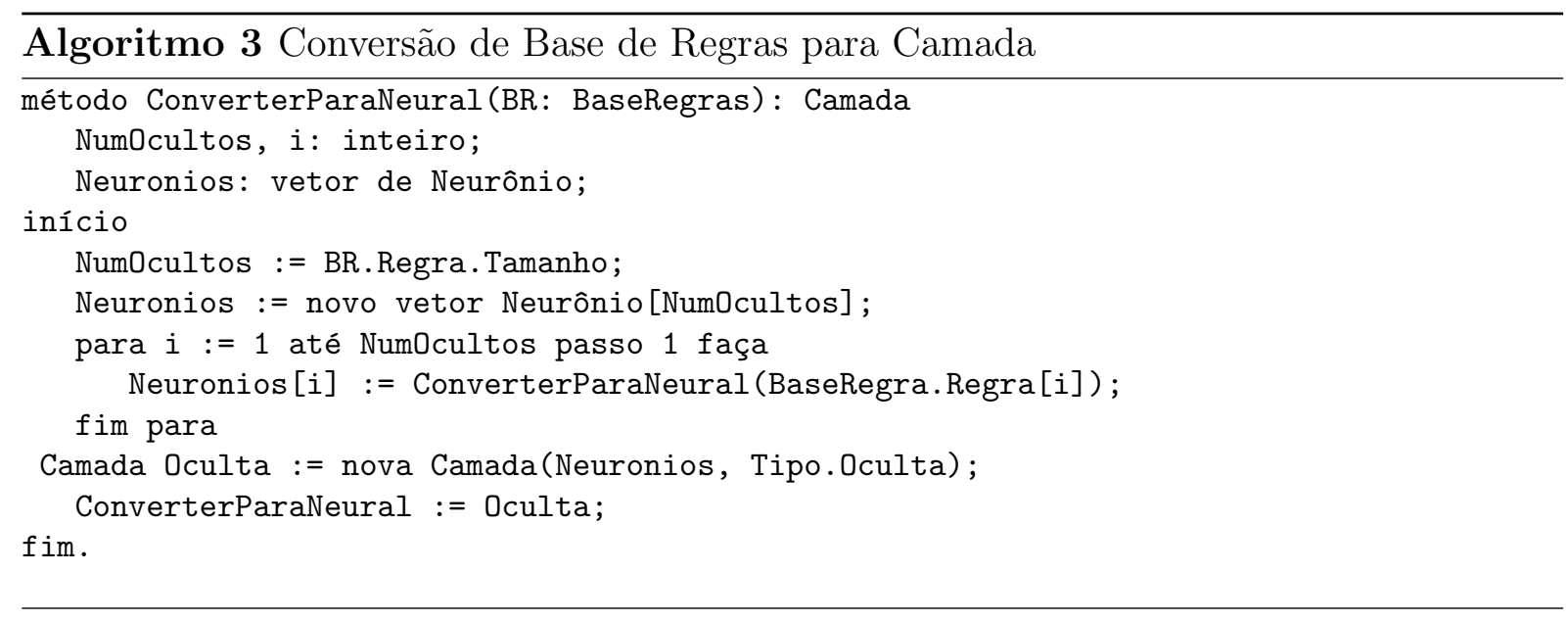

Esta é a camada oculta da rede. Para compor um SIN completo, as entradas e saídas devem ser acopladas (serão as camadas de entrada e saída da RNA) e um método de defuzzificação deve ser definido. Finalmente foi incorporado à classe FuzzyTransform, além da função descrita no algoritmo 3, um método para realizar a transformação de um SIN em RNA foi implementado e está detalhado no algoritmo 4.

Alguns métodos de classes utilizadas no algoritmo 4:

- SIN.Entradas e SIN.Saidas: vetores que contém as variáveis lingüísticas da entrada e saída do sistemas, respectivamente.

- Sinapse.OrigemSinal: o neurônio que fornece o sinal para uma determinada sinapse. 


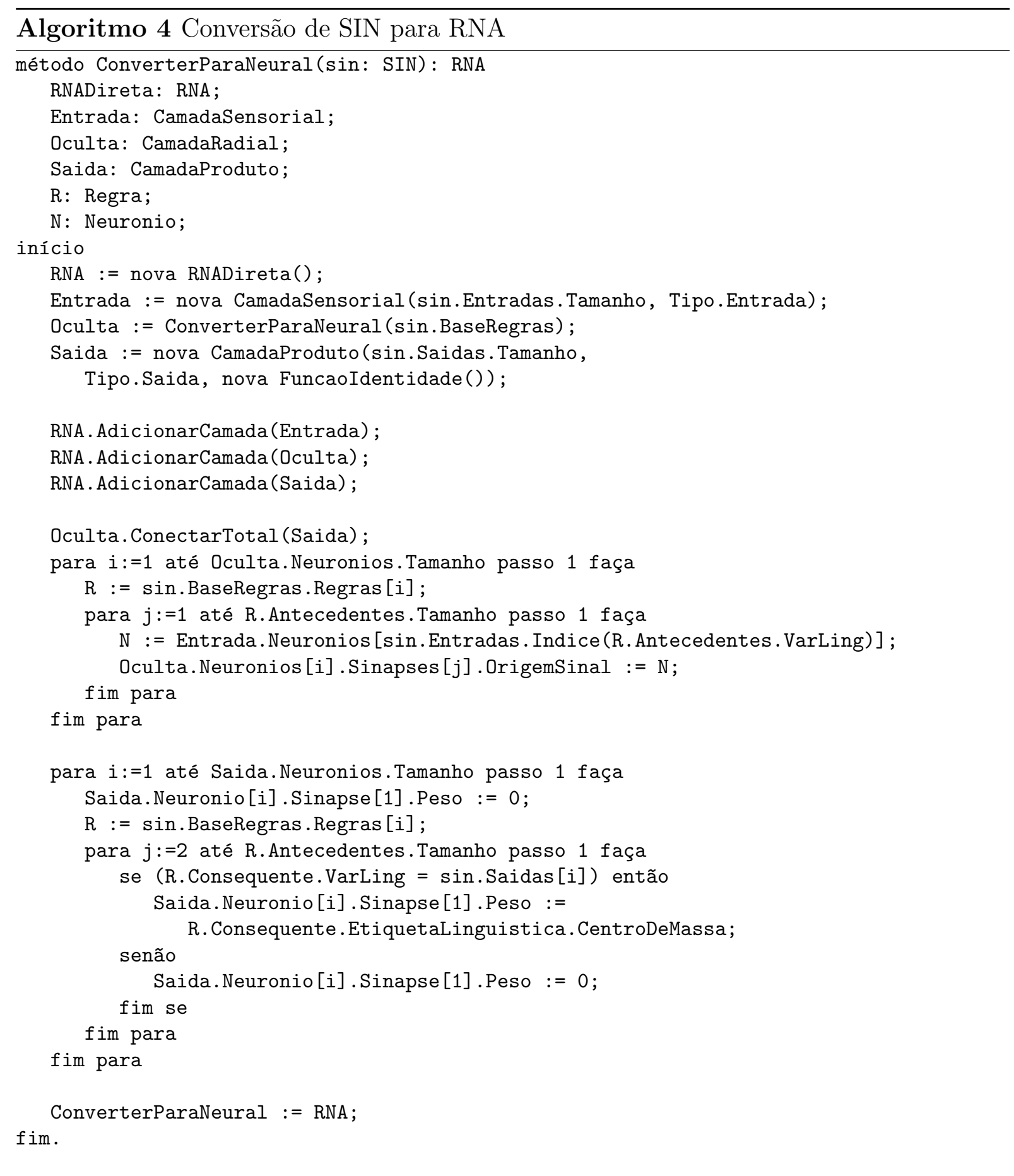


Primeiramente, os objetos correspondentes à RNA e as camadas são criados. A camada de entrada ou sensorial com o número de variáveis de entrada, a camada oculta utilizando a função de conversão de base de regras para camada, e a camada de saída, com o número de variáveis de saída e uma função de transferência do tipo identidade. As camadas são adicionadas na RNA.

Em seguida, a camada oculta é totalmente conectada à camada de saída. A conexão da camada oculta com a sensorial requer um pouco mais de cuidado. Cada um dos neurônios da camada oculta é conectado ao neurônio da camada sensorial, se em seus antecedentes ele possui uma variável lingüística correspondente àquele neurônio de entrada.

Finalmente, a defuzzificação é realizada pela camada de saída. Para cada neurônio de saída os primeiros pesos correspondentes ao bias são anulados. Em seguida, se o neurônio representa uma determinada saída do SIN cada uma de suas sinapses recebe um peso correspondente ao centro de massa da regra que originou o neurônio da camada oculta ao qual está conectada.

Um detalhe deve ser observado: a saída da rede não está normalizada. Para obter a saída correspondente ao SIN, o valor de saída deve ser dividido pela soma dos potenciais de ativação (saídas dos neurônios da camada oculta).

Estes algoritmos são a generalização dos experimentos descritos na subseção 5.2.1. Tal transformação foi aplicada ao modelo de navegação de robô nebuloso descrito na subseção 5.1.2 e os resultados são apresentados na seção seguinte.

\subsection{Transformação do SIN do Robô em RNA}

Implementada a proposta de transformação, a ferramenta de simulação foi alterada para converter um SIN em RNA no início da navegação do robô. A cada passo, a inferência é realizada pelo SIN e pela RNA equivalente, possibilitando a escolha em tempo de execução do valor a ser utilizado.

A trajetória da navegação realizada pelo robô utilizando SIN e a RNA equivalente em dois mapas de teste é apresentada na figura 5.13. Pode-se notar que a navegação com RNA oscilou menos que a navegação com SIN, embora o robô tenha passado mais perto da parede em algumas situações.

Vale notar que a RNA não foi treinada, e já possui respostas que resolvem o problema. Poderia ser realizado algum tipo de treinamento para aperfeiçoar a navegação. Posteri- 


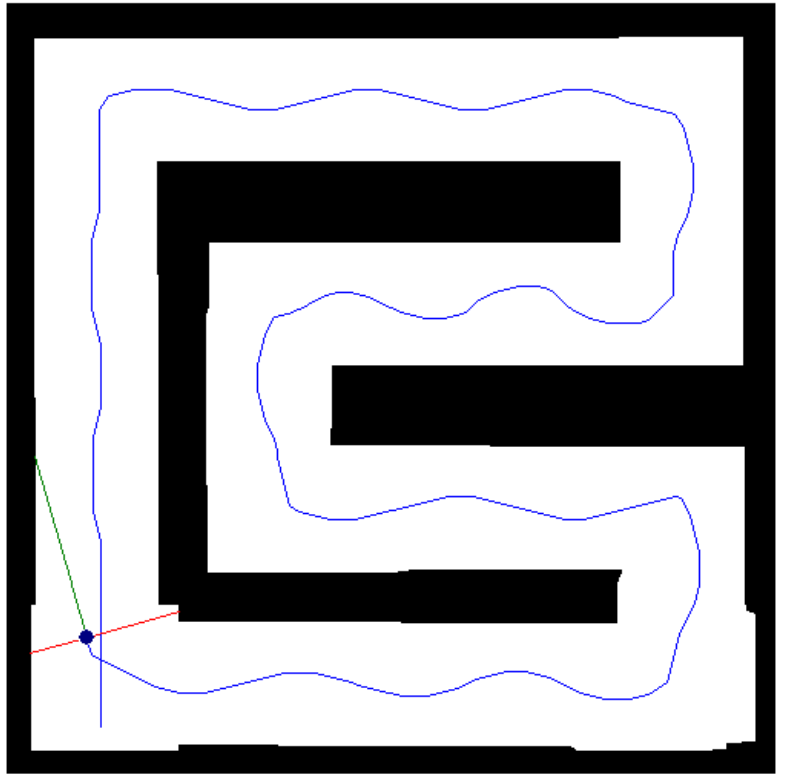

(a)

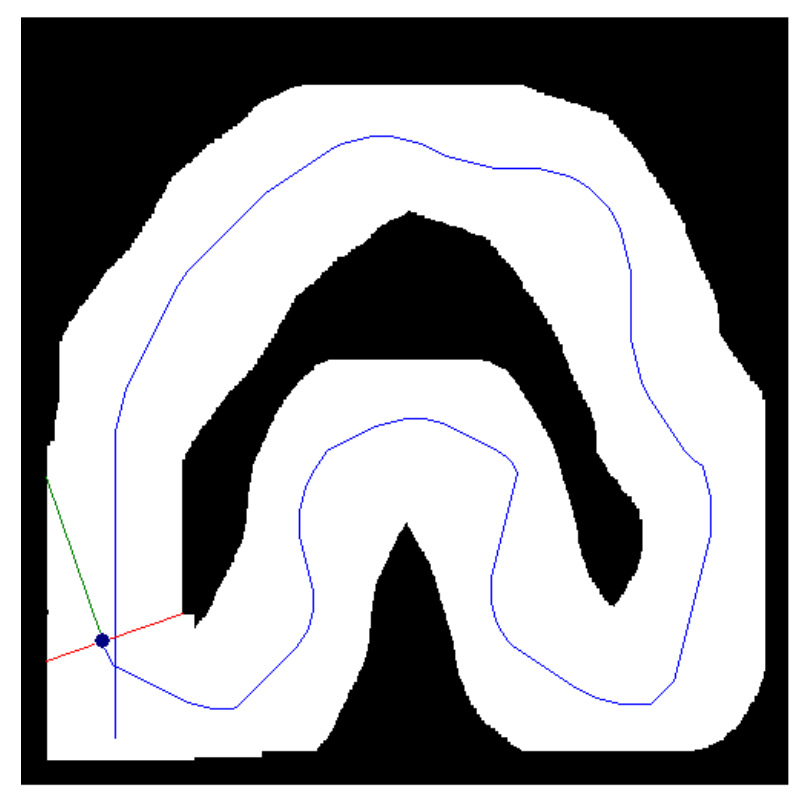

(c)

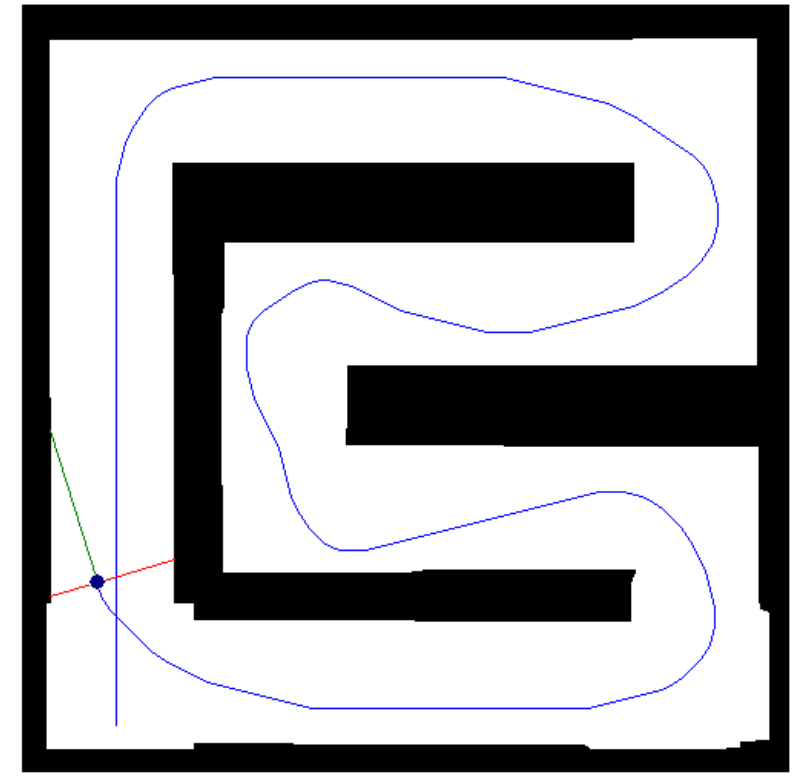

(b)

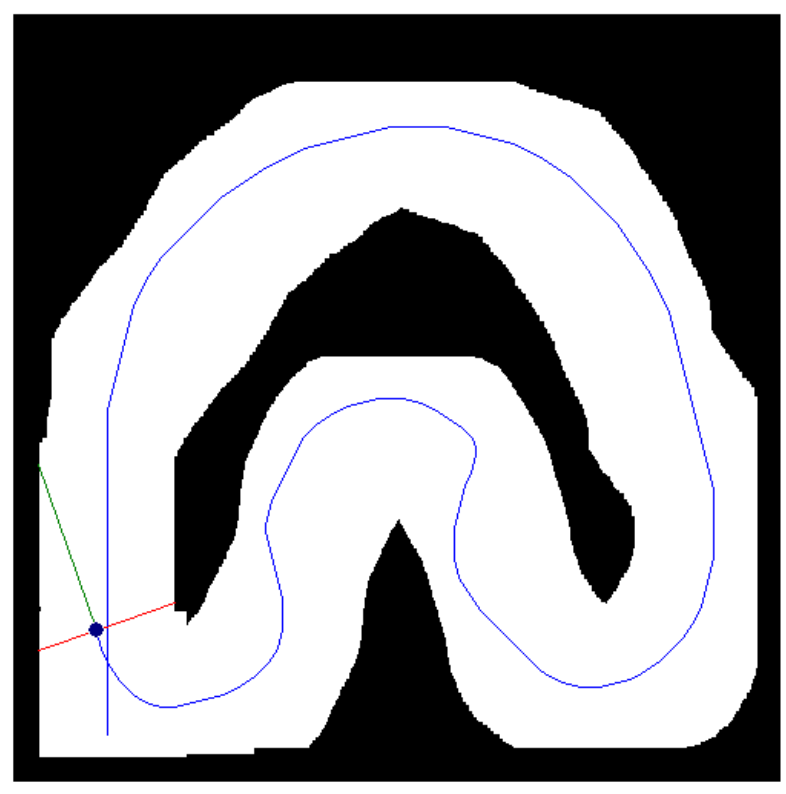

(d)

Figura 5.13: Teste comparativo da navegação do robô com SIN nos mapas (a) reto e (c) curvo com a navegação com RNA nos mapas reto (b) e curvo (d). 
ormente, as alterações de centros e pesos das funções poderia ser refletida no modelo nebuloso, aperfeiçoando-o da mesma forma.

Assim, a conversão do SIN completo pode ser considerada uma solução aproximada satisfatória, visto que resolveu o mesmo problema de navegação evitando colisões. Uma diferença de comportamento pode ser observada, quando guiado pela RNA o robô demonstrou uma reação mais suave em longas distâncias, resultado da interpolação que a rede é capaz de realizar. O SIN, por sua vez, pode gerar saídas mais bruscas dependendo da granularização das partições primárias.

Este experimento demonstrou que, utilizando aproximações, alguns elementos de modelos nebulosos apresentam um certo grau de equivalência. Assim, os conjuntos nebulosos podem ser vistos como sinapses, as regras nebulosas como neurônios, um conjunto de regras como uma camada, podendo ser usados para converter um SIN em uma RNA.

\subsection{Considerações Finais do Capítulo}

O problema de navegação de robôs autoguiados em ambientes desconhecidos utilizado para os experimentos deste capítulo contempla aplicações de grande importância em diversos ramos e possui, em ambientes reais, situações bem mais complexas que o ambiente de simulação aqui apresentado. Uma das simplificações adotadas, de velocidade constante é um exemplo disso. Em situações reais normalmente é importante um controle não só da direção mas da velocidade também. Um exemplo de modelagem deste tipo de veículos com elementos nebulosos que envolve velocidade pode ser encontrado em Martinez, Tunstel e Jamshidi (1994).

O ambiente implementado mostrou-se de fundamental importância na avaliação dos modelos nebulosos e neurais. Certamente uma análise puramente numérica dos resultados não teria o mesmo significado que a aplicação em um problema "quase real". Pode até ser real se considerado uma ambiente de jogos interativos ou similar, nos quais a movimentação do robô é de fato em um mapa virtual.

Os pacotes parciais da FC e NC da UCIP, bem como os algoritmos de transformação incorporados ao pacote MT, além do próprio ambiente de simulação foram desenvolvidos utilizando a linguagem de programação C\#. Apenas o código da classe FuzzyTransform, mais relevante para este trabalho, foi incluído no apêndice B. Mais detalhes sobre este linguagem de programação e das plataformas que a envolvem podem ser encontrados em Watson et al. (2002) e Jeffries (2004). 
A capacidade de modelos nebulosos e neurais em realizar a inferência das ações de agentes reativos foi demonstrada através da aplicação isolada dos dois modelos. Este fato prova, também, que ao menos uma equivalência nos níveis mais altos existe entre os sistemas nebulosos e neurais, mesmo que aproximada. A questão da igualdade versus aproximação, já discutida no capítulo 3, é por natureza subjetiva, principalmente tratando-se de modelos nebulosos. Do ponto de vista de significado, pode-se dizer que uma "igualdade nebulosa" existe entre os componentes transformados.

Em termos do algoritmo de transformação, vale notar uma característica interessante da conexão entre as camadas de entrada e oculta da rede construída a partir do modelo nebuloso. Um neurônio da entrada pode ter uma ou mais ligações com um mesmo neurônio da camada oculta. Se uma regra utilizar, em mais de um antecedente, a mesma etiqueta lingüística, este efeito ocorrerá.

O sucesso da transformação do sistema nebuloso completo não deve, entretanto, ocultar algumas falhas que podem comprometer uma generalização maior da técnica. Em primeiro lugar, a transformação necessita aplicar uma mesma função de transferência para todos os conjuntos nebulosos envolvidos em um dado antecedente de regra. Isto pode ser observado facilmente na passagem da equação 2.36 para a 2.37. Na primeira equação uma função $H($.$) era aplicada em cada um dos elementos, enquanto que na se-$ gunda passou a ser aplicada no conjunto, para viabilizar a transformação. Isto limita claramente os conjuntos nebulosos a formatos similares em um sistema.

Uma segunda falha que pode ser observada, ainda relacionada ao formato do conjunto nebuloso é quando se tem que trabalhar com LFNs, RFNs ou qualquer outra função não simétrica. No algoritmo proposto, os conjuntos LFNs e RFNs tiveram sua forma duplicada para viabilizar uma função simétrica. Tal aproximação pode ter um efeito colateral grave se um valor de entrada sair muito do esperado para um conjunto destes, atingindo a descida da função espelhada, na qual o valor que deveria ser sempre máximo decresce gradualmente.

Finalmente, a etapa de defuzificação não pôde ser completamente transformada, restando a normalização dos valores por fazer. O valor da saída deve ser dividido pela soma das saídas das camadas ocultas. O impacto desta alteração na estrutura da rede neural deve ser estudado, principalmente no que diz respeito aos processos de aprendizado. 


\section{Considerações Finais}

A área de IA e de ciência cognitiva se encontra em ampla expansão em todos os ramos da atividade humana. Desde robôs industriais até casas inteligentes, o que antes parecia supérfulo e do domínio da ficção, hoje é responsavel até por decisões críticas que podem salvar vidas.

Dentro deste domínio se encontra a IC, cuja inspiração são os modelos que obtiveram maior sucesso trabalhando em um ambiente altamente complexo: os sistemas biológicos no mundo real. As aplicações existentes falam por si, e dispensam a necessidade de explanação da importância destas técnicas.

Este trabalho contribui para a IC, visualizando suas técnicas sob uma ótica raramente considerada. Esta visão é a de um único modelo da inteligência biológica, do qual as técnicas são partições ou até mesmo especializações. Alguns resultados de estudos e experimentos reforçam esta visão. Mais ainda, o trabalho convida à pesquisa e desafia à exploração de uma linha que foi apenas arranhada na história e que pode expandirse muito ainda, revelando mais sobre a polêmica, porém inegavelmente bem sucedida, habilidade denominada inteligência.

\subsection{Cumprimento dos Objetivos Propostos}

A organização das idéias e sistematização do conhecimento existente sobre as duas técnicas de interesse deste trabalho, além das propostas de unificação existentes foram realizadas no capítulo 2.

No capítulo 3, algumas discussões sobre abordagem de pesquisa para realizar a exploração são realizadas, e um modelo proposto é adotado para a especificação de um plataforma computacional para realização de experimentos descrita no capítulo 4.

Finalmente, um protótipo funcional desta plataforma é implementado e aplicado em um problema real, bem como seus resultados apresentados, no capítulo 5 . 
Tais realizações estão alinhadas com os objetivos iniciais deste trabalho, que foram cumpridos. Embora aproximações tenham sido realizadas para este intuito, em particular nos algoritmos descritos no capítulo 5, os problemas foram, de fato, resolvidos, e este resultado é suficientemente significativo, principalmente na área de IC.

\subsection{Contribuições do Trabalho}

Os objetivos propostos e alcançados já resultaram em algumas contribuições deste trabalho. O levantamento teórico, organizando e sistematizando o conhecimento sobre unificação de CF e CN pode ser destacado como a primeira delas.

Os modelos propostos, em particular o modelo adotado, o diagrama AC, com as idéias envolvidas na sua utilização contribuem para a exploração das relações e das próprias técnicas de IC.

Um resultado importante no campo de engenharia de computação é a criação da plataforma UCIP, através de uma especificação que utiliza técnicas de modelagem de sistemas para obter um modelo que possa representar de forma genérica soluções que tipicamente são sensíveis ao contexto. Embora o foco tenha sido a exploração das relações, pode-se propor alguns pacotes que viabilizem aplicações práticas em termos de otimização e desempenho.

Esta plataforma foi parcialmente implementada, demonstrando a viabilidade da sua construção e o valor dos modelos dela derivados na solução de problemas de IC. Uma contribuição adicional, que surgiu como efeito colateral dos experimentos, realizados foi uma ferramenta de simulação de navegação de veículos autoguiados em ambientes desconhecidos.

Tais experimentos foram realizados com algoritmos de transformações de elementos de CF e CN, contribuindo com uma tradução prática das relações apontadas na teoria, experimentos em um problema real e análise crítica dos resultados e das limitações destas propostas.

\subsection{Comentários Gerais}

Uma bifurcação de abordagens na exploração das técnicas de CF e CN acompanhou o desenvolvimento do trabalho. Embora finalmente tenha sido considerada a realização de aproximações, a idéia da existência de isomorfismos entre elementos de IC existe em 
alguns dos trabalhos que serviram como base para este.

A decisão por aproximações foi realizada por diversos motivos. Em primeiro lugar, existem trabalhos propondo métodos de aproximação formalmente. A linha de pesquisa é recente, e a obtenção de isomorfismos requer amadurecimento e profundo entendimento de técnicas que foram, muitas vezes, propostas de maneira empírica.

Além disso, resta a questão da possibilidade da existência de isomorfismos e da sua real utilidade. Em se tratando de técnicas de aproximação, a transformação exata de elementos pode resultar em um contrasenso com o próprio princípio da incompatibiliade, conforme destacado no capítulo 3. As intersecções e áreas de abrangência das sintaxes do diagrama de expressividade das técnicas de IC podem, naturalmente, serem nebulosos, tornando difícil uma formalização através de isomorfismos.

Uma questão que deve ser discutida, que não está no escopo deste trabalho, são as relações das técnicas de $\mathrm{CE}$. Em análise superficial, a natureza dos problemas de $\mathrm{CE}$ parece ser de busca de soluções, algo relacionado ao treinamento de $\mathrm{CN}$, mas não da aproximação de funções realizadas por CN e CF em si, exploradas neste trabalho.

Finalmente, pode-se destacar a necessidade de um esforço das técnicas de IC na avaliação da fidelidade de seus modelos em relação aos modelos biológicos. Novos sistemas e modelos são criados, aplicados na solução de problemas e avaliados como bem sucedidos, e se distanciam cada vez mais dos modelos biológicos. É importante a procura de elementos, sejam estruturais ou comportamentais, nos sistemas biológicos, que possam classificar novas propostas como pertencentes à IC ou ao escopo mais geral de IA.

\subsection{Trabalhos Futuros}

A característica exploratória deste trabalho levou naturalmente à abertura de um leque de possibilidades de pesquisa e trabalhos futuros. Mais diretamente relacionados ao tema do trabalho, pode-se destacar:

- Experimentos e análise de resultados com algoritmos de treinamento da RNA obtida a partir da transformação do SIN. Tal estudo poderia resultar em técnicas automáticas de ajuste fino de partições e regras nebulosas hoje executados, tipicamente, de forma manual.

- Realização de testes de transformações nas mais diversas aplicações de CF existentes, em outros modelos, com possível estabelecimento de outras limitações e aplicações 
dos algoritmos propostos.

- Estudo e possível transporte de outros elementos de CF para CN, como por exemplo os modificadores nebulosos e outros tipos de defuzzificadores.

- Desenvolvimento de idéias que envolvam a conversão dos diversos elementos dos modelos neurais existentes em elementos nebulsos. Este estudo poderia auxiliar o campo de extração de conhecimento de modelos de CN, de grande importância para a computação e também para a neurociência.

- O estudo de métricas para avaliar transformações, que por si só já é motivo de polêmica, e pode resultar em um trabalho independente de pesquisa.

- A implementação completa e refinamento da plataforma UCIP proposta neste trabalho, e possível proposta de novos pacotes que viabilizem sua aplicação em problemas práticos que exigem desempenho e otimizações.

Em termos mais amplos, relacionados à linha de pesquisa em geral, pode-se destacar alguns outros trabalhos possíveis. A análise e realização de experimentos com CE, explorando possíveis relações entre seus elementos e os elementos de CF e CN é um deles.

A nova proposta de modelagem das técnicas de IC através do formalismo de expressividade de linguagens, abordada superficilamente neste trabalho, parece ser muito promissora. Este estudo pode também ser um trabalho derivado do atual.

Finalmente, extrapolando a própria IA, uma possibilidade de derivação deste trabalho pode ser encontrada nos campos de interesse da ciência cognitiva, em particular a neurofilosofia. As propostas de trasporte realizadas aqui poderiam encontrar elementos biológicos que permitissem relacionar estruturas cerebrais com o processo de raciocínio aproximado. Um trabalho deste seria uma contribuição importante na caminhada rumo à compreensão da inteligência. 


\section{Referências}

ANDRADE, M. T. C. de. Uma contribuição à pesquisa em inteligência computacional. Tese (Livre Docência) - Escola Politécnica da Universidade de São Paulo, São Paulo, 2002.

ASSOCIATES, I. P. Software engineering document templates: adaptable process model. Disponível em: http://www.rspa.com/docs/index.html, Acesso em: 01 de agosto de 2005.

BENDER, E. A. Mathematical methods in artificial intelligence. Los Alamitos: IEEE Computer Society Press, 1996.

BERARDI, F.; CHIABERGE, M.; MIRANDA, E.; REYNERI, L. A walking hexapod machine controlled by a neuro-fuzzy system. In: Proceedings of Secound International Workshop on Mechanical Computer Systems for Perception and Action. Pisa: MCPA, 1997. p. $95-104$.

BODEN, M. A. Computer models of mind. New York: Press Syndicate of the University of Cambridge, 1988.

BONISSONE, P. P.; CHEN, Y. to; GOEBEL, K.; KHEDKAR, P. S. Hybrid soft computing systems: Industrial and commercial applications. In: Proceedings of the IEEE. Los Alamitos: IEEE Press, 1999. v. 87, n. 9, p. 1641-1667.

BOOCH, G.; RUMBAUGH, J.; JACOBSON, I. The unified modeling language reference manual. New York: Addison-Wesley, 1999.

. UML: guia do usuário. Rio de Janeiro: Editora Campus, 2000.

BRAY, T.; PAOLI, J.; SPERBERG-MCQUEEN, C. M.; YERGEAU, E. M. F. Extensible markup language (XML) 1.0 (Third Edition). Disponível em: http://www.w3.org/TR/REC-xml/, Acesso em: 03 de agosto de 2005.

CAVERSAN, F. L. Reconhecimento de padrões utilizando redes neurais artificiais. Trabalho de Conclusão de Curso (Graduação): Faculdade de Engenharia de Sorocaba, Sorocaba, 2002.

CAVERSAN, F. L.; ANDRADE, M. T. C. de. Exploração de relações isomórficas entre técnicas simbólicas e conexionistas da inteligência computacional. INFOCOMP, v. 4, n. 1, p. 19-26, Março 2004.

CHEN, C. H. Fuzzy logic and neural network handbook. New York: Mcgraw-Hill, 1996.

CHURCHLAND, P. M. Matéria e consciência: uma introdução contemporânea à filosofia da mente. São Paulo: Editora Unesp, 2004. 
CHURCHLAND, P. S. Neurophilosophy: toward a unified science of the mind/brain. Cambridge: The MIT Press, 1989.

COBO, J. E. A. Considerações e modelos arquiteturais para prototipagem rápida emhardware de modelos nebulosos. Tese (Doutorado) - Escola Politécnica da Universidade de São Paulo, São Paulo, 2000.

ECKEL, B. Thinking in Java. 3. ed. [S.l.]: Prentice-Hall, 2002.

FOGEL, D. B. Evolutionary computation: toward a new philosophy of machine. Piscataway: IEEE Press, 1995.

FOGEL, D. B.; FUKUDA, T.; GUAN, L. Scanning the special issue/technology on computational intelligence. In: Proceedings of the IEEE. Los Alamitos: IEEE Press, 1999. v. 87, n. 9, p. 1415-1422.

FURLAN, J. D. Modelagem de objetos através da UML. São Paulo: Makron Books, 1998.

GAJSKI, D. D.; KUHN, R. H. New VLSI tools. IEEE Computer, v. 16, p. 11-14, December 1983.

GILES, L. C.; OMLIN, C. W.; THORNBER, K. K. Equivalence in knowledge representation: automata, recurrent neural networks, and dynamical fuzzy systems. In: Proceedings of the IEEE. Los Alamitos: IEEE Press, 1999. v. 87, n. 9, p. 1623-1640.

HAYKIN, S. Redes neurais: princípios e prática. Porto Alegre: Bookman, 2001.

JANG, J.-S. R. Neuro-fuzzy modeling: architecture, analisys and applications. Tese (Doutorado) — University of California, Berkeley, 1992.

JANG, J.-S. R. Anfis: adaptive-network-based fuzzy inference system. IEEE Transactions on Systems, Man, and Cybernetics, v. 23, p. 665-684, 1993.

JEFFRIES, R. Extreme programming adventures in C\#. Redmond: Microsoft Press, 2004.

JORDAN, M. I. Why the logistic function? A tutorial discussion on probabilities and neural networks. Massachusetts Institute of Technology (Technical Report 9503), August 1995.

KANDEL, E. R.; SCHWARTZ, J. H.; JESSEL, J. H. Principles of neural science. Norwalk: Appleton \& Lange, 1991.

KNOMA. Laboratório de Engenharia de Conhecimento. Disponível em: http://www.knoma.pcs.usp.br/index.html, Acesso em: 01 de setembro de 2005.

KOLMOGOROV, A. N.; FOMIN, S. V. Introductory real analysis. Mineola: Dover Publications, 1975.

KOSKO, B. Fuzzy engineering. New York: Prentice Hall, 1997.

LEE, C. C. Fuzzy logic in control systems: fuzzy logic controller - part I. IEEE Transactions on Systems, Man and Cybernetics, v. 20, n. 2, p. 404-418, March/April 1990. 
Fuzzy logic in control systems: fuzzy logic controller - part II. IEEE Transactions on Systems, Man and Cybernetics, v. 20, n. 2, p. 419-435, March/April 1990.

LEWIS, H. R.; PAPADIMITRIOU, C. H. Elementos de teoria da computação. Porto Alegre: Bookman, 2000.

LIPPMANN, R. P. An introduction to computing with neural nets. IEEE Acoustics, Speech, and Signal Processing Magazine, v. 1, p. 4-22, April 1987.

MARTINEZ, A.; TUNSTEL, E.; JAMSHIDI, M. Fuzzy logic based collision avoidance for a mobile robot. Robotica, v. 12, p. 521-527, 1994.

MEHRA, P.; WAH, B. W. Artificial neural networks: concepts and theory. Los Alamitos: IEEE Computer Society Press, 1992.

MEHROTRA, K.; MOHAN, C. K.; RANKA, S. Elements of artificial neural networks. Cambridge: The MIT Press, 1997.

MINSKY, M. L.; PAPERT, S. A. Perceptrons: an introduction to computational geometry. Cambridge: The MIT Press, 1969.

MITCHELL, M. An introduction to genetic algorithms. Cambridge: MIT Press, 1996.

NERO, H. S. D. O sítio da mente: pensamento, emoção e vontade no cérebro humano. São Paulo: Collegium Cognitio, 1997.

NETO, J. J. Adaptive automata for context-sensitive languages. SIGPLAN NOTICES, v. 29, n. 9, p. 115-124, September 1994.

NETO, J. J.; ROCHA, R. L. A. Autômato adaptativo, limites e complexidade em comparação com máquina de turing. In: Proceedings of the Second Congress of Logic Applied to Technology. São Paulo: Faculdade SENAC de Ciências Exatas e Tecnologia, 2001. p. 33-48.

NGUYEN, H. T.; WALKER, E. A. A first course in fuzzy logic. Boca Raton: CRC Press, Inc., 1996.

NILSSON, N. J. Artificial intelligence: a new synthesis. San Francisco: Morgan Kaufmann, 1998.

POSNER, M. L. Foundations of cognitive science. Cambridge: MIT Press, 1996.

PRESSMAN, R. S. Engenharia de software. São Paulo: Makron Books, 1995.

REYNERI, L. M. Weighted radial basis functions for improved pattern recognitionand signal processing. Neural Processing Letters, v. 2, n. 2, p. 2-6, May 1995.

Unification of neural and fuzzy computing paradigms, tutorial. In: First International Symposium on Neuro-Fuzzy Systems. Lausanne: Advanced and Applied Technologies Institute, 1996. p. 29-31.

An introduction to fuzzy state automata. In: Int'l Workshop on Artificial Neural Networks. Lanzarote: [s.n.], 1997. p. 273-283. 
REZENDE, S. O. Sistemas inteligentes: fundamentos e aplicações. Barueri: Editora Manole, 2003.

RUSSEL, S.; NORVIG, P. Inteligência artificial. Rio de Janeiro: Campus, 2004.

SAFFIOTTI, A. The uses of fuzzy logic for autonomous robot navigation: a catalogue raisonné. Soft Computing Research journal, v. 1, n. 4, p. 180-197, 1997.

SEBESTA, R. W. Conceitos de linguagem de programação. 5. ed. Porto Alegre: Bookman, 2003.

TREMBLAY, J. P.; MANOHAR, R. Discrete mathematical structures with applications to computer science. New York: McGraw-Hill, 1975.

TSOUKALAS, L. H.; UHRIG, R. E. Fuzzy and neural approaches in engineering. New York: Wiley-Interscience, 1997.

WAGNER, F. R.; JANSH-PôRTO, I.; WEBER, R. F. W. T. S. Métodos de validação de sistemas digitais. Campinas: VI Escola de Computação, 1988.

WATSON, K.; BELLINASO, M.; CORNES, O.; ESPINOSA, D.; GREENVOSS, Z.; NAGEL, C.; HAMMER, J.; REID, J. D.; SKINNER, E. W. M. Beginning $C$ \# programando. São Paulo: Makron Books, 2002.

ZADEH, L. A. Fuzzy sets. Information and Control, v. 8, p. 338-353, 1965.

. Fuzzy algorithms. Information and Control, v. 12, n. 2, p. 94-102, February 1968.

. Outline of a new approach to the analysis of complex systems and decision processes. IEEE Transactions on Systems, Man and Cybernetics, v. 3, p. 28-44, 1973.

Commonsense knowledge representation based on fuzzy logic. IEEE Computer, v. 16, n. 10 , p. $61-65,1983$.

Fuzzy logic, neural networks, and soft computing. Commun. ACM, ACM Press, New York, v. 37, n. 3, p. 77-84, 1994.

Fuzzy logic $=$ computing with words. IEEE Transactions on Fuzzy Systems, v. 4, p. 103-111, May 1996. 


\section{Apêndice A - SIN no formato XML}

Neste anexo é apresentado o SIN utilizado par realizar a navegação de um veículo autoguiado com o objetivo de evitar colisões, descrito no capítulo 5.

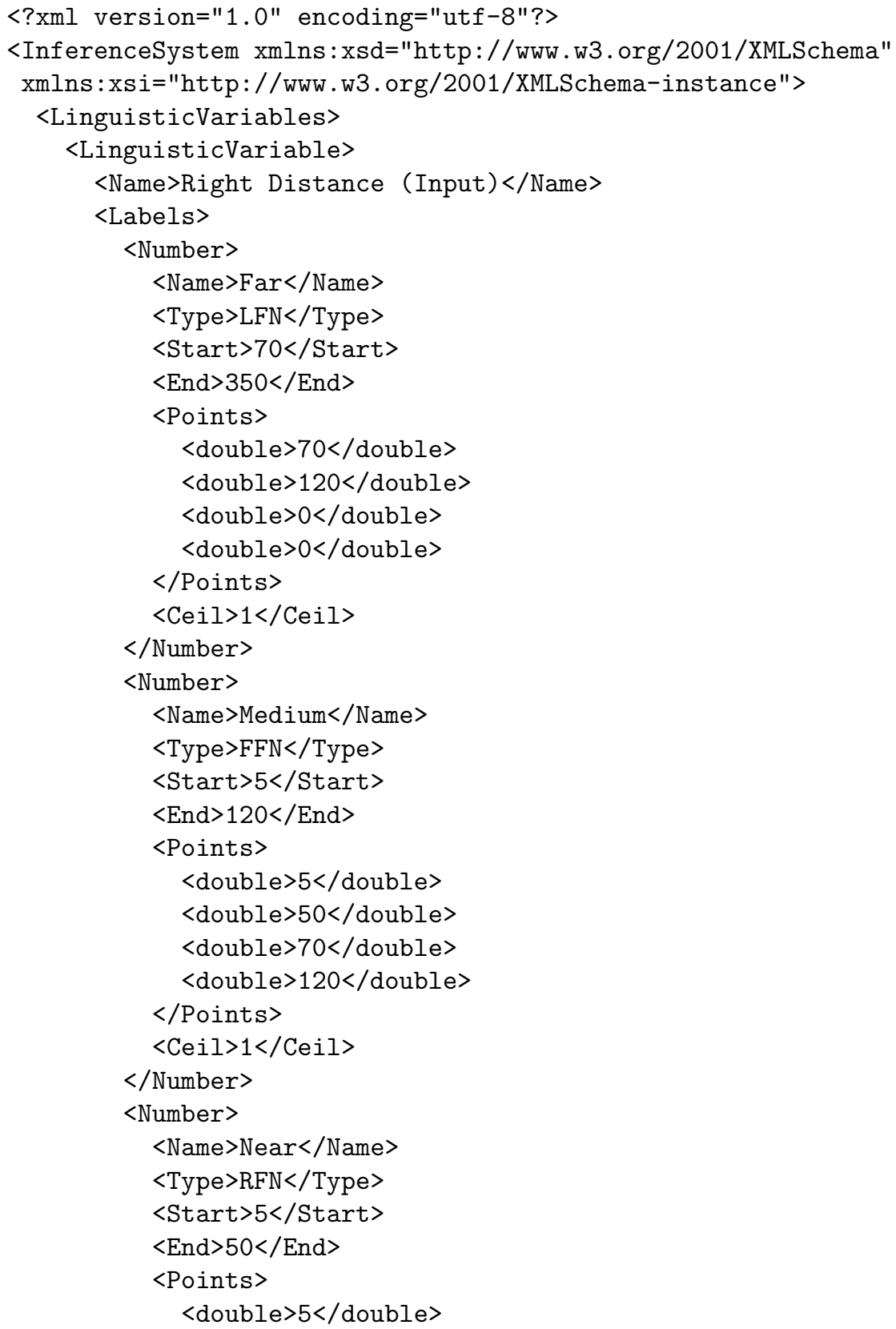




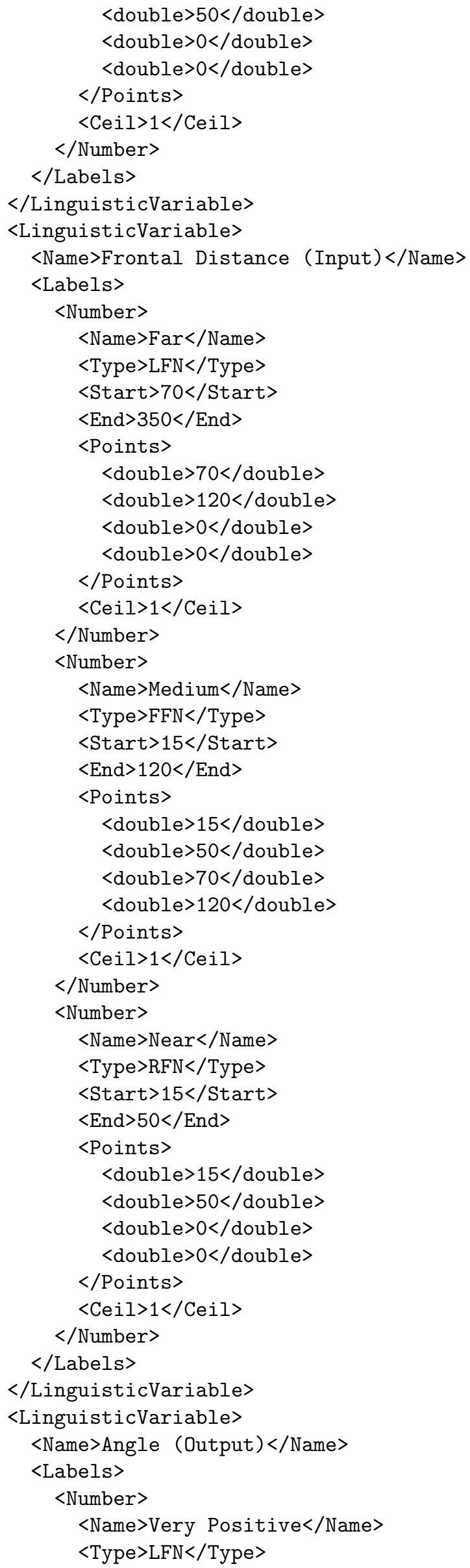




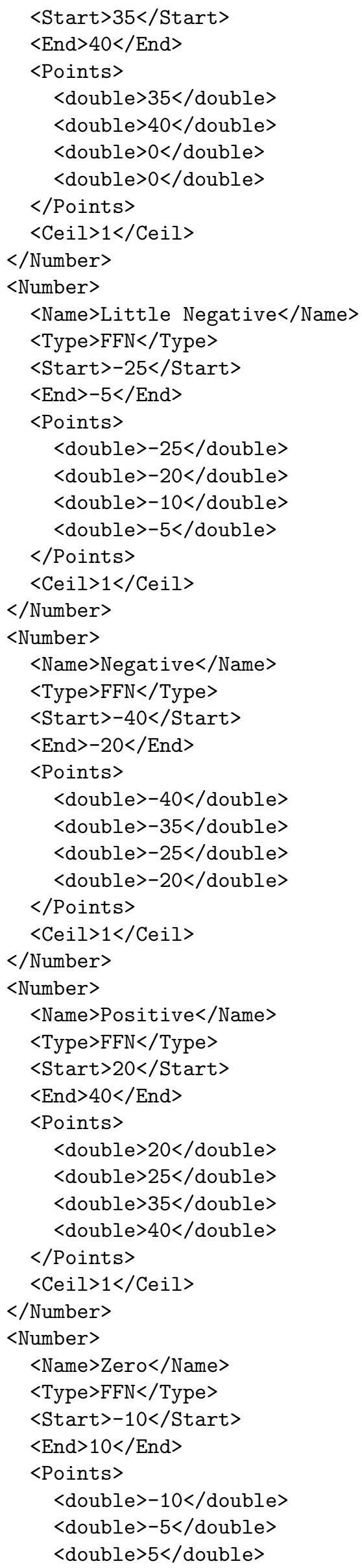




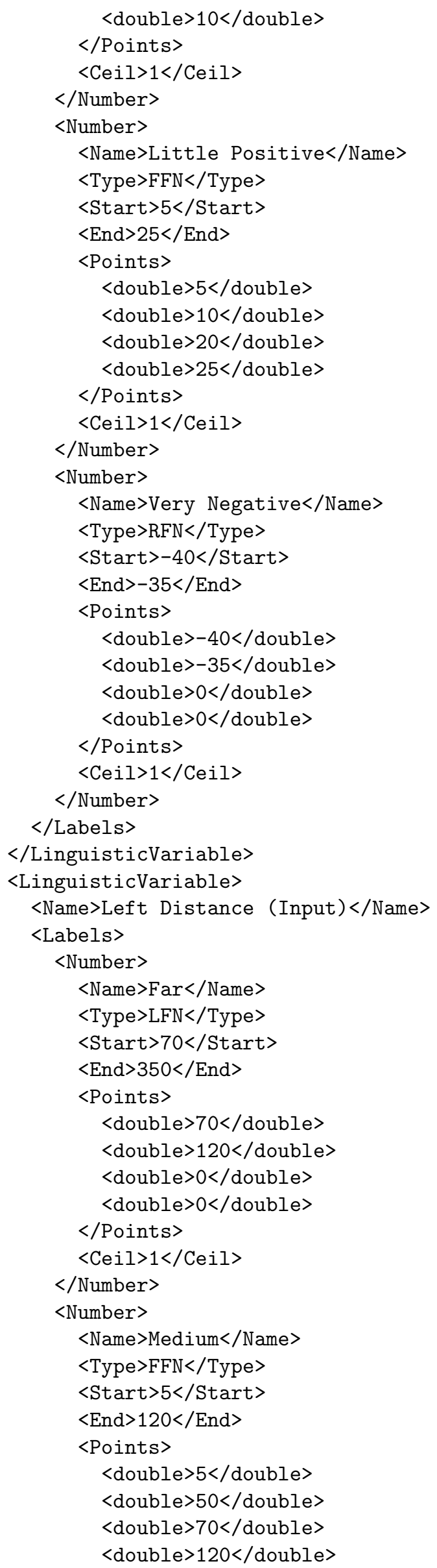




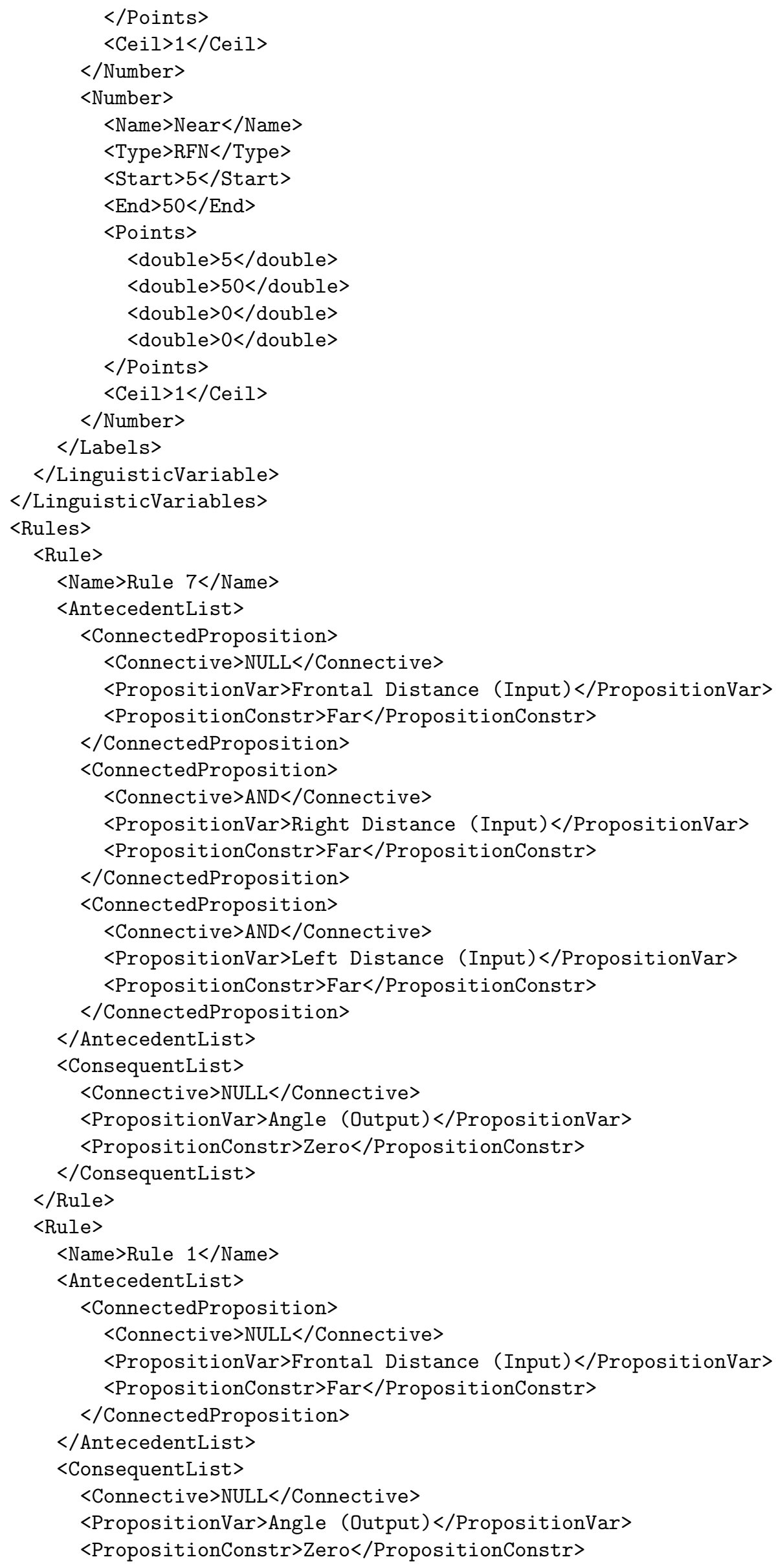




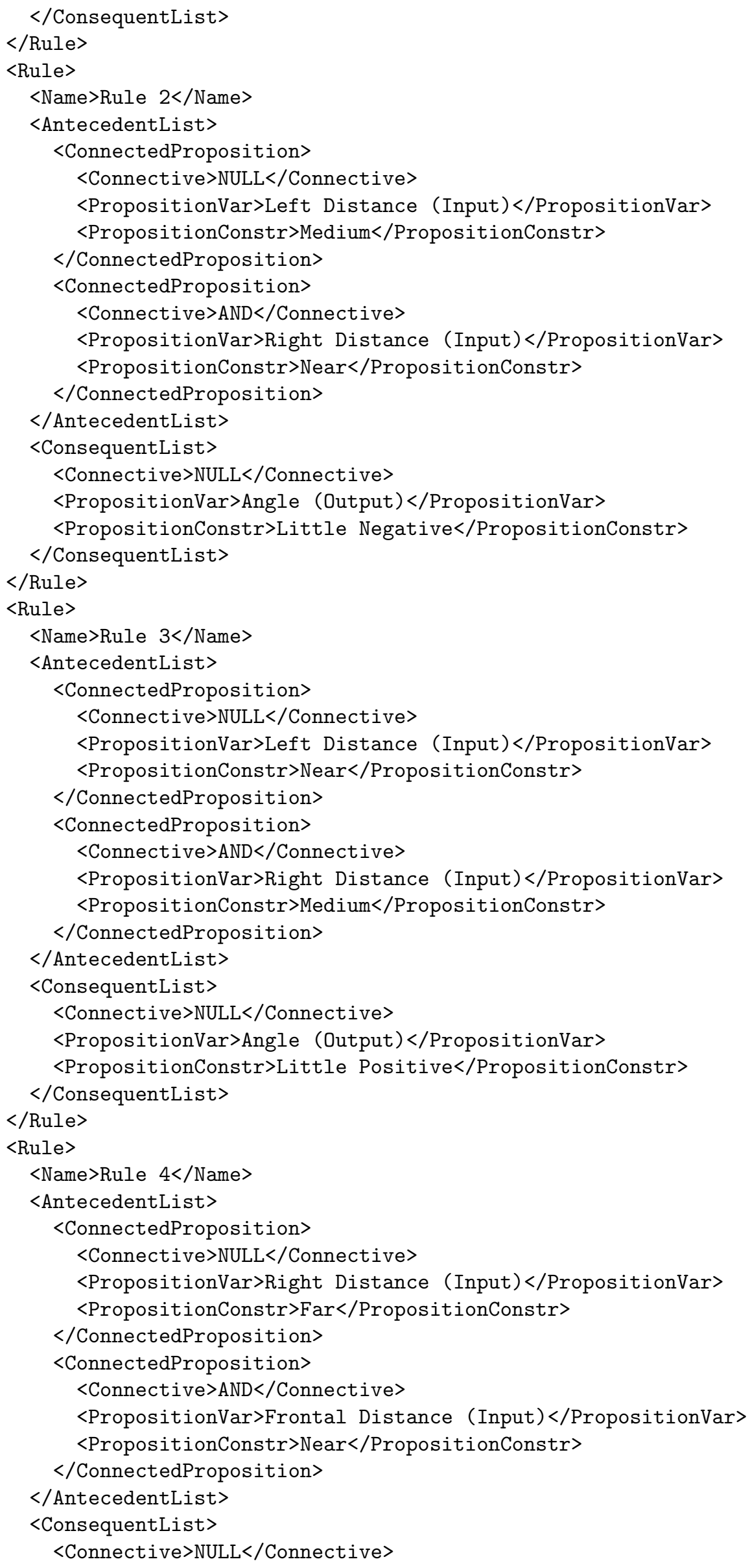




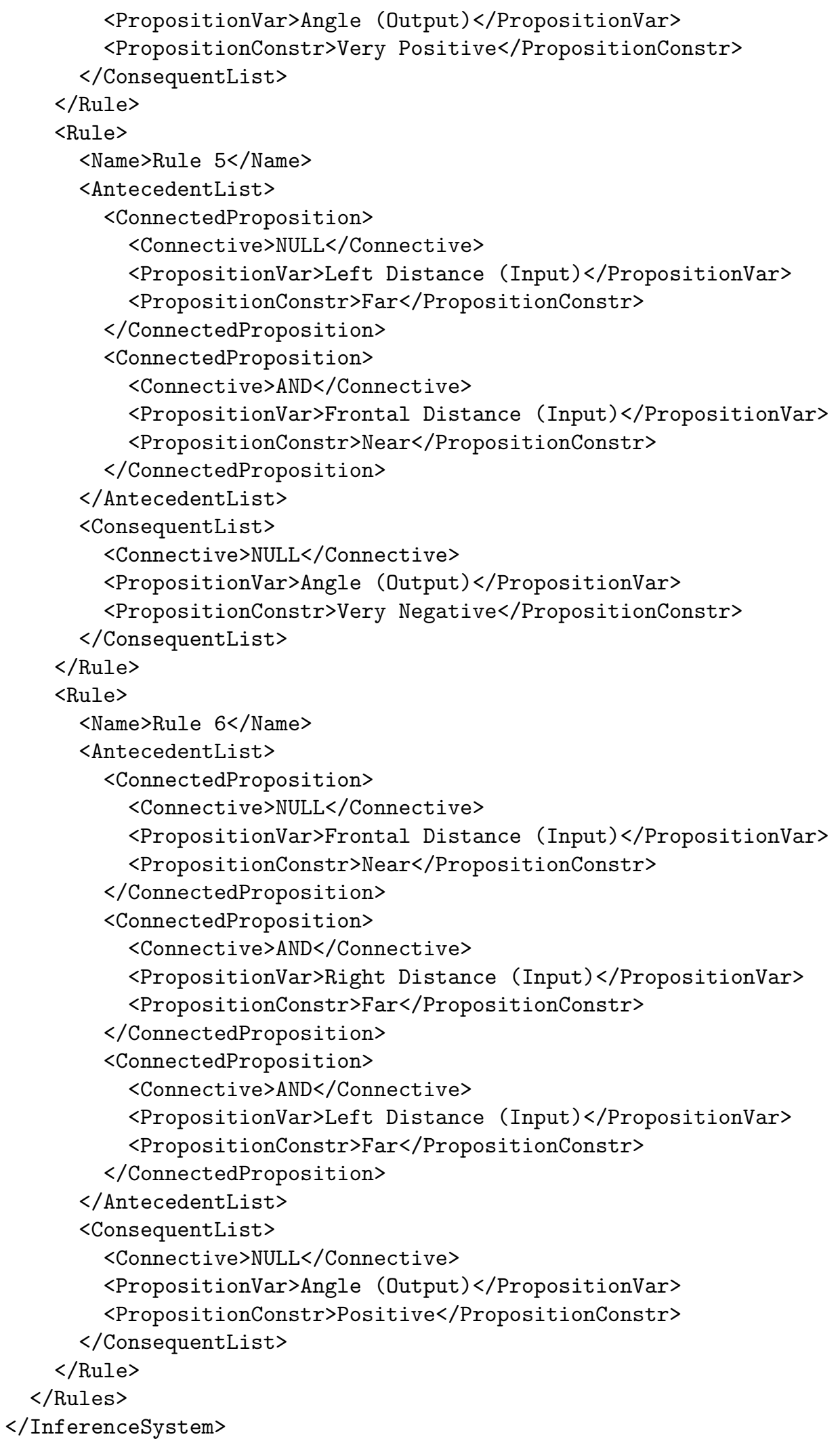




\section{Apêndice B - Código da Classe FuzzyTransform}

Neste anexo é apresentado o código em linguagem C\# da classe que realiza transformações de alguns elementos nebulosos em neurais. A descrição completa de cada passo dos métodos pode ser encontrada no capítulo 5.

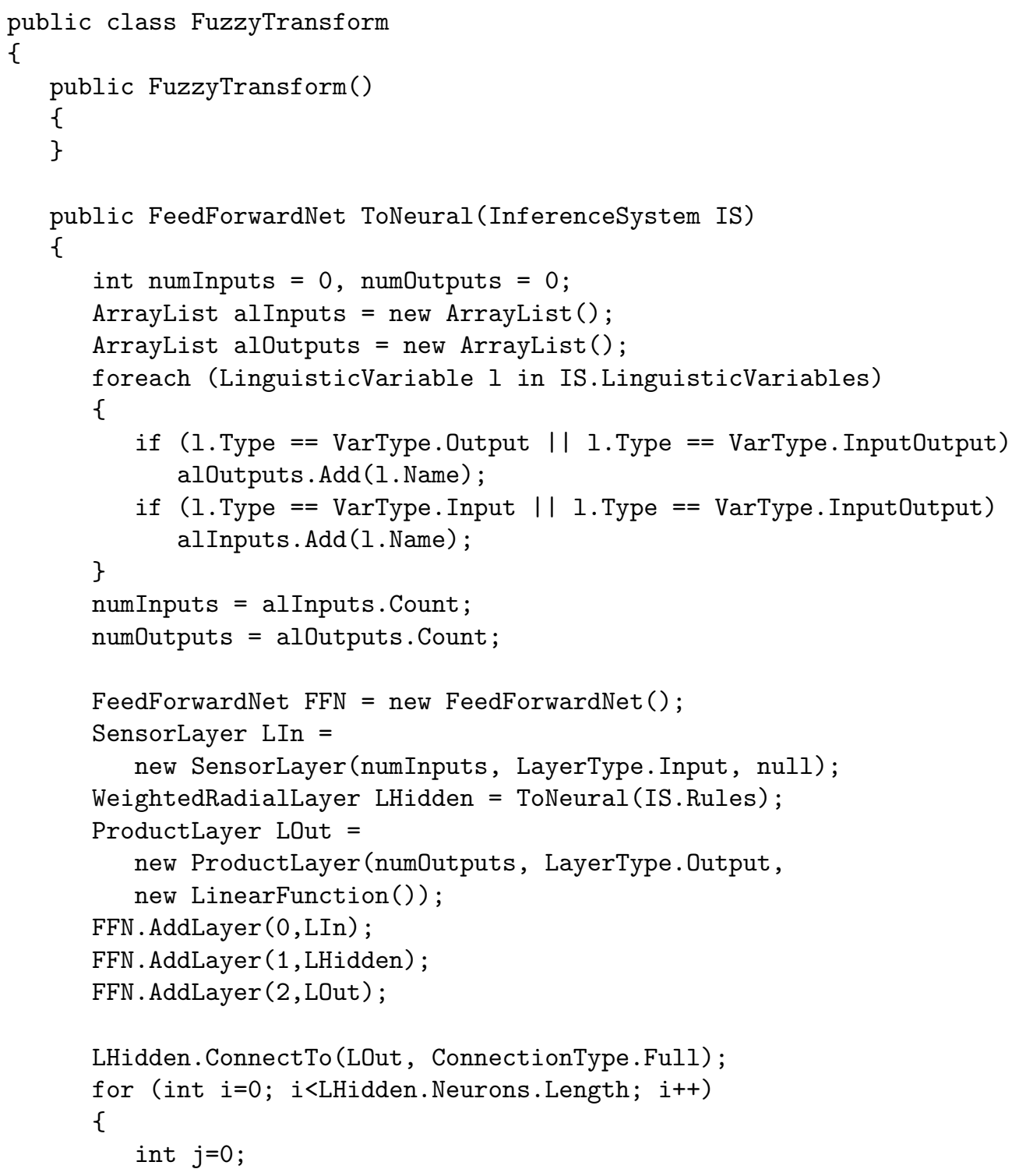




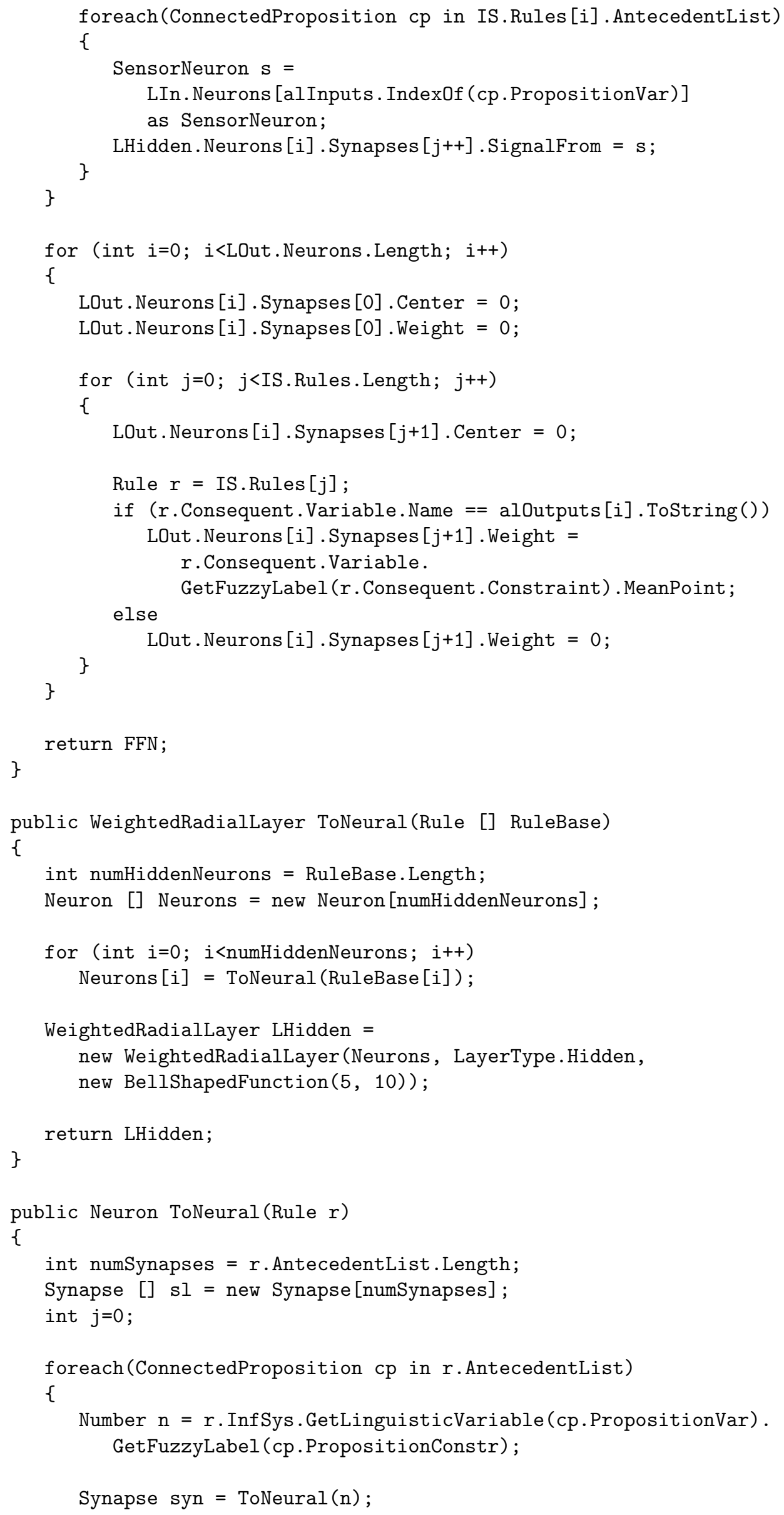




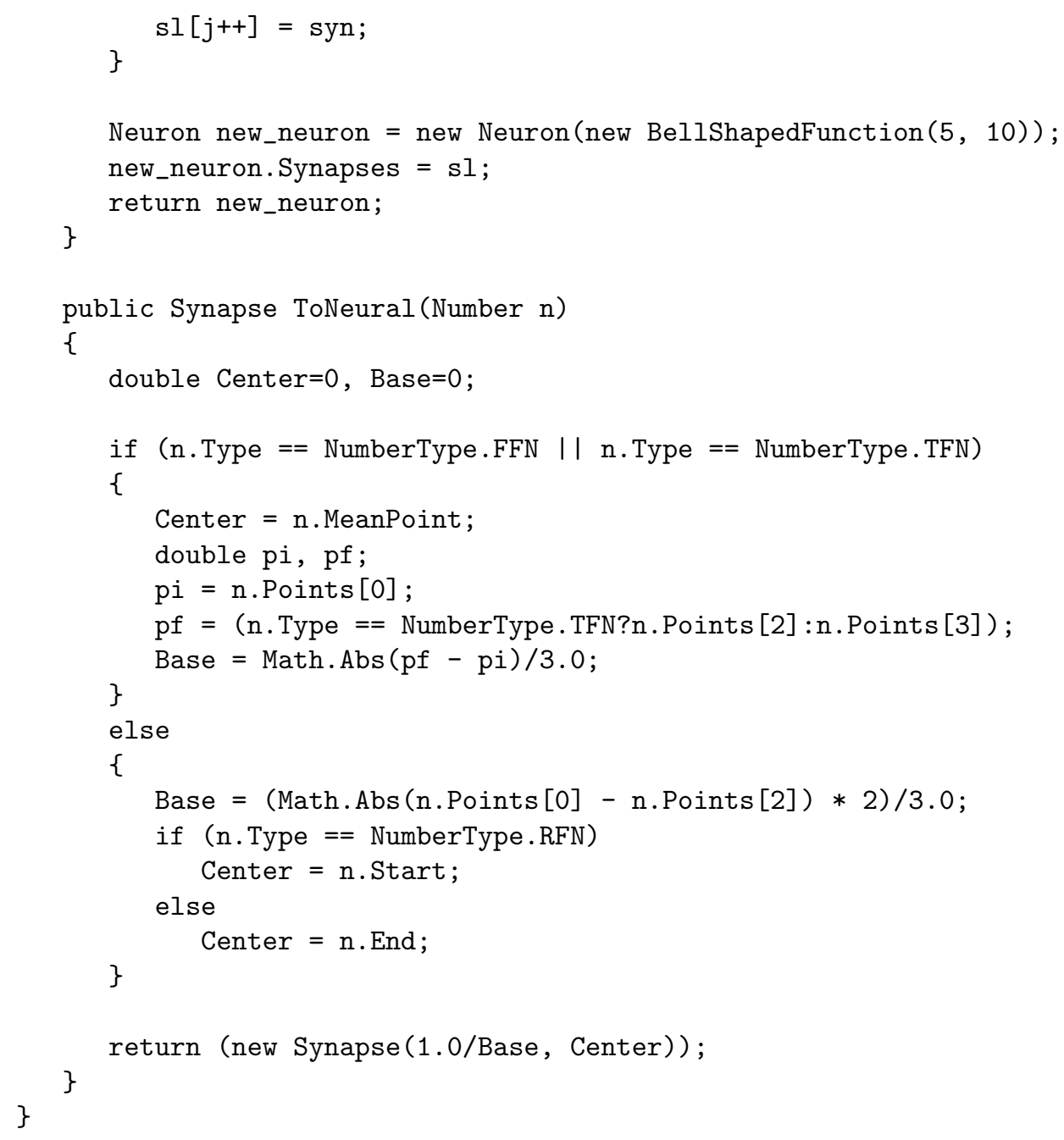

